\title{
WestVirginiaUniversity
}

THE RESEARCH REPOSITORY @ WVU

Graduate Theses, Dissertations, and Problem Reports

2002

\section{Comparison of 19mm Superpave and Marshall Base II mixes in West Virginia}

Vasavi Kanneganti

West Virginia University

Follow this and additional works at: https://researchrepository.wvu.edu/etd

\section{Recommended Citation}

Kanneganti, Vasavi, "Comparison of $19 \mathrm{~mm}$ Superpave and Marshall Base II mixes in West Virginia" (2002). Graduate Theses, Dissertations, and Problem Reports. 1232.

https://researchrepository.wvu.edu/etd/1232

This Thesis is protected by copyright and/or related rights. It has been brought to you by the The Research Repository @ WVU with permission from the rights-holder(s). You are free to use this Thesis in any way that is permitted by the copyright and related rights legislation that applies to your use. For other uses you must obtain permission from the rights-holder(s) directly, unless additional rights are indicated by a Creative Commons license in the record and/ or on the work itself. This Thesis has been accepted for inclusion in WVU Graduate Theses, Dissertations, and Problem Reports collection by an authorized administrator of The Research Repository @ WVU. For more information, please contact researchrepository@mail.wvu.edu. 


\section{COMPARISON OF 19mm SUPERPAVE AND MARSHALL BASE II MIXES IN WEST VIRGINIA}

\section{Vasavi Kanneganti}

Thesis submitted to the College of Engineering and Mineral Resources at West Virginia University in partial fulfillment of the requirements for the degree of

Masters of Science

In

Civil and Environmental Engineering

Dr. John P. Zaniewski, Chair

Dr. Ronald W. Eck,

Dr. W.V. Thayne

Department of Civil and Environmental Engineering

Morgantown, West Virginia

2002

Keywords: Marshall, Superpave, Mix designs 


\section{ABSTRACT \\ COMPARISON OF 19mm SUPERPAVE AND MARSHALL BASE II MIXES IN WEST VIRGINIA \\ Vasavi Kanneganti}

$\underline{\text { The Superior Performing Asphalt Pavements (Superpave }}{ }^{\mathrm{TM}}$ ) asphalt concrete mix design method was developed through Strategic Highway Program (SHRP) in 1993. With the introduction of Superpave mix design, the Marshall method of mix design is becoming obsolete for highway pavements. Superpave implementation varies by state. The WVDOH has implemented Superpave on all National Highway System projects since 1997. The decision regarding implementation of Superpave for low volume roads in WV is still under review.

The primary objective of this research work was to compare the $19 \mathrm{~mm}$ Superpave and Base II Marshall design mixes in WV to supplement information required for WVDOH to make a suitable decision regarding the implementation of Superpave for low volume roads.

The Marshall and Superpave methods were compared by preparing similar mix design with each method. The mix designs from each method were cross-compared with the conclusion that mixes developed under one method meet the criteria of the other method. In addition, the Asphalt Pavement Analyzer (APA) was used to evaluate rutting performance of gyratory compacted samples in the laboratory. The statistical analysis of rut depth results indicated there is not enough evidence to conclude there is a significant difference between the Marshall and Superpave mix design methods. It can be concluded that for the materials evaluated in this research, the Marshall and Superpave methods produce interchangeable results. 


\section{ACKNOWLEDGEMENTS}

The author would like to express her gratitude to Dr. John Zaniewski, the author's advisor. Without the guidance, and support, the author would never have had the opportunity to pursue his Master of Science degree and participate in this research.

The author would also like to extend thanks to Dr. Ronald Eck and Dr. W. V. Thayne, the author's other committee members for their assistance and support during the research work and in classes.

Special thanks are given to J.F. Allen Company, Buckhannon, WV, for all their assistance throughout the project.

Final thanks are given to the author's family and her fiancé Murali. Their love and support have been a source of strength and motivation. 


\section{Table of Contents}

ABSTRACT

CHAPTER 1 INTRODUCTION 1

1.1 INTRODUCTION 1

1.2 PROBLEM STATEMENT 1

1.3 OBJECTIVES 2

1.4 SCOPE OF WORK AND LIMITATIONS 2

1.5 THESIS OVERVIEW 3

CHAPTER 2 LITERATURE REVIEW

2.1 INTRODUCTION 4

2.2 MARSHALL MIX DESIGN 4

2.2.1 MATERIAL SELECTION 4

2.2.2 AGGREGATE GRADATION 5

2.2.3 SPECIMEN FABRICATION 6

2.2.4 VOLUMETRIC ANALYSIS 6

2.2.5 STABILITY AND FLOW MEASUREMENTS 7

2.2.6 OPTIMUM ASPHALT CONTENT 8

2.3 SUPERPAVE MIX DESIGN 9

2.3.1 GYRATORY COMPACTOR

2.3.2 MATERIAL SELECTION 10

2.3.3 DESIGN AGGREGATE STRUCTURE 11

2.3.4 DESIGN ASPHALT BINDER CONTENT 17

2.3.5 MOISTURE SENSITIVITY OF DESIGN MIXTURE 18

2.5 ASPHALT PAVEMENT ANALYZER 18

2.5.1 Evaluation of Permanent Deformation: 19

2.5.2 Results of Ruggedness Study of the APA 20

2.5.3 Effect of Compaction and Specimen Type 21

2.5.4 Effect of Position $\quad 21$

2.6 Conclusions $\quad 21$

CHAPTER 3 RESEARCH METHODOLOGY 23

3.1 INTRODUCTION 23

3.2 MATERIALS 23

3.3 AGGREGATE PREPARATION 23 
3.4 SIEVE ANALYSIS 23

3.5 SPECIFIC GRAVITY OF AGGREGATES 24

3.6 AGGREGATE CONSENSUS PROPERTY TESTS 25

3.7 MARSHALL MIX DESIGN PROCEDURE 25

3.7.1 AGGREGATE GRADATION 26

3.7.2 SPECIFIC GRAVITY 26

3.7.3 THEORETICAL MAXIMUM SPECIFIC GRAVITY 27

3.7.4 MARSHALL STABILITY AND FLOW TEST 27

3.7.5 TABULATING AND PLOTTING TEST RESULTS 28

3.7.6 DETERMINATION OF DESIGN ASPHALT CONTENT 29

3.8 SUPERPAVE MIX DESIGN PROCEDURE 29

3.8.1 AGGREGATE TRIAL BLENDS 29

3.8.2 DESIGN AGGREGATE STRUCTURE 30

3.8.3 DESIGN ASPHALT CONTENT 33

3.9 SPECIMENS FOR APA TESTING 36

3.10 ASPHALT PAVEMENT ANALYZER RUNS 36

3.11 TESTS FOR OTHER CRITERIA

CHAPTER 4 RESULT AND ANALYSIS 38

CHAPTER 5 CONCLUSIONS AND RECOMMENDATIONS 41

5.1 CONCLUSIONS 41

5.2 RECOMMENDATIONS 41

5.3 FUTURE RESEARCH $\quad 42$

REFERENCES $\quad 43$

APPENDIX A AGGREGATE TESTS AND PROPERTIES 46

APPENDIX B Marshall Mix Design Data and Analysis 49

APPENDIX C Superpave Mix Design Data and Analysis 58

APPENDIX D Data and Analysis for Exchanging Superpave and Marshall Mix Designs 68 


\section{List of Figures}

$\begin{array}{ll}\text { Fig. 2.1 Superpave Gyratory Compactor } & 10\end{array}$

Figure 3.1 Marshall gradation plot with control points 26

Fig 4.1 Output of Analysis of Variance 39

Figure B.1 Asphalt content versus Density - Marshall heavy 52

Figure B.2 Asphalt content versus Stability - Marshall heavy traffic mix. 52

Figure B.3 Asphalt content versus Flow - Marshall heavy traffic mix 53

Figure B.4 Asphalt content versus VTM - Marshall heavy traffic mix 53

Figure B.5 Asphalt content versus VMA - Marshall heavy traffic mix 54

Figure B.6 Asphalt content versus VFA -Marshall heavy traffic mix. 54

Figure B. 7 Asphalt content versus density, Marshall medium traffic mix. 55

Figure B.8 Asphalt content versus Stability - Marshall medium traffic mix. 55

Figure B.9 Asphalt content versus Flow - Marshall light traffic level 56

Figure B.10 Asphalt content versus Air voids -Marshall medium traffic mix. $\quad 56$

Figure B.11 Asphalt content versus VMA - Marshall light traffic mix. 57

Figure B.12 Asphalt content versus VFA - Marshall 57

Figure C.1 Asphalt content versus Air voids-Superpave heavy traffic mix. $\quad 60$

$\begin{array}{ll}\text { Figure C.2 Asphalt content versus VMA-Superpave heavy traffic mix. } & 60\end{array}$

Figure C.3 Asphalt content versus Percent Gmm at Nd-Superpave heavy traffic mix 61

Figure C.4 Asphalt content versus VFA - Superpave heavy traffic mix. 61

Figure C.5 Asphalt content versus Air voids-Superpave medium traffic mix. 63

Figure C.6 Asphalt content versus VMA-Superpave medium traffic level 63

Figure C.7 Asphalt content versus Percent of Gmm at Nd-Superpave medium traffic mix $\quad 64$ 
Figure C.8 Asphalt content versus VFA-Superpave medium traffic mix. 64

Figure C.9 Asphalt content versus Air voids-Supeprave light traffic mix. 66

Fgure C.10 Asphalt content versus VMA-Superpave light traffic mix. 66

Figure C.11 Asphalt content versus percent Gmm at Nd-Supeprave light traffic mix. 67

Figure C.12 Asphalt content versus VFA - Superpave light traffic level 67

\section{List of Tables}

Table 2.1 Tolerance Limits of Master Gradation Range for Base II Mix-WVDOH Standard Specifications $\quad 5$

Table 2.2 Stability Correlation Ratios from AASHTO T245 8

Table 2.3 Marshall Mix Design Criteria (WVDOH MP 401.02.22). 9

Table 2.4 Superpave Aggregate Consensus Property Requirements as set forth by WVDOH 12

Table 2.5 Gradation Specifications for 19mm Nominal Maximum Size 13

Table 2.6 Superpave Compaction Criteria (WVDOH MP 401.02.28) 15

Table 2.7 Superpave Volumetric Mix Design Criteria (WVDOH MP 401.02.28) 18

Table 2.8 APA Specifications (APAC Procedure) 20

Table 3.1 Washed Sieve Analysis for Material Passing \#200 Sieve. 24

Table 3.2 Dry Sieve Gradation Analysis Results. 24

Table 3.3 Specific Gravity and Absorption Values. 24

Table 3.4 Average Consensus Property Test Results for Individual Aggregates 25

Table 3.6 Maximum Theoretical Specific Gravity for Marshall Mix Designs. 27

Table 3.7 Volumetric Parameters for Marshall Heavy Traffic Mix 28

Table 3.8 Volumetric Parameters for Marshall Medium Traffic Mix 28

Table 3.9 Summary of Marshall Mix Designs 29 
Table 3.10 Trial Blends for Evaluation of Aggregate Structure 32

Table 3.11 Trial Blends Bulk and Apparent Specific Gravity 32

Table 3.12 Theoretical Maximum Specific Gravity for Superpave Trial Blends 32

Table 3.13 Trial Blends Compaction Data 32

Table 3.14 Adjusted Volumetric Parameters for Superpave Trial Blends 32

Table 3.15 Blend 1 Volumetric Parameters for Medium and Light Traffic Level Mix Designs 33

Table 3.16 Adjusted Volumetric Parameters for Medium and Light Traffic Level Mix Designs 33

Table 3.17 Average $G_{\mathrm{mm}}$ Values for Superpave Mixes 34

Table 3.18. Volumetric Data for Superpave Heavy Traffic Level. 34

Table 3.19 Volumetric Data for Superpave Medium Traffic Level 35

Table 3.20 Volumetric Data for Superpave Light Traffic Level 35

Table 3.21 Summary of Superpave Mix Designs. 35

Table 3.19 Treatments Used in Experimental Design 36

Table 3.20 Rut Depth Results.

Table 4.1 Confidence Interval Computed for Various Parameters 40

Table A.1 Gradation Data for Aggregates 46

Table A.2 Specific Gravity of Aggregates 47

Table A.3. Aggregate Consensus Property Tests 48

Table B.1 Theoretical Maximum Specific Gravity Calculations $\quad 49$

Table B.2 Marshall Heavy Traffic Level Mix Design 50

Table B.3 Marshall Medium Traffic Mix Design 51

Table C.1 Theoretical Specific Gravity for Trial Blends 58

Table C.2 Bulk Specific Gravity for Trial Blends 58 
Table C.3 Theoretical Maximum Specific Gravity Calculations for Superpave Heavy Traffic Mix

Table C.4 Bulk Specific Gravity for Superpave Heavy Traffic Level Mix

Table C.5 Blend Bulk Specific Gravity Calculations -Superpave Medium Traffic Mix.

Table C.6 Theoretical maximum Specific Gravity Calculations-Superpave Medium Traffic Mix

Table C.7 Bulk Specific Gravity-Superpave Medium Traffic Mix.

Table C.8 Blend Bulk Specific Gravity Calculations -Superpave Light Traffic Mix. 65

Table C.9 Theoretical Maximum Specific Gravity Calculations-Superpave Light Traffic Mix.

Table C.10 Bulk Specific Gravity-Superpave Light Traffic Mix. 65

Table D.1 Marshall Mix Designs with Superpave Methodology 68

Table D.2 Superpave Mix Designs with Marshall Methodology 69 


\section{CHAPTER 1 INTRODUCTION}

\subsection{INTRODUCTION}

Most hot mix asphalt (HMA) produced during the 50 years between the 1940s and mid 1990s were designed using the Marshall or Hveem methods. Increases in traffic volumes and heavier loads became initiative for the Strategic Highway Research Program (SHRP) in 1988. After a five year of effort, a new mix design, Superior Performing

Asphalt Pavements (Superpave) ${ }^{\mathrm{TM}}$, was developed. Superpave takes into consideration the factors that are responsible for the typical distresses on asphalt pavements: rutting, fatigue and thermal cracking. With the introduction of Superpave mix design, the Marshall method of mix design is becoming obsolete for highway pavements.

Superpave implementation varies by state. Some have completely switched over to the national Superpave standards. Others have implemented the Superpave concepts, but have adjusted criteria to suit local conditions. Others have partially implemented Superpave for some projects but are using their legacy method for other projects. Finally, two states, California and Nevada, are continuing to use legacy methods. The West Virginia Division of Highways (WVDOH), constructed its first Superpave project on I-79 in 1997. Since then, WVDOH has implemented Superpave on all National Highway System (NHS) projects. The decision regarding implementation of Superpave for non-NHS roads in West Virginia is still under review. The primary objective of this research work was to compare the Superpave and Marshall design mixes in West Virginia to supplement information required for WVDOH to make a suitable decision regarding the implementation of Superpave for low volume roads.

\subsection{PROBLEM STATEMENT}

One of the advantages of the Marshall mix design method in West Virginia is that the performance of the mixes is known for local conditions and materials. There are no Superpave projects for low volume roads in West Virginia to evaluate the performance of mixes. An investigation is needed to compare the performance of Superpave and Marshall mix design methods, to support replacement of conventional mix design with the new mix design. This research work compared the Superpave and Marshall mixes in 
West Virginia using the Asphalt Pavement Analyzer (APA) to evaluate rutting performance in the laboratory. Mix designs were prepared under the Marshall and Superpave methodologies. The resulting Marshall mix designs were evaluated under the Superpave criteria, and vice versa. If the mixes prepared under the Superpave method met the Marshall criteria, it was hypothesized that these mixes would perform well in the field. If the mixes prepared under the Marshall method pass the Superpave criteria, it was hypothesized that contractors would not encounter any undue hardships in designing and constructing pavements to the Superpave criteria.

\subsection{OBJECTIVES}

The objective of this research was to compare $19 \mathrm{~mm}$ Superpave and Base II Marshall mixes in West Virginia. The primary area of interest for this comparison was for medium and light traffic volume loads since the WVDOH has not implemented Superpave for these traffic levels. The research included mix designs for high traffic volume roads for completeness and to provide insight on how the research methodology would rank these mixes.

\subsection{SCOPE OF WORK AND LIMITATIONS}

In this research work 19mm Superpave and Base II Marshall mixes were designed for Heavy, Medium, and Light traffic levels. Marshall and Superpave mixes were designed from locally available materials. The Marshall and Superpave mix design procedures of the West Virginia Division of Highways (WVDOH) were followed. Gyratory compactor was used to make the Asphalt Pavement Analyzer (APA) samples to evaluate permanent deformation (rutting). Results from tests with different aggregates, gradations, and binder types show that the APA is sensitive to these factors and, therefore, has a potential to predict relative rutting of hot mix asphalt mixtures ( 2 ).

The experimental design used for this research work provides comparison between the mixes, traffic levels and their interactions. The work was limited to Base-II mixes in West Virginia and to one source of aggregate and asphalt cement. The $19 \mathrm{~mm}$ nominal maximum size aggregate was used for the two mix design methods. The J.F. 
Allen Company, Buckhannon, WV, provided the aggregate used for the research. The asphalt used was PG 70-22 from the source Marathon Ashland.

The work was also limited to laboratory testing. Field evaluation could not be performed since WVDOH has not constructed medium and light traffic volume Superpave mixes.

\subsection{THESIS OVERVIEW}

This thesis is organized into five chapters and five appendices. After the first chapter of Introduction, Chapter 2 is a summary of literature review. Superpave and Marshall mix design procedures are outlined with standard test procedures and specifications required by the WVDOH. The method of rut testing with the Asphalt Pavement Analyzer (APA), as specified by the device manufacturer, is explained in detail. The research methodology and procedures for preparing, testing and analyzing samples is presented in Chapter 3. Chapter 4 presents the results of the experimental design and the analysis of the results. Chapter 5 concludes the thesis with the conclusions and recommendations.

The aggregate test data are presented in the Appendix A. Detailed test data and interim calculations of Marshall and Superpave mix designs are presented in Appendix B and Appendix C respectively. Appendix D presents the data for evaluating Superpave mix design with Marshall methodology and vice versa. 


\section{CHAPTER 2 LITERATURE REVIEW}

\subsection{INTRODUCTION}

It was in 600's B.C. that the first Asphalt road was paved in Babylon. The first bituminous Hot Mix Asphalt (HMA) pavement in the United States was built in Washington D.C, in 1873. In the years between the 1940s and mid 1990s, most of the hot mix asphalt projects in United States were designed using the Marshall and Hveem methods. According to survey in 1984, approximately 75 percent of the State Highway Departments used some variation of the Marshall method while the remaining 25 percent used some variation of Hveem method (4). In 1995, a few states began to use the Superpave design procedures (4). The 2000 Superpave Implementation survey shows that almost every state in United States is at some stage or the other in Superpave implementation ( 8).

The Superpave and Marshall mix design methods, the Gyratory Compaction, and Asphalt Pavement Analyzer (APA) are discussed in this chapter.

\subsection{MARSHALL MIX DESIGN}

Bruce Marshall, formerly the Bituminous Engineer with the Mississippi State Highway Department, developed the original concept of the Marshall Method of designing asphalt pavements. The present form of Marshall mix design method originated from an investigation started by the U.S Army Corps of Engineers in 1943 (4). The purpose of the Marshall method is to determine the optimum asphalt content for a particular blend of aggregates and traffic level. The optimum asphalt content is determined by the ability of a mix to satisfy stability, flow, and volumetric properties.

\subsubsection{MATERIAL SELECTION}

The materials used in the mix design should conform to the requirements set forth in the Standard Specifications of WVDOH. Specifications for aggregate are covered under sections 702 and 703 while asphalt cement is covered under section 705 . 


\subsubsection{AGGREGATE GRADATION}

The aggregate blend gradation requirements for base II mixes is presented in Table 2.1 (WVDOH Standard Specifications; Section 401). Aggregates meeting these requirements are not placed in single stockpile, as this would promote segregation. Therefore, stockpiles must be blended to meet the gradation specifications. Equation 2.1 is used to estimate the blended gradation from multiple stockpiles.

Table 2.1 Tolerance Limits of Master Gradation Range for Base II Mix-WVDOH Standard Specifications

\begin{tabular}{|c|c|}
\hline $\begin{array}{c}\text { SIEVE } \\
\text { SIZE (mm) }\end{array}$ & $\begin{array}{l}\text { BASE II } \\
\text { LEVEL }\end{array}$ \\
\hline 25 & 100 \\
\hline 19 & $90-100$ \\
\hline 12.5 & $90 \mathrm{max}$ \\
\hline 9.5 & \\
\hline 4.75 & \\
\hline 2.36 & $20-50$ \\
\hline 1.18 & \\
\hline 0.600 & \\
\hline 0.300 & \\
\hline 0.075 & $2.0-8.0$ \\
\hline
\end{tabular}

$$
p=A a+B b+C c+\ldots
$$

where,

$\mathrm{p}=$ the percent of material passing a given sieve for the combined aggregates $\mathrm{A}, \mathrm{B}, \mathrm{C} \ldots$; $\mathrm{A}, \mathrm{B}, \mathrm{C}, \ldots=$ the percent of material passing a given sieve for each aggregate $\mathrm{A}, \mathrm{B}, \mathrm{C}, \ldots$; $\mathrm{a}, \mathrm{b}, \mathrm{c}, \ldots=$ proportions of aggregates $\mathrm{A}, \mathrm{B}, \mathrm{C}, \ldots$ to be used in the blend.

The specific gravity for the blend is computed as:

$$
G=\frac{P_{1}+P_{2}+\ldots+P_{n}}{\frac{P_{1}}{G_{1}}+\frac{P_{2}}{G_{2}}+\ldots+\frac{P_{n}}{G_{n}}}
$$

where, 
$\mathrm{G}=$ blend specific gravity;

$\mathrm{G}_{1}, \mathrm{G}_{2}, \ldots \mathrm{G}_{\mathrm{n}}=$ specific gravity values for fraction $1,2, \ldots \mathrm{n}$; and

$\mathrm{P}_{1}, \mathrm{P}_{2}, \ldots \mathrm{P}_{\mathrm{n}}=$ weight percentages of fraction $1,2, \ldots \mathrm{n}$.

\subsubsection{SPECIMEN FABRICATION}

For determining the design asphalt content for a particular blend of aggregates by the Marshall method, a series of test specimens are required to include a range of asphalt contents of at least $2.0 \%$, at intervals not to exceed $0.5 \%$. Three specimens are required for each asphalt content used in the design. The standard method for compacting the test specimens is to immediately compact them after mixing process is completed. The WVDOH requires that the specimens are oven aged for two hours. The WVDOH uses compaction effort of 50 and 75 blows per side for medium and heavy traffic levels, respectively. WVDOH uses the medium traffic level procedures for light traffic levels.

At least one specimen is required at the estimated asphalt content to determine the maximum specific gravity (AASHTO T209). WVDOH requires two maximum specific gravity samples. These samples are prepared at the estimated asphalt content for the mix.

\subsubsection{VOLUMETRIC ANALYSIS}

The bulk specific gravity of the compacted samples is measured and used with the maximum theoretical specific gravity to perform the volumetric analysis. The volumetric parameters and formulae for their calculation are:

$$
\begin{aligned}
& V M A=100\left(1-\frac{G_{m b}\left(1-P_{b}\right)}{G_{s b}}\right) \\
& V T M=\left(1-\frac{G_{m b}}{G_{m m}}\right) 100 \\
& V F A=\frac{V M A-V T M}{V M A} \times 100
\end{aligned}
$$

where,

$\mathrm{VMA}=$ Volume of voids in mineral aggregate; 
$\mathrm{G}_{\mathrm{mb}}=$ Bulk specific gravity of compacted mixture;

$\mathrm{P}_{\mathrm{b}}=$ Asphalt content;

$\mathrm{G}_{\mathrm{sb}}=$ Bulk specific gravity of aggregate;

$\mathrm{VTM}=$ Air voids in compacted mixture:

$\mathrm{G}_{\mathrm{mm}}=$ Theoretical maximum specific gravity; and

$\mathrm{VFA}=$ Voids filled with asphalt

Since the theoretical maximum specific gravity $\left(\mathrm{G}_{\mathrm{mm}}\right)$ is only measured for one asphalt content (preferably near the optimum), its value at the other asphalt contents is computed as:

$$
\begin{aligned}
G_{s e} & =\frac{1-P_{b}}{\frac{1}{G_{m m}}-\frac{P_{b}}{G_{b}}} \\
G_{m m}^{\prime} & =\frac{1}{\frac{1-P_{b}^{\prime}}{G_{s e}}+\frac{P_{b}^{\prime}}{G_{b}}}
\end{aligned}
$$

where,

$\mathrm{G}_{\mathrm{se}}=$ Effective specific gravity of aggregates;

$\mathrm{G}_{\mathrm{mm}}=$ Theoretical maximum specific gravity measured;

$P_{b}=$ Asphalt content used for $G_{m m}$ samples;

$G_{m m}^{\prime}=$ Calculated theoretical maximum specific gravity;

$P_{b}^{\prime}=$ Asphalt content used for other compacted samples; and

$\mathrm{G}_{\mathrm{b}}=$ Binder specific gravity (generally provided by binder supplier).

\subsubsection{STABILITY AND FLOW MEASUREMENTS}

Marshall stability is defined as the maximum load carried by a compacted specimen tested at $140^{\circ} \mathrm{F}\left(60^{\circ} \mathrm{C}\right)$ at a loading rate of 2 inches/minute (4). The flow is measured at the same time as the Marshall stability. The flow is equal to the vertical 
deformation of the sample (measured from start of loading to the point at which stability begins to decrease) in hundredths of an inch (4). The stability and flow measurements procedure (AASHTO T245) indicates that the stability reading for a test specimen is only accurate if the test specimen measures $63.5 \mathrm{~mm}$ in height. For test specimens that vary slightly from $63.5 \mathrm{~mm}$, the stability reading should be multiplied with a correlation ratio in Table 2.2 (AASHTO T245).

Table 2.2 Stability Correlation Ratios from AASHTO T245

\begin{tabular}{|c|c|}
\hline Specimen Height & Correlation Ratio \\
\hline 58.7 & 1.14 \\
\hline 60.3 & 1.09 \\
\hline 61.9 & 1.04 \\
\hline 63.5 & 1.00 \\
\hline 65.1 & 0.96 \\
\hline 66.7 & 0.93 \\
\hline 68.3 & 0.89 \\
\hline 69.8 & 0.86 \\
\hline 71.4 & 0.83 \\
\hline 73.0 & 0.81 \\
\hline 74.6 & 0.78 \\
\hline 76.2 & 0.76 \\
\hline
\end{tabular}

\subsubsection{OPTIMUM ASPHALT CONTENT}

The stability, flow, unit weight, air voids, VMA and VFA are plotted versus the asphalt content. The optimum asphalt content of the mix is determined from the data obtained from the plots. WVDOH specifies that the asphalt content that corresponds to the specification's median air void content $(4.0 \%)$ is the optimum asphalt content. Using the asphalt content at $4.0 \%$ air voids, the corresponding values for VMA, VFA, stability and flow are determined from the plots and compared to the acceptance criteria in Table 2.3 (WVDOH MP 401.02.22). The mix must be redesigned using different aggregate blends if design criteria are not satisfied. 
Table 2.3 Marshall Mix Design Criteria (WVDOH MP 401.02.22).

\begin{tabular}{|l|c|c|}
\hline Design Criteria & Medium traffic design & Heavy traffic design \\
\hline $\begin{array}{l}\text { Compaction, number of } \\
\text { blows per side }\end{array}$ & 50 & 75 \\
\hline Stability (Newton) & 5300 & 8000 \\
\hline Flow $(0.25 \mathrm{~mm})$ & $8-16$ & $8-14$ \\
\hline Air voids $(\%)$ & $3-5$ & $3-5$ \\
\hline VFA, $\%$ & $65-78$ & $65-75$ \\
\hline VMA, \% & $13 *$ & $13^{*}$ \\
\hline
\end{tabular}

*VMA specifications are for Base II mix.

\subsection{SUPERPAVE MIX DESIGN}

Despite the best efforts put with the existing mix design methods, it is common to see severe rutting and cracking in asphalt pavements due to increased traffic loads and environmental conditions. In the 1988, a research program called Strategic Highway Research Program (SHRP) was started in USA. The major funds of the SHRP research program were allocated to establish new procedures for the selection of binders and mix designs with regard to the rutting and cracking problems in the asphalt pavements. The research program was completed in 1993, producing the Superpave mix design method (7).

\subsubsection{GYRATORY COMPACTOR}

The key piece of equipment used in the Superpave mix design method is the gyratory compactor, Figure 2.1. One of the main goals of the SHRP was to develop a laboratory compaction method, which can consistently produce specimens representative of in-service pavements. The Superpave gyratory compactor compacts HMA samples to densities achieved under traffic loading conditions. Its ability to estimate specimen density at any point during the compaction process is its key feature (4).

Gyratory compaction has been used in asphalt mix design since early 1900's. Midway through the Strategic Highway Research Program, an evaluation of available gyratory compaction research was done to develop a gyratory protocol, which would simulate the density achieved at the end of pavement's life. Studies conducted during SHRP show that the density of the HMA sample is influenced mostly by the angle of 
gyration, and slightly by the speed of gyration and the vertical pressure. The stresses applied to the mixture and the mixture properties are the two parameters that would influence asphalt mixture density (3).

Fig. 2.1 Superpave Gyratory Compactor

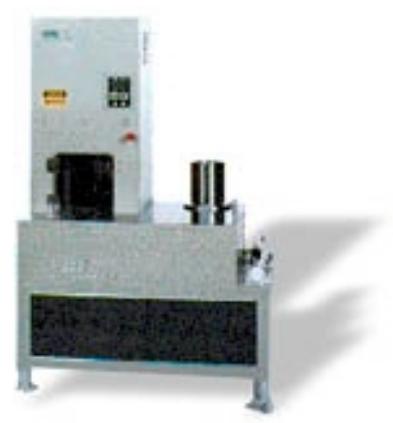

The AASHTO provisional standard TP 4-00 covers the compaction of cylindrical specimens of hot-mix asphalt (HMA) using the Superpave gyratory compactor. This standard specifies the compaction criteria of the Superpave gyratory Compactor. The ram shall apply and maintain a pressure of $600 \pm 18 \mathrm{kPa}$ perpendicular to the cylindrical axis of the specimen during compaction. The compactor shall tilt the specimen at an angle of $1.25 \pm 0.02^{\circ}$ and rotate the specimen molds at a rate of $30.0 \pm 0.5$ gyrations per minute throughout compaction.

The ruggedness evaluation of AASHTO TP4 conducted by FHWA arrived at the conclusions that (9):

- The tolerance on compaction angle $\left( \pm 0.02^{\circ}\right)$ is reasonable and necessary

- The tolerance on compaction pressure $( \pm 18 \mathrm{kPa})$ is too high

\subsubsection{MATERIAL SELECTION}

Binder selection is based on environmental data, traffic level and traffic speed. A Performance Grade asphalt binder is designated with a high and low temperature grade, such as PG 70-22. For this binder, 70 is the high temperature grade and is the 7 -day 
maximum pavement design temperature in degrees centigrade for the project. The low temperature grade, -22 , is the minimum pavement design temperature in centigrade (5).

The SHRP made no research effort to specifically look at aggregates. However, guidance was eventually provided based on a consensus approach by a group of experts. Superpave requires both consensus and source aggregate tests be performed to assure that the combined aggregates selected for the mix design are acceptable. The consensus property criteria are the minimum requirements for the aggregates to be used in the Superpave mix design method and they are the same regardless of geographic location. The source property criteria are specified by the state highway agencies (5). Superpave requires the following consensus properties be determined for the design aggregate blend:

- Coarse aggregate angularity (ASTM D 5821) -materials retained on $4.75 \mathrm{~mm}$ sieve.

- Fine Aggregate angularity (AASHTO T304) - materials passing the $2.36 \mathrm{~mm}$ sieve.

- Flat \& Elongated particles (ASTM D4791) -materials retained on $9.5 \mathrm{~mm}$ sieve.

- Sand Equivalent (AASHTO T176) -materials passing the $4.75 \mathrm{~mm}$ sieve.

The flat and elongated test follows the general procedures of ASTM D 4791, but is modified for Superpave. Under the Superpave guidelines an aggregate particle coarser than $4.75 \mathrm{~mm}$ sieve is flat and elongated if the ratio of the maximum to minimum dimension is greater than 5 ( 5).

Aggregate property requirements set forth by WVDOH is shown in Table

\section{4(WVDOH MP-2)}

\subsubsection{DESIGN AGGREGATE STRUCTURE}

Trial blends are established by mathematically combining the gradations of individual stockpiles into a single blend using Equation 2.1. The gradation of the aggregate blend must be within the control limits to meet the Superpave requirements. The gradation control is based on four control sieves: the maximum sieve, the nominal 
Table 2.4 Superpave Aggregate Consensus Property Requirements as set forth by WVDOH

\begin{tabular}{|l|c|c|c|c|c|c|}
\hline $\begin{array}{l}\text { Design } \\
\text { ESALs } \\
\text { (Million) }\end{array}$ & $\begin{array}{l}\text { Coarse Aggregate } \\
\text { angularity }(\% \mathrm{~min}) \\
100 \mathrm{~mm} \\
\text { from } \\
\text { surface }\end{array}$ & $\begin{array}{l}>100 \mathrm{~mm} \\
\text { from } \\
\text { surface }\end{array}$ & $\begin{array}{l}\text { Fine aggregate } \\
\text { angularity (\%min) } \\
100 \mathrm{~mm} \\
\text { from } \\
\text { surface }\end{array}$ & $\begin{array}{l}>100 \mathrm{~mm} \\
\text { from } \\
\text { surface }\end{array}$ & $\begin{array}{l}\text { Sand } \\
\text { equivalent } \\
\text { Percent } \\
\text { minimum }\end{array}$ & $\begin{array}{l}\text { Flat \& } \\
\text { elongated } \\
\text { Percent } \\
\text { minimum }\end{array}$ \\
\hline$<0.3$ & $55 /-$ & - & - & - & 40 & - \\
\hline 0.3 to $<3$ & $75 /-$ & $50 /-$ & 40 & 40 & 40 & 10 \\
\hline 3 to $<10$ & $85 / 80$ & $60 /-$ & 45 & 40 & 40 & 10 \\
\hline 10 to $<20$ & $90 / 95$ & $80 / 75$ & 45 & 40 & 45 & 10 \\
\hline 20 to $<30$ & $95 / 90$ & $80 / 75$ & 45 & 40 & 45 & 10 \\
\hline 30 & $100 / 100$ & $100 / 100$ & 45 & 45 & 50 & 10 \\
\hline \multicolumn{7}{|c|}{ Percent of one/more than one fractured faces } \\
\hline
\end{tabular}

maximum sieve, the 2.36-millimeter sieve, and the 75-micron sieve. The Superpave definitions for nominal maximum aggregate size and maximum aggregate size are:

- Nominal Maximum Aggregate Size: One sieve size larger than the first sieve to retain more than $10.0 \%$ of the material.

- Maximum Aggregate Size: One sieve size larger than the nominal maximum aggregate size.

The restricted zone is another part of grading specification. Aggregate blends that pass through the restricted zone that do not use excessive amounts of rounded aggregates and that meet the minimum VMA requirements perform satisfactorily (4). However, the WVDOH specifications do not allow any mix with a gradation passing through the restricted zone. There is evidence to support the belief that mixtures closer to the low end of the control limits (those going underneath the restricted zone) provide a desirable structure for resisting rutting (4). WVDOH Specifications for $19 \mathrm{~mm}$ nominal maximum size are shown in Table 2.5.

Once an aggregate blend is identified, which meets the gradation criteria, the consensus propery for the blend is determined as:

$$
X=\frac{x_{1} P_{1} p_{1}+x_{2} P_{2} p_{2}+\ldots}{P_{1} p_{1}+P_{2} p_{2}+\ldots}
$$


Table 2.5 Gradation Specifications for 19mm Nominal Maximum Size

\begin{tabular}{|c|c|c|c|c|}
\hline \multirow{2}{*}{$\begin{array}{c}\text { SIEVE } \\
\text { SIZE } \\
(\mathrm{mm})\end{array}$} & \multicolumn{2}{|c|}{ CONTROL POINTS } & \multicolumn{2}{c|}{ RESTRICTED ZONE } \\
\cline { 2 - 5 } & Lower & Upper & Lower & Upper \\
\hline 25 & 100 & 100 & - & - \\
\hline 19 & 90 & 100 & - & - \\
\hline 12.5 & - & 90 & - & - \\
\hline 9.5 & - & - & - & - \\
\hline 4.75 & - & - & - & - \\
\hline 2.36 & 23 & 49 & 34.6 & 34.6 \\
\hline 1.18 & - & - & 22.3 & 28.3 \\
\hline 0.6 & - & - & 16.7 & 20.7 \\
\hline 0.3 & - & - & 13.7 & 13.7 \\
\hline 0.15 & - & - & - & - \\
\hline 0.075 & 2 & 8 & - & - \\
\hline
\end{tabular}

where

$\mathrm{X}=$ Blended consensus property;

$\mathrm{X}_{\mathrm{i}}=$ Consensus property for stockpile;

$P_{i}=$ Percent of stockpile $\mathrm{i}$ in the blend; and

$\mathrm{p}_{\mathrm{i}}=$ Percent of stockpile which either passes or is retained on the dividing sieve.

The Superpave process requires evaluating the aggregate blends to determine a design aggregate structure. The Superpave guidelines suggest selecting two blends with gradation below the restricted zone and one blend with a gradation above the restricted zone. The asphalt content for the blends may be estimated based on experience or using the equations:

$$
\begin{aligned}
G_{s e} & =G_{s b}+F\left(G_{s a}-G_{s b}\right) \\
V_{b a} & =\frac{P_{s}\left(1-V_{a}\right) \times}{\left(\frac{P_{b}}{G_{b}}+\frac{P_{s}}{G_{s e}}\right)}\left(\frac{1}{G_{s b}}-\frac{1}{G_{s a}}\right) \\
V_{b e} & =0.176-0.0675 \times \ln \left(S_{n}\right)
\end{aligned}
$$




$$
\begin{aligned}
& W_{s}=\frac{P_{s} \times\left(1-V_{a}\right)}{\left(\frac{P_{b}}{G_{b}}+\frac{P_{s}}{G_{s e}}\right)} \\
& P_{b i}=\frac{G_{b} \times\left(V_{b e}+V_{b a}\right)}{\left(G_{b} \times\left(V_{b e}+V_{b a}\right)\right)+W_{s}}
\end{aligned}
$$

where,

$\mathrm{G}_{\mathrm{se}}=$ Effective specific gravity of aggregate;

$\mathrm{G}_{\mathrm{sb}}=$ Bulk specific gravity of aggregate;

$\mathrm{G}_{\mathrm{sa}}=$ Apparent specific gravity of aggregate;

$\mathrm{F}=$ factor for absorption;

$\mathrm{V}_{\mathrm{ba}}=$ volume of absorbed binder;

$\mathrm{P}_{\mathrm{b}}=$ Asphalt content, percent by weight of mix;

$\mathrm{P}_{\mathrm{c}}=$ percent of aggregate;

$\mathrm{G}_{\mathrm{b}}=$ Specific gravity of binder;

$\mathrm{V}_{\mathrm{a}}=$ volume of air voids;

$\mathrm{W}_{\mathrm{s}}$ = weight of aggregate;

$\mathrm{V}_{\mathrm{ba}}=$ volume of absorbed binder;

$\mathrm{V}_{\mathrm{be}}=$ volume of effective binder;

$\mathrm{S}_{\mathrm{n}}=$ nominal maximum sieve size of aggregate blend; and

$\mathrm{P}_{\mathrm{bi}}=$ percent (by weight) of binder;

Two samples are prepared for each aggregate blend. The samples are mixed, cured for 2 hours and compacted and the $\mathrm{G}_{\mathrm{mb}}$ is determined. The Superpave gyratory compactor is used to compact the samples. The number of gyrations applied to the mix regulates the compactive effort. The number of gyrations required is a function of the traffic level. As shown in the Table 2.6, Superpave defines three compaction requirements for a mix. 
Table 2.6 Superpave Compaction Criteria (WVDOH MP 401.02.28)

\begin{tabular}{|c|c|c|c|}
\hline ESALs (million) & \multicolumn{3}{|c|}{ Compaction Parameters } \\
\cline { 2 - 4 } & $\mathrm{N}_{\mathrm{i}}$ & $\mathrm{N}_{\mathrm{d}}$ & $\mathrm{N}_{\mathrm{m}}$ \\
\hline$<0.3$ & 6 & 50 & 75 \\
\hline 0.3 to $<3$ & 7 & 75 & 115 \\
\hline 3 to $<30$ & 8 & 100 & 160 \\
\hline$>30$ & 9 & 125 & 205 \\
\hline
\end{tabular}

The number of gyrations for design, $\mathrm{N}_{\mathrm{d}}$, was selected to simulate the compacted state of an asphalt pavement following construction. An initial compactive effort, $\mathrm{N}_{\mathrm{i}}$, was defined to identify "tender" mixes. Some mixes are difficult to compact in the field because the mix lacks the internal friction required to prevent the excessive deformation. As traffic is applied to a pavement, the mix will continue to compact until an equilibrium condition is achieved. The maximum Superpave compactive effort, $\mathrm{N}_{\max }$ was selected to ensure the material does not over compact under traffic. $\mathrm{N}_{\max }$ and $\mathrm{N}_{\mathrm{i}}$ are a function of $\mathrm{N}_{\mathrm{d}}$ :

$$
\begin{aligned}
& N_{i}=\left(N_{d}\right)^{0.45} \\
& N_{\max }=\left(N_{d}\right)^{1.10}
\end{aligned}
$$

where

$\mathrm{N}_{\mathrm{i}}=$ Initial number of gyrations;

$\mathrm{N}_{\mathrm{d}}=$ Design number of gyrations; and

$\mathrm{N}_{\mathrm{m}}=$ maximum number of gyrations.

The WVDOH requirements for compactive effort are given in Table 2.6.The design aggregate structure samples are compacted to $\mathrm{N}_{\mathrm{d}}$. The bulk specific gravity of the mix at $\mathrm{N}_{\mathrm{i}}$ must be computed as:

$$
G_{m b, N_{i}}=\frac{h_{d}}{h_{i}}\left(G_{m b, N_{d}}\right)
$$

where

$\mathrm{G}_{\mathrm{mb}, \mathrm{Ni}}=$ Bulk specific gravity at $\mathrm{N}_{\mathrm{i}}$;

$\mathrm{h}_{\mathrm{d}}=$ Height of the specimen at $\mathrm{N}_{\mathrm{d}}$; 
$\mathrm{h}_{\mathrm{i}}=$ Height of the specimen at $\mathrm{N}_{\mathrm{i}}$;

$\mathrm{G}_{\mathrm{mb}, \mathrm{Nd}}=$ Bulk specific gravity at $\mathrm{N}_{\mathrm{d}}$

The percent maximum specific gravity at $\mathrm{N}_{\mathrm{i}}$ is computed as:

$$
\% G_{m m, N_{i}}=100 \frac{G_{m b, N_{i}}}{G_{m m}}
$$

Two samples for each aggregate blend are prepared and evaluated to determine $\mathrm{G}_{\mathrm{mm}} \cdot \mathrm{G}_{\mathrm{mb}}$ and $\mathrm{G}_{\mathrm{mm}}$ are used for a volumetric analysis. VTM, VMA and VFA are computed using equations 2.3 to 2.5 .

Since $\mathrm{P}_{\mathrm{b}}$ was only estimated, the VTM is generally not equal to the criteria of $4.0 \%$ air voids. Thus, the volumetric parameters are "corrected" to a $4.0 \%$ air content using the equations:

$$
\begin{aligned}
& P_{b, e s t}=P_{b t}-\left(0.4 \times\left(4-V_{a} @ N_{d}\right)\right) \\
& V M A_{e s t}=V M A @ N_{d}+C \times\left(4-V_{a} @ N_{d}\right) \\
& V F A_{e s t}=100\left(V M A_{e s t}-V_{a} @ N_{d}\right) / V M A_{e s t} \\
& E s t \% G_{m m, i}=\% G_{m m, i}-\left(4.0-V_{a} @ N_{d}\right) \\
& E s t \% G_{m m, m}=\% G_{m m, m}-\left(4.0-V_{a} @ N_{d}\right)
\end{aligned}
$$

where

$\mathrm{P}_{\mathrm{b}, \text { est }}=$ Estimated asphalt binder content;

$\mathrm{P}_{\mathrm{bt}}=$ Trial percent asphalt binder content;

$\mathrm{V}_{\mathrm{a}}=$ percent air voids in total mix at $\mathrm{N}_{\mathrm{d}} ;$

$\mathrm{VMA}_{\text {est }}=$ Estimated voids in mineral aggregate;

$\mathrm{C}=0.1$ when $\mathrm{V}_{\mathrm{a}}$ is less than $4.0 \%$,

$\mathrm{C}=0.2$ when $\mathrm{V}_{\mathrm{a}}$ is $4.0 \%$ or greater

$\mathrm{VFA}_{\text {est }}=$ Estimated voids filled with asphalt; 
Est $\% \mathrm{G}_{\mathrm{mm}, \mathrm{i}}=$ Estimated percentage of maximum specific gravity at $\mathrm{N}_{\mathrm{i}}$;

Est $\% \mathrm{G}_{\mathrm{mm}, \mathrm{m}}=$ Estimated percentage of maximum specific gravity at $\mathrm{N}_{\mathrm{d}}$;

In addition the dust to binder ratio is computed as:

$$
\begin{aligned}
& P_{b e, e s t}=\left(P_{s} \times G_{b}\right) \times \frac{\left(G_{s e}-G_{s b}\right)}{\left(G_{s e} G_{s b}\right)} \times P_{b, e s t} \\
& F / P_{b e, e s t}=\frac{\% P_{0.075 \mathrm{~mm}}}{P_{b e, e s t}}
\end{aligned}
$$

where

$\mathrm{F} / \mathrm{P}_{\mathrm{be}, \mathrm{est}}=$ Estimated fines to effective asphalt ratio; and $\% \mathrm{P}_{0.075 \mathrm{~mm}}=$ percent material finer than $0.075 \mathrm{~mm}$ sieve.

The corrected volumetric parameters are compared to the Superpave criteria, Table 2.7. The design aggregate structure, which "best" meets the criteria is selected for determining the design binder content. If none of the aggregate blends produce an acceptable mix, a new aggregate blend must be determined and evaluated.

\subsubsection{DESIGN ASPHALT BINDER CONTENT}

The design binder content is defined by Superpave as the asphalt content that produces $4.0 \%$ air voids at $\mathrm{N}_{\mathrm{d}}$ and meets all other criteria. A good estimate of design asphalt content is established from the design aggregate blend trials. Two or three samples depending on the agency are prepared at four levels of binder content: $\mathrm{P}_{\mathrm{b}, \text { est }}-0.5 \%, \mathrm{P}_{\mathrm{b}, \text { sst }}, \mathrm{P}_{\mathrm{b}, \text { est }}+0.5 \%$ and $\mathrm{P}_{\mathrm{b}, \text { est }}+1.0 \%$. The samples are compacted to $\mathrm{N}_{\mathrm{d}}$ gyrations and a volumetric analysis is performed and the results are plotted. As with the Marshall procedure, the asphalt content corresponding to $4.0 \%$ air voids is determined. This asphalt content is used with other plots to determine the other volumetric properties. The design mixture must meet the requirements for $\mathrm{N}_{\mathrm{i}}$, VMA, VFA and dust to binder ratio as presented in Table 2.7. Two additional samples are mixed with the selected asphalt content and compacted to $\mathrm{N}_{\mathrm{m}}$ to verify the mix meets the criteria. 


\subsubsection{MOISTURE SENSITIVITY OF DESIGN MIXTURE}

The moisture sensitivity of the design mixture is evaluated by performing AASHTO T-283 on the design aggregate blend at the design asphalt content. Specimens are compacted to $7.0 \pm 1.0 \%$ air voids. The conditioned subset of three specimens is subjected to partial vacuum saturation followed by an optional freeze cycle, followed by a 24 hour heating cycle at $60^{\circ} \mathrm{C}$. The conditioned subset and unconditioned subset of three specimens each are tested to determine indirect tensile strengths. The moisture sensitivity is determined as a ratio of the tensile strengths of the conditioned subset divided by the tensile strengths of the control subset. The use of AASHTO T-283 is not required to design a Superpave mix. However, some method of moisture sensitivity should be employed ( 5).

Table 2.7 Superpave Volumetric Mix Design Criteria (WVDOH MP 401.02.28)

\begin{tabular}{|c|c|c|c|c|}
\hline \multicolumn{4}{|c|}{ Design air voids } & $4.0 \%$ \\
\hline \multicolumn{4}{|c|}{ Fines to effective asphalt ratio } & $0.6-1.2$ \\
\hline \multicolumn{4}{|c|}{$\begin{array}{l}\text { Tensile strength } \\
\text { ratio }\end{array}$} & $\begin{array}{c}80 \% \\
\text { minimum } \\
\end{array}$ \\
\hline \multicolumn{5}{|c|}{ VMA, $\% \quad$ Nominal maximum size } \\
\hline $37.5 \mathrm{~mm}$ & $25 \mathrm{~mm}$ & $19 \mathrm{~mm}$ & $12.5 \mathrm{~mm}$ & $9.5 \mathrm{~mm}$ \\
\hline 11.0 & 12.0 & 13.0 & 14.0 & 15.0 \\
\hline \multirow{2}{*}{$\begin{array}{l}\text { Design } \\
\text { ESALs } \\
\text { (millions) }\end{array}$} & \multicolumn{3}{|c|}{$\begin{array}{l}\text { \% Theoretical maximum } \\
\text { specific gravity }\end{array}$} & \multirow{2}{*}{$\begin{array}{l}\text { Percent voids } \\
\text { filled with } \\
\text { asphalt } \\
\text { (VFA) }\end{array}$} \\
\hline & $\mathrm{N}_{\mathrm{i}}$ & $\mathrm{N}_{\mathrm{d}}$ & $\mathrm{N}_{\max }$ & \\
\hline$<0.3$ & 91.5 & 96.0 & 98.0 & $70-80$ \\
\hline $0.3<3$ & 90.5 & 96.0 & 98.0 & $65-78$ \\
\hline $3<10$ & 89.0 & 96.0 & 98.0 & $65-75$ \\
\hline $10<30$ & 89.0 & 96.0 & 98.0 & $65-75$ \\
\hline$\geq 30$ & 89.0 & 96.0 & 98.0 & $65-75$ \\
\hline
\end{tabular}

\subsection{ASPHALT PAVEMENT ANALYZER}

Ruts are depressions, which occur in the pavement's wheel path. Traffic compaction or displacement of unstable material causes ruts. Negligible amount of rutting occurs in HMA surfaces due to continued densification under traffic after initial 
compaction during construction. Rutting in a pavement can be larger if the HMA layer, underlying layers, or the subgrade soil is overstressed and significant densification or shear failures occur. Some common mistakes made when designing the HMA mixes like selection of high asphalt content, use of excessive filler material (material passing \#200 sieve), use of too many rounded particles in aggregates are all contributors to rutting in HMA (4). In recent years, the potential for rutting on the nation's highways has increased due to higher traffic volumes and the increased use of radial tires that typically exhibit higher inflation pressures ( 6).

The most common type of laboratory equipment that predicts field-rutting potential is a loaded wheel tester (LWT). The LWTs currently being used in United States include the Georgia Loaded Wheel Tester (GLWT), Asphalt pavement Analyzer (APA), Hamburg Wheel Tracking Device (HWTD), LCPC (French) Wheel Tracker, Purdue University Laboratory Wheel Tracking Device (PURWheel), and one-third scale Model Mobile Load Simulator ( 6).

The APA is the new generation of the Georgia Loaded GLWT and was first manufactured in 1996 by Pavement Technology, Inc. The APA is a multi-functional LWT that can be used for evaluating rutting, fatigue cracking, and moisture susceptibility of hot and cold asphalt mixes (2).

\subsubsection{Evaluation of Permanent Deformation:}

The standard method followed to determine rutting susceptibility using APA is developed by APAC Materials Services in ASTM format. Rutting susceptibility of mixes is estimated by placing beam or cylindrical samples under repetitive wheel loads and measuring the amount of permanent deformation under the wheel loads. Triplicate beam samples or cylindrical samples can be tested in APA under controllable high temperature and in dry or submerged-in water conditions. The rut depth is measured after the desired number of cycles (usually 8000) of load application (11). The Table 2.8 shows the test parameters specified in the APAC procedure. 
Table 2.8 APA Specifications (APAC Procedure)

\begin{tabular}{|l|l|}
\hline Factors & $\begin{array}{l}\text { Range specified in } \\
\text { APAC procedure }\end{array}$ \\
\hline Air void content & $7 \pm 1 \%$ \\
\hline $\begin{array}{l}\text { Test } \\
\text { temperature }\end{array}$ & $\begin{array}{l}\text { Based on average } \\
\text { high pavement } \\
\text { temperature }\end{array}$ \\
\hline Wheel load & $100 \pm 5 \mathrm{lb}$ \\
\hline Hose pressure & $100 \pm 5 \mathrm{psi}$ \\
\hline Specimen type & Beams, cylinders \\
\hline Compaction & $\begin{array}{l}\text { Rolling, vibratory, } \\
\text { and gyratory }\end{array}$ \\
\hline
\end{tabular}

\subsubsection{Results of Ruggedness Study of the APA}

APAC Materials Services conducted a ruggedness study of the Asphalt Pavement Analyzer rutting test in 1999 ( 11). Six factors; air void content of the test specimens, the test temperature, specimen preheating time, wheel load, hose pressure, and specimen compaction method were investigated and the following conclusions and recommendations were made regarding the specifications of the standard procedure.

1. The air void content range of the specimens given in the procedure should be changed from $7 \pm 1.0 \%$ to $7 \pm 0.5 \%$. This will reduce the variability in the test results but it will also affect the productivity of the labs because of having to discard samples out of the tighter range.

2. The test temperature has a major effect on the test results. Proper calibration of the APA chamber temperature and ovens for preheating specimens is critical in obtaining meaningful test results.

3. Compaction and specimen type had a significant effect on the test results.

4. The ranges evaluated in the study for preheat time, wheel load, and the hose pressure did not have a significant effect on the rut results. Therefore, it was concluded that the standard procedure gives adequate guidance on the control of each of these test parameters. 


\subsubsection{Effect of Compaction and Specimen Type}

The results from the ruggedness study of the APA shows that for the low rut potential mixes, the Superpave Gyratory Compactor (SGC) cylinders tended to have higher rut depths, while for the high rut potential mixes the Asphalt Vibratory Compactor (AVC) beams yielded collectively higher rutting. The reasons postulated for this behavior are:

- In high rut potential mixes, the center part of the cylinder mold supports the load when the rut depth advances to the depth of the contour at the center of the mold (12).

- The compaction modes of cylinder and beam samples may produce different density gradients in the samples (12).

The evaluation of density gradients in APA samples shows that vibratory compaction tends to result in more compaction at the top and less compaction at the bottom for both beams and cylinders. Gyratory compacted samples showed less compaction in the top and bottom of samples and significantly more compaction in the middle. The top of the AVC specimens should be loaded in APA. This type of specification is not needed for SGC compacted samples as the density in the top and bottom layers were not significant not significantly different (12).

\subsubsection{Effect of Position}

Studies have shown that there is variation in the left, center and right rut depth measurements of the APA. Although the wheel loads are individually calibrated, it has been observed that the wheel loads are not necessarily independent. During calibration, the load applied by any wheel is affected by whether or not the other wheels are in loading or rest position indicating the is an interaction between the wheel loads.

\subsection{CONCLUSIONS}

The Marshall and Superpave mix design methods were briefly described. State highway agencies have some discretion in the specific details of how the methods are implemented. The specifics for the WVDOH method were presented since they are the methods and procedures followed during this research. 
The literature on the APA demonstrates it is a useful device for evaluating the rutting potential of a mix. However, there is an inherent variability in the results produced with the device, particularly with respect to load position. The experimental plan developed for this research was designed to minimize the effect of the variability in the APA results. 


\section{CHAPTER 3 RESEARCH METHODOLOGY}

\subsection{INTRODUCTION}

This research compares $19 \mathrm{~mm}$ nominal maximum aggregate size Superpave to Marshall Base II mixes in West Virginia. Mix designs were prepared for Heavy, Medium and Light traffic levels using the Superpave methodology and for Heavy and Medium traffic level using the Marshall methodology. The resulting Marshall mix designs were evaluated under the Superpave criteria and vice versa. APA samples were made using Gyratory Compactor to evaluate rutting potential of the mixes. The following sections of this chapter explain the laboratory-testing program conducted in the Asphalt Technology Laboratory of West Virginia University, Morgantown. The data and interim calculations for the aggregates are presented in Appendix A.

\subsection{MATERIALS}

The aggregate used in this research work was provided by J.F Allen Company, Buckhannon, WV. Four types of aggregates (\#57, \#8, \#9, Limestone Sand) and bag fines were used to develop aggregate blends meeting the gradation requirements. The asphalt used for both Superpave and Marshall mix design methods was PG 70-22 obtained from Marathon, Ashland.

\subsection{AGGREGATE PREPARATION}

The aggregates were obtained from J.F. Allen Company. Three of the aggregate types were ASTM coarse aggregate sizes \#57, \#8, and \#9. The fourth aggregate type was crushed limestone sand. The aggregates were processed by washing, oven drying and sieving. Dried aggregates were separated with a nest of sieves, consisting of: 1", 3/4", 3/8", \#4, \#8, \#16, \#30, \#50, and \#200 and the material retained on each sieve and pan was placed in storage bins.

\subsection{SIEVE ANALYSIS}

Three samples of each aggregate type were tested to determine the amount of material passing the \#200 sieve (ASTM C117) and to determine gradation (ASTM C136). The amount of material passing the \#200 sieve was determined by washed 
sieving for each type of aggregate is shown in Table 3.1. The average gradation results for each aggregate type are shown in Table 3.2.

Table 3.1 Washed Sieve Analysis for Material Passing \#200 Sieve.

\begin{tabular}{|c|c|c|c|c|}
\hline Sample No. & $\# 57$ & $\# 8$ & $\# 9$ & L. Sand \\
\hline 1 & 0.9 & 1.3 & 1.3 & 6.9 \\
\hline 2 & 0.9 & 2.0 & 1.5 & 6.7 \\
\hline 3 & 1.1 & 1.2 & 1.9 & 6.4 \\
\hline Average & 1.0 & 1.5 & 1.6 & 6.7 \\
\hline
\end{tabular}

Table 3.2 Dry Sieve Gradation Analysis Results.

\begin{tabular}{|l|l|c|c|c|c|c|}
\hline Sieve No. & Sieve size & $\# 57$ & $\# 8$ & \#9 & Limestone Sand & Bag fines \\
\hline & & \% passing & \% passing & \% passing & \% passing & \%passing \\
\hline $1 "$ & $25 \mathrm{~mm}$ & 100 & 100 & 100 & 100 & 100 \\
\hline $3 / 4 "$ & $19 \mathrm{~mm}$ & 84 & 100 & 100 & 100 & 100 \\
\hline $3 / 8 "$ & $12.5 \mathrm{~mm}$ & 36 & 100 & 100 & 100 & 100 \\
\hline $1 / 2 "$ & $9.5 \mathrm{~mm}$ & 14 & 96 & 100 & 100 & 100 \\
\hline$\# 4$ & $4.75 \mathrm{~mm}$ & 2.4 & 14 & 69 & 99 & 100 \\
\hline$\# 8$ & $2.36 \mathrm{~mm}$ & 1.6 & 3.5 & 5.0 & 77 & 100 \\
\hline$\# 16$ & $1.18 \mathrm{~mm}$ & 1.4 & 2.3 & 2.1 & 45 & 100 \\
\hline$\# 30$ & $0.6 \mu \mathrm{m}$ & 1.3 & 1.9 & 1.9 & 29 & 100 \\
\hline$\# 50$ & $0.3 \mu \mathrm{m}$ & 1.2 & 1.7 & 1.8 & 17 & 97.0 \\
\hline$\# 200$ & $0.075 \mu \mathrm{m}$ & 1.0 & 1.5 & 1.7 & 6.6 & 92.0 \\
\hline
\end{tabular}

\subsection{SPECIFIC GRAVITY OF AGGREGATES}

Three samples of each aggregate type and one sample of bag fines were tested to determine the specific gravity and absorption (AASHTO T85 for coarse aggregate AASHTO T84 for fine aggregate). The average specific gravity and absorption values are shown in Table 3.3.

Table 3.3 Specific Gravity and Absorption Values.

\begin{tabular}{|l|c|c|c|c|c|}
\cline { 2 - 6 } \multicolumn{1}{c|}{} & $\# 57$ & $\# 8$ & $\# 9$ & L. sand & $\begin{array}{c}\text { Bag } \\
\text { Fines }\end{array}$ \\
\hline Bulk Specific Gravity & 2.687 & 2.686 & 2.648 & 2.665 & \\
\hline Apparent Specific Gravity & 2.731 & 2.734 & 2.751 & 2.732 & 2.680 \\
\hline \% Absorption & 0.6 & 0.7 & 1.4 & 0.9 & \\
\hline
\end{tabular}




\subsection{AGGREGATE CONSENSUS PROPERTY TESTS}

The aggregate properties that are specified as a result of the SHRP program are the coarse and fine aggregate angularity, flat and elongated particles, and sand equivalent results. Three samples each of \#57 and \#8 aggregate were tested to determine the average coarse aggregate angularity ( ASTM D5821). Three samples each of \#8, \#9 and Limestone Sand were tested to determine the Uncompacted Void Content of Fine Aggregate (AASHTO T304 Method A). Following the general procedures of ASTM D 4791, three samples of \#57 and \#8 aggregate were tested to determine the average Flat and Elongated particles whose maximum to minimum dimension is greater than 5. Three samples of Limestone Sand were tested to get an average sand equivalent value (AASHTO T176). The aggregate average consensus property test results are shown in Table 3.4. The aggregate blends met the Superpave mix design criteria.

Table 3.4 Average Consensus Property Test Results for Individual Aggregates

\begin{tabular}{|l|l|c|l|l|}
\hline Property & $\# 57$ & $\# 8$ & $\# 9$ & L.Sand \\
\hline Coarse aggregate angularity & $100 / 100$ & $100 / 100$ & & \\
\hline Fine aggregate angularity & & 46.0 & 46.0 & 46.0 \\
\hline Flat \& elongated particles & 0 & 0 & & \\
\hline Sand equivalent value & & & 100 & 78.0 \\
\hline
\end{tabular}

\subsection{MARSHALL MIX DESIGN PROCEDURE}

The design traffic levels used in Marshall mix design method were Medium Traffic (less than 3 million ESALs), and Heavy Traffic (greater than 3 million ESALs). The binder used in the mix design was PG 70-22 (obtained from the source Marathon/Ashland). The aggregate in the storage bins were combined as required to produce the required gradation. The steps followed in determining the two Marshall mix designs are explained in the following section. The summary of the tests performed in determining the Marshall mixes are presented in this section. The detailed test data and calculations are presented in Appendix B. 


\subsubsection{AGGREGATE GRADATION}

The result of sieve analysis of aggregates shown in Table 3.2 were used to combine the aggregate to achieve an aggregate blend used by J.F. Allen Company for Marshall Base II mix:

\begin{tabular}{cc} 
Aggregate type & $\begin{array}{c}\text { Percent of } \\
\text { blend }\end{array}$ \\
\hline$\# 57$ & 35.5 \\
$\# 8$ & 17.0 \\
$\# 9$ & 10.0 \\
Sand & 36.5 \\
Bag house fines & 1.0
\end{tabular}

The plot of gradation is shown in Figure 3.1 with control points. The aggregate blend was within the tolerance limits of Master Range and hence the aggregate structure meets the gradation requirements; Table 2.4

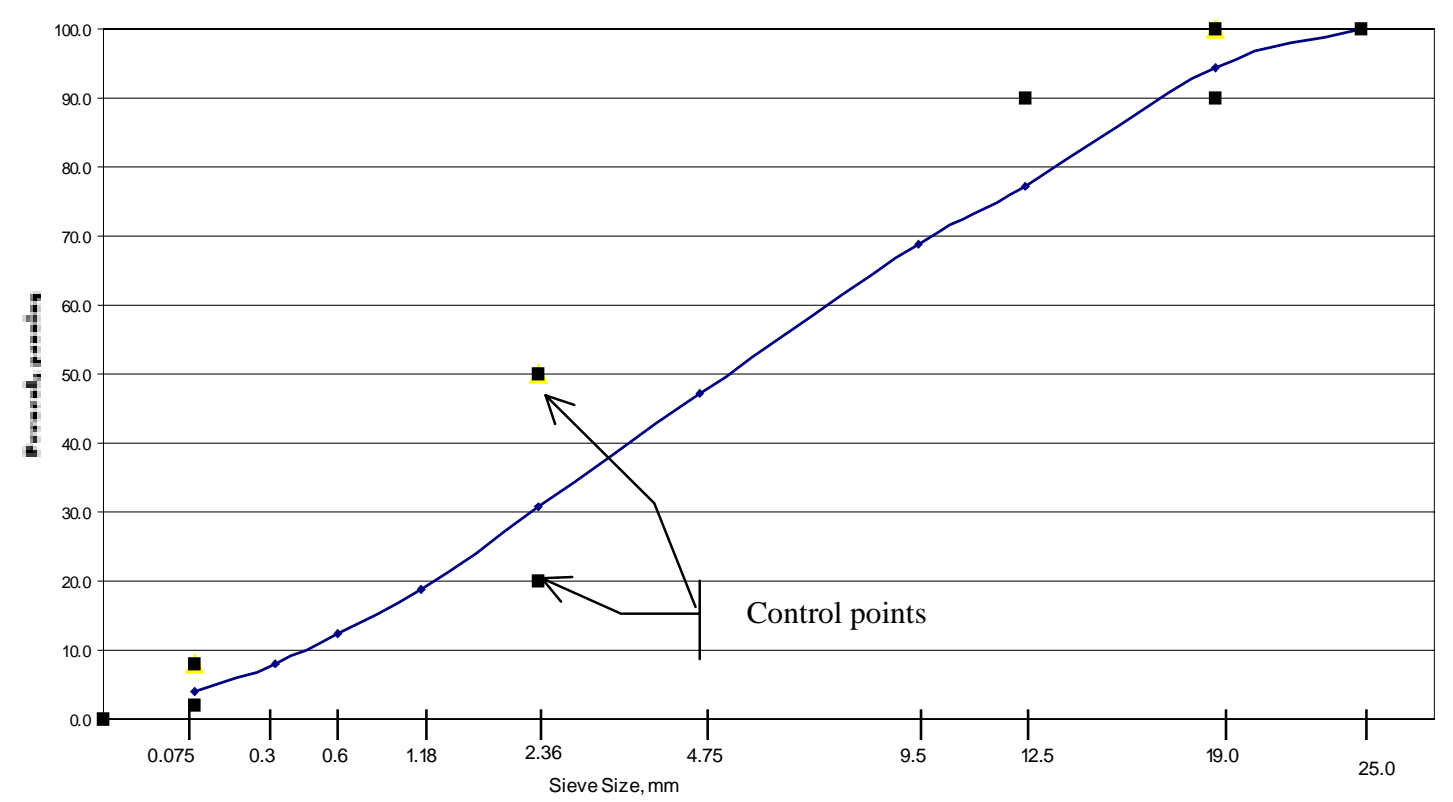

Figure 3.1 Marshall gradation plot with control points

\subsubsection{SPECIFIC GRAVITY}

The binder supplier provided the specific gravity of the asphalt binder and the value used was 1.020. The Equation 2.1 was used to calculate the specific gravity of the 
aggregate blend. The bulk specific gravity was 2.670 and the apparent specific gravity was 2.733 for the blend.

\subsubsection{THEORETICAL MAXIMUM SPECIFIC GRAVITY}

From the experience of J.F.Allen Company, the optimum asphalt content for Base II Marshall mix in West Virginia was $4.9 \%$ for Heavy traffic level. As described in Chapter 2, the maximum theoretical specific gravity is measured at one asphalt content and used to compute $\mathrm{Gmm}$ at the other asphalt contents. The validity of this approach was tested by performing the Gmm procedure on three samples at five asphalt contents, $3.9 \%, 4.4 \%, 4.9 \%, 5.4 \%, 5.9 \%$ for the heavy traffic mix and $4.4 \%, 4.9 \%, 5.4 \%, 5.9 \%$, $6.2 \%$ for the medium traffic mix. Table 3.6 shows the results for the laboratory test results, and the computed approach. The computed and measured values compare favorably. The lab-measured values were used for the Marshall volumetric analysis.

Table 3.6 Maximum Theoretical Specific Gravity for Marshall Mix Designs.

\begin{tabular}{|c|c|c|c|c|c|}
\hline \multicolumn{3}{|c|}{ Heavy traffic } & \multicolumn{3}{c|}{ Medium traffic } \\
\hline Asphalt & Average & Computed & Asphalt & Average & Computed \\
\hline content & $\mathrm{G}_{\mathrm{mm}}$ & $\mathrm{G}_{\mathrm{mm}}$ & content & $\mathrm{G}_{\mathrm{mm}}$ & $\mathrm{G}_{\mathrm{mm}}$ \\
\hline$\%$ & $\mathrm{Lab}$ & & $\%$ & $\mathrm{Lab}$ & \\
\hline 3.9 & 2.550 & 2.552 & 4.4 & 2.533 & 2.529 \\
\hline 4.4 & 2.533 & 2.533 & 4.9 & 2.513 & 2.513 \\
\hline 4.9 & 5.513 & - & 5.4 & 2.491 & - \\
\hline 5.4 & 2.491 & 2.494 & 5.9 & 2.476 & 2.472 \\
\hline 5.9 & 2.476 & 2.475 & 6.2 & 2.452 & 2.453 \\
\hline
\end{tabular}

\subsubsection{MARSHALL STABILITY AND FLOW TEST}

Three samples at each asphalt content were mixed and compacted using Marshall Hammer. The samples were $1100 \mathrm{~g}$ and $1150 \mathrm{~g}$ for the medium and heavy traffic levels respectively. The corresponding compaction level was 50 and 75 blows per side. The bulk specific gravity of each compacted sample was determined (AASHTO T166) and the average volumetrics at each asphalt content were computed using the equations 2.3 to 2.5. The Marshall Stability and Flow of each sample was determined (AASHTO T245). 


\subsubsection{TABULATING AND PLOTTING TEST RESULTS}

The volumetric data and Stability and Flow test results were tabulated and the Stability values for specimen height different than $63.5 \mathrm{~mm}$ were corrected using Table 2.3. The average value for volumetric parameters, stability and flow of each set of three specimens was calculated. The tabulated results for Heavy and Medium traffic level Marshall mix designs are presented in Tables 3.7 and Table 3.8 respectively. The following plots were prepared from the results and are presented in Appendix C.

- Asphalt content versus density

- Asphalt content versus Marshall stability

- Asphalt content versus flow

- Asphalt content versus air voids.

- Asphalt content versus VMA

- Asphalt content versus VFA

Table 3.7 Volumetric Parameters for Marshall Heavy Traffic Mix

\begin{tabular}{|c|c|c|c|c|c|c|}
\hline AC, \% & Density & \%VMA & \%VFA & Air voids, \% & $\begin{array}{l}\text { Stability } \\
\text { (Newton) }\end{array}$ & $\begin{array}{l}\text { Flow } \\
(0.25 \text { in })\end{array}$ \\
\hline 3.9 & 2347 & 15.54 & 48.68 & 7.97 & 2230.2 & 14.5 \\
\hline 4.4 & 2390 & 14.42 & 60.9 & 5.64 & 2180.4 & 17 \\
\hline 4.9 & 2402 & 14.44 & 69.46 & 4.41 & 2017.8 & 12.7 \\
\hline 5.4 & 2394 & 15.19 & 74.28 & 3.91 & 2008.9 & 16.3 \\
\hline 5.9 & 2392 & 15.68 & 78.47 & 3.38 & 2318.3 & 15.3 \\
\hline
\end{tabular}

Table 3.8 Volumetric Parameters for Marshall Medium Traffic Mix

\begin{tabular}{|c|c|c|c|c|c|c|}
\hline AC, \% & Density & \%MA & \%VFA & $\begin{array}{c}\text { Air } \\
\text { voids, \% }\end{array}$ & Stability & Flow \\
(Newton) & $(0.01$ in) \\
\hline 4.4 & 2359 & 15.5 & 55.5 & 6.9 & 2099 & 15.0 \\
\hline 4.9 & 2362 & 15.8 & 61.4 & 6.1 & 2163 & 17.0 \\
\hline 5.4 & 2377 & 15.8 & 71.0 & 4.6 & 2062 & 19.0 \\
\hline 5.9 & 2395 & 15.6 & 79.0 & 3.3 & 2073 & 14.3 \\
\hline 6.4 & 2396 & 16.0 & 85.7 & 2.3 & 2046 & 20.0 \\
\hline
\end{tabular}




\subsubsection{DETERMINATION OF DESIGN ASPHALT CONTENT}

The asphalt content that corresponds to the specification's median air void content $(4.0 \%)$ is the design asphalt content. The design asphalt content was determined from the plots for Heavy and Medium traffic level. The Marshall stability, flow, VMA and VFA at the design asphalt content were determined from the plots and were compared to the specification values. The results are summarized in the Table 3.9. All the properties met the Marshall criteria, Table 2.4.

Table 3.9 Summary of Marshall Mix Designs

\begin{tabular}{|c|c|c|c|c|c|c|}
\hline $\begin{array}{c}\text { Traffic } \\
\text { level }\end{array}$ & AC, \% & Density & $\%$ VMA & $\%$ VFA & $\begin{array}{c}\text { Stability } \\
(\text { Newton })\end{array}$ & $\begin{array}{c}\text { Flow } \\
(0.01 \text { in })\end{array}$ \\
\hline Medium & 5.5 & 2405 & 14.5 & 68.0 & 2025 & 15 \\
\hline Heavy & 5.0 & 2374 & 15.7 & 71.0 & 2100 & 17 \\
\hline
\end{tabular}

\subsection{SUPERPAVE MIX DESIGN PROCEDURE}

The design traffic levels used in Superpave mix design were Light Traffic $(<0.3$ million ESALs), Medium Traffic ( 0.3 to $<3$ million ESALs), Heavy Traffic ( 3 to $<30$ million ESALs). The asphalt binder used in the mix design was PG 70-22. The design aggregate structure for the heavy traffic level was established following the procedures presented in Chapter 2. This design aggregate structure was evaluated for the other traffic levels by preparing samples at estimated asphalt content, compacting with the appropriate number of gyrations, then performing the volumetric analyses. This process demonstrated the same design aggregate structure could be used for all traffic levels. The binder content was then determined for each traffic level.

\subsubsection{AGGREGATE TRIAL BLENDS}

Three trial blends were evaluated to determine the best aggregate structure. The percent of each aggregate type in the trial blends are shown in Table 3.10; the gradation chart is shown in Figure 3.2. All the three trial blends were within the control points of $19 \mathrm{~mm}$ nominal maximum size and below the restricted zone (Table 2.5). The restricted zone is meant to be a guide to help ensure that too much natural sand is not used in the mixture and to help ensure that minimum VMA requirements are met. 
The aggregate consensus property test values for aggregate blends and the combined average aggregate bulk and apparent specific gravities were determined using the Equation 2.8 and 2.2, respectively, and are presented in Table 3.11

The initial binder contents for heavy-traffic level mix design were computed using the Equations 2.9 to 2.13. The initial binder content was $4.4 \%$ for blend 1 and $4.5 \%$ for blend 2 and blend 3 .

Three samples for each trial blend at their corresponding initial binder content were tested to determine the average Theoretical Maximum Specific Gravity (AASHTO T209) in Table 3.12.

\subsubsection{DESIGN AGGREGATE STRUCTURE}

Three samples for each trial blend at their corresponding initial binder content were compacted to 100 gyrations, which is $\mathrm{N}_{\mathrm{d}}$ for heavy traffic level. The bulk specific gravity (AASHTO T 166) and volumetrics (Equations 2.3 to 2.5) of the compacted samples were determined and the average values are presented in Table 3.13.

The estimated design asphalt content was computed using Equation 2.17. The volumetric data at the estimated design asphalt content for all three blends were computed (Equations 2.18 to 2.21) and summarized in Table 3.14.

All the three blends meet the Superpave volumetric criteria, Table 2.3. The trial Blend 1 was selected as design aggregate structure for Heavy Traffic level Superpave mix design because it was used by J.F. Allen Company for a Superpave project in West Virginia and has proven performance.

The initial binder content of Superpave mix design for medium and light traffic levels was estimated to be $5.0 \%$. Three samples with blend 1 were tested to determine the average Theoretical Maximum Specific Gravity (AASHTO T209) at 5.0\% asphalt content. 


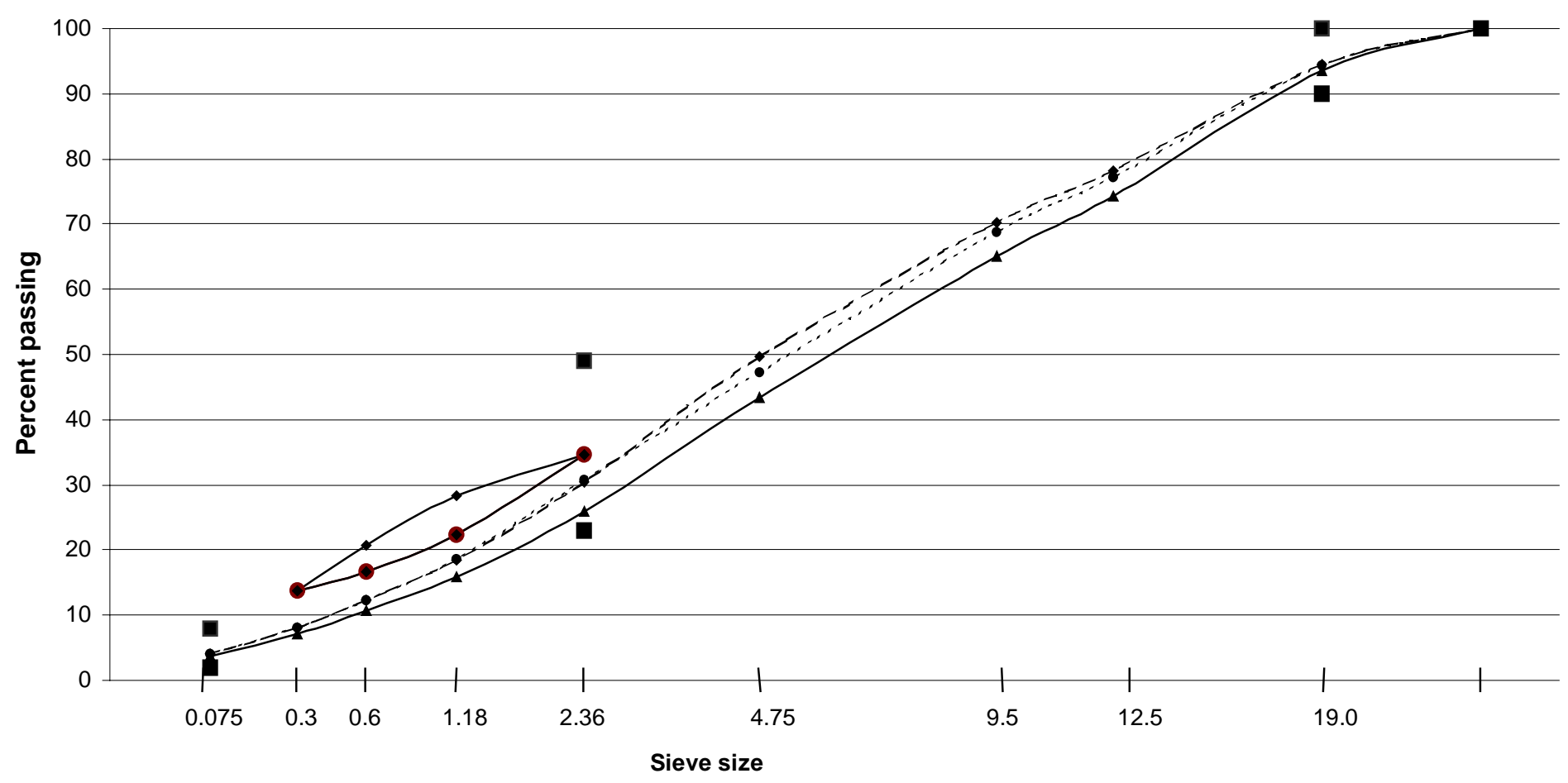

FIGURE 3.2 Superpave trial blend gradations 
Table 3.10 Trial Blends for Evaluation of Aggregate Structure

\begin{tabular}{|c|c|c|c|c|c|}
\hline Blend & $\# 57$ & $\# 8$ & $\# 9$ & L. Sand & Bag fines \\
\hline 1 & $34.0 \%$ & $14.0 \%$ & $15.0 \%$ & $36.0 \%$ & $1.0 \%$ \\
\hline 2 & $35.5 \%$ & $17.0 \%$ & $10.0 \%$ & $36.5 \%$ & $1.0 \%$ \\
\hline 3 & $40.0 \%$ & $15.0 \%$ & $14.0 \%$ & $30.0 \%$ & $1.0 \%$ \\
\hline
\end{tabular}

Table 3.11 Trial Blends Bulk and Apparent Specific Gravity

\begin{tabular}{|l|c|c|c|}
\hline & Blend 1 & Blend 2 & Blend 3 \\
\hline Bulk Specific Gravity & 2.669 & 2.669 & 2.672 \\
\hline Apparent Specific Gravity & 2.712 & 2.724 & 2.724 \\
\hline
\end{tabular}

Table 3.12 Theoretical Maximum Specific Gravity for Superpave Trial Blends

\begin{tabular}{|c|c|c|c|}
\hline Sample no & Blend 1 & Blend 2 & Blend 3 \\
\hline 1 & 2.539 & 2.536 & 2.536 \\
\hline 2 & 2.538 & 2.534 & 2.533 \\
\hline 3 & 2.538 & 2.534 & 2.533 \\
\hline Average & 2.538 & 2.535 & 2.535 \\
\hline
\end{tabular}

Table 3.13 Trial Blends Compaction Data

\begin{tabular}{|c|c|c|c|c|}
\hline Blend no. & $\mathrm{G}_{\mathrm{mb}}$ & $\mathrm{P}_{\mathrm{b}}$ & VTM & $\begin{array}{c}\% \mathrm{Gmm} \\
\text { at } \mathrm{N}_{\mathrm{d}}\end{array}$ \\
\hline 1 & 2.384 & 4.4 & 6.1 & 93.9 \\
\hline 2 & 2.361 & 4.5 & 6.9 & 93.1 \\
\hline 3 & 2.370 & 4.5 & 6.5 & 93.5 \\
\hline
\end{tabular}

Table 3.14 Adjusted Volumetric Parameters for Superpave Trial Blends

\begin{tabular}{|c|c|c|c|c|}
\hline Blend & $\begin{array}{c}\text { Est } \\
\text { Design } \\
\text { AC }\end{array}$ & $\begin{array}{c}\text { Est } \\
\% \\
\text { VMA }\end{array}$ & $\begin{array}{c}\text { Est } \\
\% \\
\text { VFA }\end{array}$ & $\begin{array}{c}\text { Est } \\
\text { D/B ratio }\end{array}$ \\
\hline 1 & 5.2 & 14.2 & 71.8 & 0.90 \\
\hline 2 & 5.7 & 14.9 & 73.2 & 0.84 \\
\hline 3 & 5.5 & 14.8 & 72.9 & 0.81 \\
\hline
\end{tabular}


Samples at 5.0\% asphalt content were compacted using 75 gyrations and 50 gyrations, which is the design number of gyrations for light and medium traffic level respectively. Two samples were prepared at each compaction level. The volumetric results determined using Equations 2.3 to 2.5 are shown in Table 3.15.

Table 3.15 Blend 1 Volumetric Parameters for Medium and Light Traffic Level Mix Designs

\begin{tabular}{|l|c|c|c|c|c|c|}
\hline Traffic level & Avg. $\mathrm{G}_{\mathrm{sb}}$ & Avg. $\mathrm{G}_{\mathrm{mm}}$ & $\mathrm{P}_{\mathrm{b}}$ & VTM & VMA & $\%$ Gmm at $\mathrm{N}_{\mathrm{d}}$ \\
\hline Medium & 2.367 & 2.513 & 5.0 & 5.8 & 15.8 & 94.2 \\
\hline Light & 2.513 & 2.513 & 5.0 & 7.6 & 17.3 & 92.4 \\
\hline
\end{tabular}

The estimated design asphalt content for medium and light traffic level Superpave mixes was computed using Equation 2.17. The volumetric data at the estimated design asphalt content for the two traffic levels are computed (Equations 2.18 to 2.21) and presented in Table 3.16.

Table 3.16 Adjusted Volumetric Parameters for Medium and Light Traffic Level Mix Designs

\begin{tabular}{|l|c|c|c|c|}
\hline Traffic level & $\begin{array}{l}\text { Estimated } \\
\text { Design AC }\end{array}$ & $\begin{array}{l}\text { Estimated } \\
\text { \% VMA }\end{array}$ & $\begin{array}{l}\text { Estimated } \\
\text { \% VFA }\end{array}$ & $\begin{array}{l}\text { Estimated } \\
\text { D/B }\end{array}$ \\
\hline Medium & 5.7 & 15.4 & 75.9 & 0.81 \\
\hline Light & 6.4 & 16.6 & 74.0 & 0.71 \\
\hline
\end{tabular}

The volumetric parameters at the estimated design asphalt content met Superpave criteria and hence blend 1 was selected as design aggregate structure for the medium and light traffic level Superpave mixes.

\subsubsection{DESIGN ASPHALT CONTENT}

The design aggregate structure process showed the same aggregate blends could be used for all traffic levels. The estimated asphalt contents were $6.4 \%, 5.7 \%$, and 5.2\% for the light, medium and heavy traffic levels respectively. The first procedure for determining the design binder content is to measure $\mathrm{G}_{\mathrm{mm}}$. Since the binder content the medium and heavy traffic were separated by $0.5 \%$, six binder contents cover the needed binder contents for $\mathrm{G}_{\mathrm{mm}}$ testing; 4.7 to $6.7 \%$ at $0.5 \%$ increments. The $\mathrm{G}_{\mathrm{mm}}$ for the low 
traffic level was determined for percent binder contents of 5.9 to $7.4 \%$ in $0.5 \%$ increments. Table 3.17 gives the average $\mathrm{G}_{\mathrm{mm}}$ values at each asphalt content.

Table 3.17 Average $\mathrm{G}_{\mathrm{mm}}$ Values for Superpave Mixes

\begin{tabular}{|c|c|}
\hline $\begin{array}{c}\text { Asphalt Content } \\
\text { Percent }\end{array}$ & $\begin{array}{c}\text { Average } \\
\mathrm{G}_{\mathrm{mm}}\end{array}$ \\
\hline $4.7 \%$ & 2.523 \\
\hline $5.2 \%$ & 2.502 \\
\hline $5.7 \%$ & 2.495 \\
\hline $6.2 \%$ & 2.485 \\
\hline $6.7 \%$ & 2.464 \\
\hline $5.9 \%$ & 2.487 \\
\hline $6.4 \%$ & 2.469 \\
\hline $6.9 \%$ & 2.452 \\
\hline $7.4 \%$ & 2.434 \\
\hline
\end{tabular}

Two samples each at 4.7\%, 5.2\%, 5.7\%, and 6.2\% asphalt content were compacted to 100 gyrations. The average bulk specific gravities determined (AASHTO T166) and the volumetrics computed using Equations 2.2 to 2.5 at each asphalt content were tabulated in Table 3.18 .

Table 3.18. Volumetric Data for Superpave Heavy Traffic Level.

\begin{tabular}{|c|c|c|c|c|c|}
\hline Percent Asphalt Content & Air voids & \% $_{\mathrm{mm}, \mathrm{Nd}}$ & VMA at $_{\mathrm{d}}$ & VFA N $_{\mathrm{d}}$ & Avg $_{\mathrm{mb}}$ \\
\hline 4.7 & 5.3 & 94.7 & 14.7 & 63.8 & 2.389 \\
\hline 5.2 & 3.8 & 96.2 & 14.5 & 73.6 & 2.406 \\
\hline 5.7 & 3.0 & 97.0 & 14.6 & 79.3 & 2.420 \\
\hline 6.2 & 2.7 & 97.3 & 15.0 & 82.3 & 2.419 \\
\hline
\end{tabular}

Two samples each at 5.2\%, 5.7\%, 6.2\%, and 6.7\% asphalt content were compacted to 75 gyrations. The average bulk specific gravities determined (AASHTO T166) and the volumetrics computed using Equations 2.2 to 2.5 at each asphalt content were tabulated in Table 3.19. 
Table 3.19 Volumetric Data for Superpave Medium Traffic Level

\begin{tabular}{|c|c|c|c|c|c|}
\hline $\begin{array}{c}\text { Percent Asphalt } \\
\text { Content }\end{array}$ & Air voids & $\% \mathrm{G}_{\mathrm{mm}, \mathrm{Nd}}$ & VMA at $\mathrm{N}_{\mathrm{d}}$ & VFA N $_{\mathrm{d}}$ & Avg $_{\mathrm{mb}}$ \\
\hline 5.2 & 5.2 & 94.7 & 15.7 & 67.2 & 2.373 \\
\hline 5.7 & 4.0 & 96.2 & 15.4 & 73.8 & 2.394 \\
\hline 6.2 & 3.4 & 97.0 & 15.7 & 78.1 & 2.400 \\
\hline 6.7 & 2.4 & 97.3 & 15.9 & 85.2 & 2.406 \\
\hline
\end{tabular}

Two samples each at 5.9\%, 6.4\%, 6.9\%, 7.4\% asphalt content were compacted to 50 gyrations. The average bulk specific gravities determined (AASHTO T166) and the volumetrics computed using Equations 2.2 to 2.5 at each asphalt content were tabulated in Table 3.20 .

Table 3.20 Volumetric Data for Superpave Light Traffic Level

\begin{tabular}{|c|c|c|c|c|c|}
\hline Percent Asphalt Content & Air voids & $\% \mathrm{G}_{\mathrm{mm}, \mathrm{Nd}}$ & VMA at $\mathrm{N}_{\mathrm{d}}$ & VFA N $_{\mathrm{d}}$ & Avg G $_{\mathrm{mb}}$ \\
\hline 5.9 & 4.8 & 95.2 & 16.5 & 71.0 & 2.368 \\
\hline 6.4 & 3.7 & 96.3 & 16.6 & 77.6 & 2.377 \\
\hline 6.9 & 2.8 & 97.2 & 16.8 & 83.5 & 2.384 \\
\hline 7.4 & 1.6 & 98.4 & 16.9 & 90.7 & 2.396 \\
\hline
\end{tabular}

The volumetric data was plotted versus asphalt content for all three traffic design levels. The design asphalt content corresponding to $4.0 \%$ air voids was determined for three mixes. The volumetric properties at design asphalt content were determined from the plots. The summary of the three mix designs is shown in Table 3.21.

Table 3.21 Summary of Superpave Mix Designs.

\begin{tabular}{|l|c|c|c|c|c|}
\hline Design Traffic Level & $\begin{array}{c}\text { Design } \\
\text { AC }\end{array}$ & $\% \mathrm{G}_{\mathrm{mm}, \mathrm{Nd}}$ & VTM & VMA & VFA \\
\hline Heavy & 5.1 & 96.0 & 4.0 & 14.5 & 70.2 \\
\hline Medium & 5.7 & 96.0 & 4.0 & 15.4 & 73.7 \\
\hline Traffic & 6.2 & 96.0 & 4.0 & 16.6 & 75.0 \\
\hline
\end{tabular}

The complete data and interim calculations of Superpave mix designs are presented in Appendix C. 


\subsection{SPECIMENS FOR APA TESTING}

The Superpave Gyratory Compactor was used to make the specimens for testing with the APA. The APA specimens were made to $95 \mathrm{~mm}$ height with $7.0 \pm 0.5 \%$ air voids range. The specimens out of this air voids range were discarded.

\subsection{ASPHALT PAVEMENT ANALYZER RUNS}

The APA procedure described in Chapter 2 was followed to obtain rut depth results of the specimens. All samples were tested at $140^{\circ} \mathrm{F}$ with a hose pressure of $100 \mathrm{psi}$ and a wheel load of $100 \mathrm{lb}$. Rut depths were measured after 8000 cycles.

There are 18 combinations of factors and levels. The combinations of mix design and traffic levels were assigned a treatment number as defined in Table 3.19. Two sets of test results were obtained for each combination, providing 36 experimental units. Each test result is an average of two test specimens, one in the front position of the mould and the other in the back. The factor levels in the experimental design were:

$\begin{array}{ll}\text { Factors } & \text { Levels } \\ \text { Mix design method } & \text { Superpave, Marshall } \\ \text { Traffic level } & \text { Light, Medium, High } \\ \text { APA position } & \text { Left, Center, Right }\end{array}$

Table 3.19 Treatments Used in Experimental Design

$\begin{array}{cll}\text { Treatment } & \begin{array}{l}\text { Type of mix } \\ \text { design }\end{array} & \begin{array}{l}\text { Design } \\ \text { traffic level }\end{array} \\ \text { No. } & \text { Superpave } & \text { Heavy } \\ 1 & \text { Superpave } & \text { Medium } \\ 2 & \text { Superpave } & \text { Light } \\ 3 & \text { Marshall } & \text { Heavy } \\ 4 & \text { Marshall } & \text { Medium } \\ 5 & \text { Marshall } & \text { Light }\end{array}$

The WVDOH uses the medium traffic level for all pavements with less than 3 million ESALs. Thus, the Marshall medium traffic level mix design was used to prepare the samples for the Marshall light traffic level. Since the Marshall light and medium traffic level mix designs were equivalent one would expect similar performance. 
To minimize the effects of position in the APA machine and test sequence, the order of testing the specimens was randomized. The Table 3.20 presents the order of testing the specimens and average rut depth results.

Table 3.20 Rut Depth Results.

\begin{tabular}{|c|c|c|c|}
\cline { 2 - 4 } \multicolumn{1}{c|}{} & \multicolumn{3}{c|}{ Positions } \\
\cline { 2 - 4 } \multicolumn{1}{c|}{} & Left & Center & Right \\
\hline $\begin{array}{c}\text { APA TEST } \\
\text { SEQUENCE }\end{array}$ & 1 & 2 & 3 \\
\hline 1 & $5.59_{1^{*}}$ & $6.16_{2}$ & $9.39_{3}$ \\
\hline 2 & $9.34_{6}$ & $4.73_{1}$ & $9.32_{5}$ \\
\hline 3 & $6.26_{5}$ & $5.80_{4}$ & $4.75_{6}$ \\
\hline 4 & $9.39_{3}$ & $9.17_{5}$ & $6.45_{3}$ \\
\hline 5 & $8.39_{2}$ & $4.61_{6}$ & $5.03_{4}$ \\
\hline 6 & $5.26_{3}$ & $3.89_{4}$ & $6.90_{1}$ \\
\hline 7 & $4.09_{1}$ & $6.54_{2}$ & $6.58_{6}$ \\
\hline 8 & $6.32_{4}$ & $6.53_{3}$ & $6.02_{2}$ \\
\hline 9 & $9.29_{6}$ & $5.09_{5}$ & $5.62_{4}$ \\
\hline 10 & $6.83_{2}$ & $3.62_{1}$ & $7.68_{5}$ \\
\hline 11 & $5.20_{4}$ & $5.49_{3}$ & $6.58_{2}$ \\
\hline 12 & $8.70_{5}$ & $8.50_{6}$ & $5.12_{1}$ \\
\hline
\end{tabular}

*Subscript indicates treatment number as defined in Table 3.19

\subsection{TESTS FOR OTHER CRITERIA}

Two samples for each mix design were evaluated to check for the other mix design criteria. Marshall samples were made using Superpave mix designs and checked for the criteria and vice versa. Both the mix designs passed the other mix design's criteria. The data are presented in Appendix D. 


\section{CHAPTER 4 RESULT AND ANALYSIS}

There are indications in the literature that Superpave mixes have lower optimum binder content than Marshall mixes. This was not the case for the mixes designed during the research. The Superpave mixes consistently had a greater binder content than Marshall mixes, ranging from $0.2 \%$ to $0.7 \%$ higher. The largest range was for the Superpave light traffic level versus the Marshall, since the WVDOH does not have Marshall procedure for light traffic level, the Superpave light traffic design was compared to a Marshall medium traffic design.

An Analysis of Variance shown in Figure 4.1 was performed using the SAS program. The factors of mix design type, test sequence, and position indicate that there is insufficient evidence to identify a difference. The traffic level indicates a difference at the $95 \%$ confidence level. The interaction effect of mix design type versus traffic level indicates there is not sufficient evidence to identify a difference.

The confidence interval for the difference in the means of two mixes is -1.98 to 0.62 . This interval is not within the detection limits.

The SAS program was run to compare possible combinations of mix and traffic on one to one bases. The results were used to compute a confidence interval about the difference in the adjusted means as:

$$
\left(\mu_{1}^{\prime}-\mu_{2}^{\prime}\right) \pm t_{\alpha / 2},{ }_{d f} \times S E_{\mu_{1}-\mu_{2}}
$$

where,

$\mu_{1}^{\prime}=$ adjusted mean $\mu_{1}$

$\mu_{2}{ }_{2}=$ adjusted mean $\mu_{2}$

$\mathrm{SE}=$ standard error

If the test is conducted a number of times under the same conditions, the difference in the adjusted means would fall within this range, $95 \%$ of the time. 
Fig 4.1 Output of Analysis of Variance

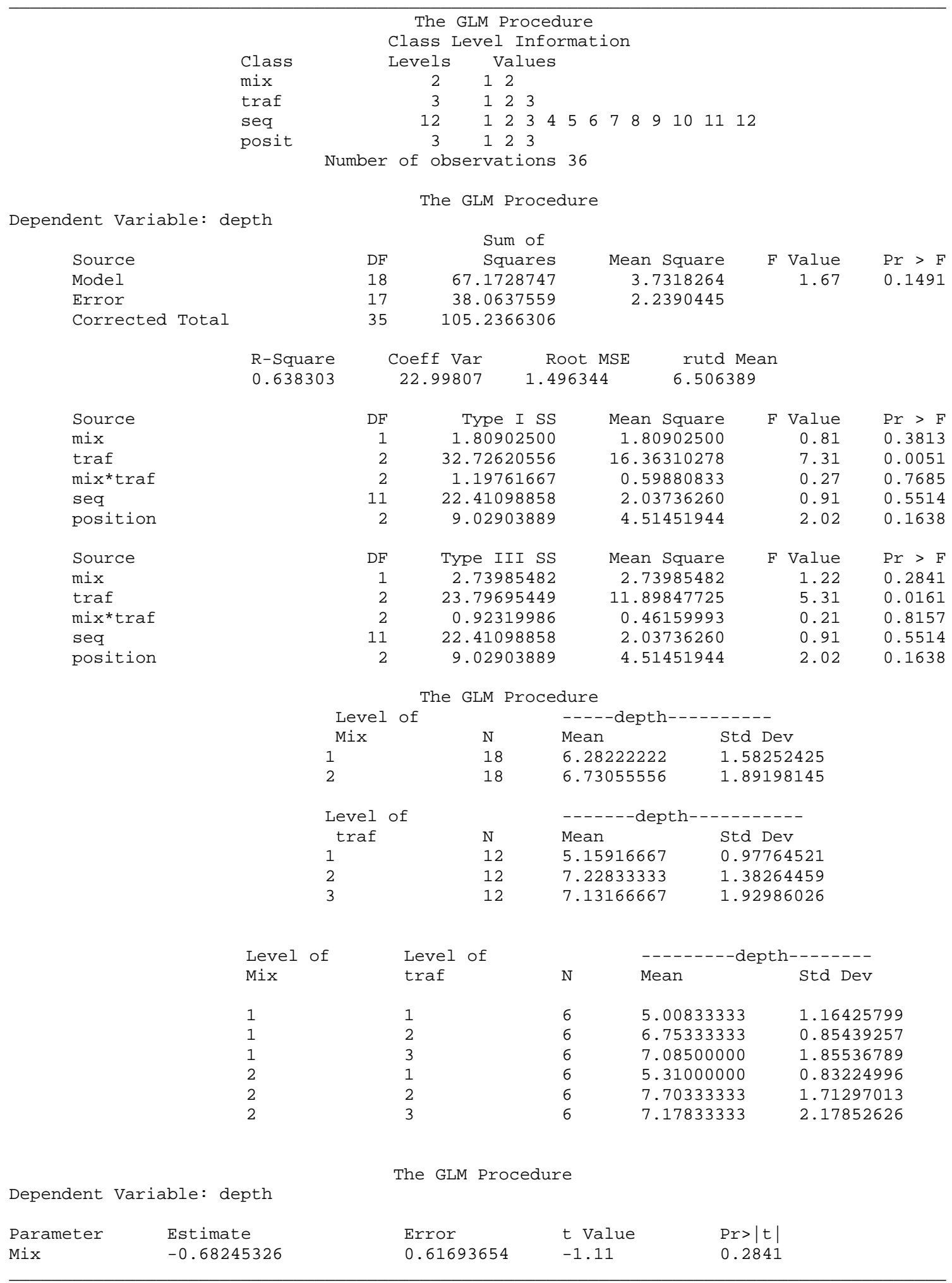


Table 4.1 shows the range of the difference in adjusted means computed from the results of the SAS General Linear Models procedure. When zero is outside the range, there is an indication of consistent difference in the test result. The comparisons which doesn't include zero in its range are

- Superpave Light - Superpave Heavy

- Superpave Medium - Superpave Heavy

- Marshall Medium - Marshall Heavy

- Marshall Light - Marshall Heavy

These comparisons are consistent with the concept, mixes for higher traffic levels are designed for higher rut resistance.

Zero within the range for the comparisons of the different mix design methods for a given traffic level is consistent with the ANOVA result.

Table 4.1 Confidence Interval Computed for Various Parameters

\begin{tabular}{|c|c|c|c|c|c|}
\hline Comparison & & \multicolumn{2}{|c|}{ SAS program Results } & \multicolumn{2}{c|}{ Confidence interval range } \\
\hline$\mu_{1}$ & $\mu_{2}$ & Estimate & Standard Error & Lower limit & Upper limit \\
\hline SPL & ML & 0.515 & 1.120 & -2.88 & 1.85 \\
\hline SPL & MM & 0.641 & 1.052 & -2.86 & 1.58 \\
\hline SPL & MH & -0.803 & 0.996 & -1.75 & 2.43 \\
\hline SPM & ML & 0.176 & 1.005 & -2.29 & 1.94 \\
\hline SPM & MM & 0.302 & 1.026 & -2.47 & 1.86 \\
\hline SPM & MH & -1.142 & 0.953 & -0.87 & 3.15 \\
\hline SPH & ML & 2.549 & 0.958 & -4.57 & -0.53 \\
\hline SPH & MM & 2.675 & 0.953 & -4.69 & -0.66 \\
\hline SPH & MH & 1.231 & 1.020 & -3.38 & 0.92 \\
\hline SPL & SPM & 0.339 & 0.990 & -1.75 & 2.43 \\
\hline SPL & SPH & -2.034 & 1.041 & 2.60 & 6.67 \\
\hline SPM & SPH & 2.034 & 1.040 & -4.23 & -0.16 \\
\hline ML & MM & 0.126 & 0.923 & -2.073 & 1.821 \\
\hline ML & MH & -1.318 & 0.971 & 0.73 & 3.37 \\
\hline MM & MH & -1.444 & 0.993 & 0.65 & 3.54 \\
\hline
\end{tabular}




\section{CHAPTER 5 CONCLUSIONS AND RECOMMENDATIONS}

\subsection{CONCLUSIONS}

Based on the laboratory effort and statistical analysis of data, the following conclusions were made:

- The statistical analysis does not provide enough evidence to say that there is a difference in the Superpave and Marshall mix design methodologies.

- The ANOVA indicated a difference due to traffic levels. The multiple comparison procedure indicated that mixes designed for higher traffic levels are more rut resistant than mixes designed for lower traffic levels.

- The mixes prepared under the Superpave method passed the Marshall criteria.

- The mixes prepared under the Marshall method passed the Superpave criteria. This indicates that contractors using Marshall methodology to design and construct pavements should not face unusual difficulties with Superpave mixes.

- The asphalt contents of Superpave mix designs are higher than Marshall mix design for the same traffic level.

\subsection{RECOMMENDATIONS}

- Based on the information developed during this research, differences between the Marshall Base II and Superpave $19 \mathrm{~mm}$ mixes, evaluated for all traffic levels, could not be detected statistically. Thus, it would appear that Superpave implementation could proceed with concerns about pavement performance.

- The fact that the Superpave mixes required slightly higher asphalt content would increase the cost of the mixes. For non-NHS roads, this may be beneficial as pavement performance, other than rutting, is generally improved with the higher asphalt film thickness associated with higher asphalt contents. 


\subsection{FUTURE RESEARCH}

- Similar analysis could be done using PG 64-22, which is generally used for non-NHS roads in WV.

- More aggregate types should be studied to have a broader perspective. This study was limited to one source of limestone aggregates. Other aggregates commonly used in the state should be studied, including other limestone sources and natural sands.

- Field tests on the rutting performance should be considered. The performance evaluation performed during this study is based on rutting potential as evaluated by the APA. An alternative method for estimating the performance of low volume mixes is needed, since rutting may not be the controlling performance parameter on low volume roads. 


\section{REFERENCES}

1. Huber G.A., Jones J. Chris, Messersmith E. Paul, Jackson N. Mike. Contribution of Fine Aggregate Angularity and Particle Shape to Superpave Mixture Performance. Transportation Research Record 1609. 1997.

2. Kandhal P.S, Mallick B.R. Evaluation of Asphalt Pavement Analyzer for HMA Design. National Center for Asphalt Technology. April 1999.

3. Mallick B. Rajib, Buchanan Shane, Brown E.R, Huner Mike. An Evaluation of Superpave Gyratory Compaction of Hot Mix Asphalt. National Center for Asphalt Technology. May 1998.

4. Roberts L. Freddy, Kandhal S. Prithvi, Brown E. Ray, Lee Dah-Yim, Kennedy W. Thomas. Hot Mix Asphalt Materials, Mixture Design and Construction. NAPA Education Foundation, MD.1996.

5. Harman Thomas, D’Angelo John, Bukowski John. Superpave Asphalt Mixture Design-Workshop. Federal Highway Administration. 1999.

6. Cooley L.A. Jr., Kandhal P.S, Buchanan M.S, Fee F, Epps A. Loaded Wheel Testers in the United States: State of Practice. National Center for Asphalt Technology. April 2000.

7. Background of Superpave Asphalt Mixture Design and Analysis. Federal Highway Administration. Report number FHWA-SA-95-003, 1995.

8. Implementation Survey IV, 1999-2000. Federal Highway Administration. July 2000

[http://ce.ecn.purdue.edu/ spave/Technical\%20Info/Meetings/Imp99-00.htm]

9. Ruggedness Evaluation of AASHTO TP4, The Superpave Gyratory Compactor. The Superpave Asphalt research Program, The University of Texas, Austin. 1996. [http://www.utexas.edu/research/articles/sgcrugg.html] 
10. Huber A. Gerald. Development of the Superpave Gyratory Compactor. The Superpave Asphalt Research Program, The University of Texas, Austin. 1996. [http://www.utexas.edu/research/superpave/articles/gyr-hist.html]

11. West C Randy. A Ruggedness Study of the Asphalt Pavement Analyzer Rutting. APAC Materials Service. May 1999.

12. Cooley L. Allen Jr., Kandhal S. Prithvi. Evaluation of Density Gradients in APA Samples. National Center for Asphalt Technology. October 1999.

\section{SPECIFICATIONS}

1. WVDOH Standard Specifications, 2000.

2. Guide to Designing Hot-Mix Asphalt using the Marshall Design Method. WVDOT MP 401.02.22. 2000

3. Guide to designing Hot-Mix Asphalt using the Superpave Volumetric Design System. WVDOT MP 401.02.28. 2000

4. Bulk Specific Gravity of Bituminous Mixtures. AASHTO T166. 1993.

5. Maximum Specific Gravity of Bituminous Paving Mixtures. AASHTO T209. 1994.

6. Resistance to Plastic Flow of Bituminous Mixtures Using Marshall Apparatus. AASHTO T245. 1993.

7. Method for Preparing and Determining the Density of HMA specimens by Means of the Superpave Gyratory Compactor. AASHTO TP4. 2000

8. Determining the Percentage of Fractured Particles in Coarse Aggregate. ASTM D 5821.

9. Flat or Elongated Particles in Coarse Aggregate. ASTM D 4791.

10. Plastic Fines in Graded Aggregates and Soils by Use of the Sand Equivalent Test. AASHTO T 176.1986

11. Uncompacted Void Content of Fine Aggregate. AASHTO T304. 1998. 
12. Determination of Specific Gravity and Absorption of Coarse Aggregate.

AASHTO T85. 1991.

13. Determination of Specific Gravity and Absorption of Fine Aggregate. AASHTO T84. 1994.

14. Amount of Material Passing \#200 Sieve. ASTM C117. 1984.

15. Sieve Analysis. ASTM C136. 1984. 


\section{APPENDIX A AGGREGATE TESTS AND PROPERTIES}

Table A.1 Gradation Data for Aggregates

\#8 Coarse Aggregate

\begin{tabular}{|c|c|c|c|c|c|c|c|c|c|}
\hline Sample & \multicolumn{3}{|c|}{ Sample1 } & \multicolumn{3}{c|}{ Sample 2 } & \multicolumn{3}{c|}{ Sample 3 } \\
\hline $\begin{array}{c}\text { SIEVE } \\
\text { SIZE, mm }\end{array}$ & $\begin{array}{l}\text { Wt } \\
\text { retained }\end{array}$ & $\begin{array}{l}\% \text { Wt. } \\
\text { retained }\end{array}$ & $\begin{array}{l}\text { Wt } \\
\text { Passing }\end{array}$ & $\begin{array}{l}\text { Wt. } \\
\text { retained } \\
\text { Retained }\end{array}$ & $\begin{array}{l}\% \\
\text { Passing }\end{array}$ & $\begin{array}{l}\text { Wt } \\
\text { retained }\end{array}$ & $\begin{array}{l}\text { \% Wt. } \\
\text { retained }\end{array}$ & $\begin{array}{l}\% \\
\text { Passing }\end{array}$ \\
\hline 25 & 0 & 0 & 100 & 0 & 0 & 100 & 0 & 0 & 100 \\
\hline 19 & 0 & 0 & 100 & 0 & 0 & 100 & 0 & 0 & 100 \\
\hline 12.5 & 0 & 0 & 100 & 0 & 0 & 100 & 0 & 0 & 100 \\
\hline 9.5 & 37 & 3.7 & 96 & 40.5 & 3.8 & 96 & 56.4 & 4.9 & 95 \\
\hline 4.75 & 836 & 83 & 13 & 836.2 & 78.6 & 18 & 965.9 & 83.9 & 11 \\
\hline 2.36 & 108 & 11 & 2.6 & 131 & 12 & 5.3 & 98 & 8.5 & 2.6 \\
\hline 1.18 & 7.6 & 0.8 & 1.9 & 23 & 2.2 & 3.1 & 8 & 0.7 & 1.9 \\
\hline 0.6 & 1.7 & 0.2 & 1.7 & 8.2 & 0.8 & 2.3 & 1.8 & 0.2 & 1.8 \\
\hline 0.3 & 0.8 & 0.1 & 1.6 & 4.1 & 0.4 & 2.0 & 1.1 & 0.1 & 1.7 \\
\hline 0.075 & 1.3 & 0.1 & 1.5 & 4.3 & 0.4 & 1.6 & 1.6 & 0.1 & 1.5 \\
\hline Pan & 14.9 & 1.5 & & 16.5 & 1.6 & & 17.5 & 1.5 & \\
\hline Total & 1007 & & & 1063.9 & & & 1150.7 & & \\
\hline
\end{tabular}

\#9 Coarse Aggregate

\begin{tabular}{|l|c|l|l|l|l|l|l|l|l|}
\hline Sample & \multicolumn{3}{|c|}{ Sample1 } & \multicolumn{3}{l|}{ Sample 2 } & \multicolumn{3}{l|}{ Sample 3 } \\
\hline $\begin{array}{l}\text { SIEVE } \\
\text { SIZE, } \\
\text { mm }\end{array}$ & rt & $\%$ Wt. & $\%$ & Wt & $\%$ Wt. & $\%$ & Wt & $\%$ Wt. & $\%$ \\
\hline 25 & 0 & 0 & 100 & 0 & 0 & 100 & 0 & 0 & 100 \\
\hline 19 & 0 & 0 & 100 & 0 & 0 & 100 & 0 & 0 & 100 \\
\hline 12.5 & 0 & 0 & 100 & 0 & 0 & 100 & 0 & 0 & 100 \\
\hline 9.5 & 0 & 0 & 100 & 0 & 0 & 100 & 0 & 0 & 100 \\
\hline 4.75 & 175 & 32 & 68 & 183.2 & 32.3 & 68 & 157.8 & 28.6 & 71 \\
\hline 2.36 & 346 & 64 & 4.1 & 359 & 63 & 4.5 & 360 & 65 & 6.3 \\
\hline 1.18 & 13 & 2.3 & 1.8 & 14 & 2.5 & 2.0 & 21 & 4 & 2.5 \\
\hline 0.6 & 0.4 & 0.1 & 1.7 & 1.2 & 0.2 & 1.8 & 2.4 & 0 & 2.0 \\
\hline 0.3 & 0.1 & 0.0 & 1.7 & 0.2 & 0.0 & 1.8 & 0.7 & 0 & 1.9 \\
\hline 0.075 & 0.2 & 0.0 & 1.7 & 0.7 & 0.1 & 1.7 & 1.4 & 0 & 1.7 \\
\hline Pan & 9.1 & 1.7 & & 9.4 & 1.7 & & 9.2 & 1.7 & \\
\hline Total & 543.6 & & & 567.4 & & & 552 & & \\
\hline
\end{tabular}


Table A.1 Gradation Data for Aggregates (continued)

\begin{tabular}{|c|c|c|c|c|c|c|c|c|c|}
\hline \multicolumn{10}{|c|}{ SAND } \\
\hline \multirow{3}{*}{$\begin{array}{l}\text { Sample } \\
\text { SIEVE } \\
\text { SIZE, } \\
\text { mm }\end{array}$} & \multicolumn{3}{|c|}{ Sample1 } & \multicolumn{3}{|c|}{ Sample 2} & \multicolumn{3}{|c|}{ Sample 3} \\
\hline & $\mathrm{Wt}$ & $\% \mathrm{Wt}$. & $\%$ & $\mathrm{Wt}$ & $\% \mathrm{Wt}$. & $\%$ & $\mathrm{Wt}$ & $\% \mathrm{Wt}$. & $\%$ \\
\hline & retained & retained & Passing & retained & & Passing & retained & retained & Passing \\
\hline 25 & 0 & 0 & 100 & 0 & 0 & 100 & 0 & 0 & 100 \\
\hline 19 & 0 & 0 & 100 & 0 & 0 & 100 & 0 & 0 & 100 \\
\hline 12.5 & 0 & 0 & 100 & 0 & 0 & 100 & 0 & 0 & 100 \\
\hline 9.5 & 0 & 0 & 100 & 0 & 0 & 100 & 0 & 0 & 100 \\
\hline 4.75 & 5.6 & 1.1 & 99 & 5.9 & 1.1 & 99 & 4.4 & 0.8 & 99 \\
\hline 2.36 & 111 & 21 & 78 & 117 & 22 & 77 & 119 & 23 & 76 \\
\hline 1.18 & 166 & 31 & 46 & 168 & 32 & 45 & 165 & 31 & 45 \\
\hline 0.6 & 91 & 17 & 29 & 88 & 17 & 28 & 87 & 17 & 28 \\
\hline 0.3 & 62 & 12 & 18 & 58 & 11 & 17 & 59 & 11 & 17 \\
\hline 0.075 & 58 & 11 & 6.6 & 54 & 10 & 6.5 & 55 & 10 & 6.6 \\
\hline Pan & 35 & 6.6 & & 34 & 6.5 & & 35 & 6.6 & \\
\hline Total & 528.8 & & & 525.4 & & & 522.8 & & \\
\hline
\end{tabular}

Table A.2 Specific Gravity of Aggregates

\begin{tabular}{|c|c|c|c|c|c|c|}
\hline & \multicolumn{3}{|c|}{$\# 57$} & \multicolumn{3}{|c|}{$\# 8$} \\
\hline & \multicolumn{3}{|c|}{ Sample No. } & \multicolumn{3}{|c|}{ Sample No. } \\
\hline & 1 & 2 & 3 & 1 & 2 & 3 \\
\hline Dry Wt. (g), A & 4886.3 & 3790.6 & 3789.8 & 2756.1 & 1746.7 & 1741.3 \\
\hline SSD Wt.(g), B & 4918.2 & 3812.6 & 3811.3 & 2773.8 & 1758.2 & 1752.6 \\
\hline Wet Wt. (g), C & 3098.8 & 2403.1 & 2400.6 & 1752.4 & 1106.4 & 1102.9 \\
\hline Bulk SG & 2.686 & 2.689 & 2.686 & 2.698 & 2.680 & 2.680 \\
\hline \multicolumn{7}{|l|}{$A /(B-C)$} \\
\hline Apparent SG & 2.734 & 2.732 & 2.728 & 2.746 & 2.728 & 2.728 \\
\hline \multicolumn{7}{|l|}{$\mathrm{A} /(\mathrm{A}-\mathrm{C})$} \\
\hline Absorption, \% & 0.7 & 0.6 & 0.6 & 0.6 & 0.7 & 0.6 \\
\hline
\end{tabular}


Table A.2 Specific Gravity of Aggregates (continued)

\begin{tabular}{|c|c|c|c|c|c|c|}
\hline & \multicolumn{3}{|c|}{$\# 9$} & \multicolumn{3}{|c|}{ Sand } \\
\hline & \multicolumn{3}{|c|}{ Sample No. } & \multirow[b]{2}{*}{1} & \multirow[b]{2}{*}{2} & \multirow[b]{2}{*}{3} \\
\hline & 1 & 2 & 3 & & & \\
\hline Dry Wt. (g), A & 495.7 & 495.4 & 496.6 & 493.1 & 493.6 & 493.4 \\
\hline $\begin{array}{l}\text { Pycnometer Wt.(g), } \\
\text { B }\end{array}$ & 1448.2 & 1448.2 & 1448.2 & 1448.2 & 1448.2 & 1448.2 \\
\hline Wt. In water $(\mathrm{g}), \mathrm{C}$ & 1761.8 & 1762.5 & 1763.2 & 1761.9 & 1762.5 & 1762.3 \\
\hline SSD Wt.(g), D & 500.3 & 500 & 501.1 & 500 & 500.6 & 500.5 \\
\hline Bulk SG & 2.655 & 2.668 & 2.673 & 2.647 & 2.649 & 2.647 \\
\hline $\mathrm{A} /(\mathrm{B}+\mathrm{D}-\mathrm{C})$ & & & & & & \\
\hline Apparent SG & 2.722 & 2.736 & 2.739 & 2.749 & 2.753 & 2.752 \\
\hline $\mathrm{A} /(\mathrm{B}+\mathrm{A}-\mathrm{C})$ & & & & & & \\
\hline Absorption, $\%$ & 0.9 & 0.9 & 0.9 & 1.4 & 1.4 & 1.4 \\
\hline
\end{tabular}

Table A.3. Aggregate Consensus Property Tests

\begin{tabular}{|c|c|c|c|}
\hline Sample & $\begin{array}{l}\text { Sand } \\
\text { reading } \\
\text { No. }\end{array}$ & $\begin{array}{l}\text { Clay } \\
\text { reading } \\
\text { (B) }\end{array}$ & $\begin{array}{l}\text { Sand } \\
\text { Equivalency } \\
\text { (A-10)/B*100 }\end{array}$ \\
\hline 1 & 13.4 & 4.3 & 79 \\
\hline 2 & 13.5 & 4.5 & 78 \\
\hline 3 & 13.5 & 4.5 & 78 \\
\hline
\end{tabular}

\begin{tabular}{|l|c|c|}
\hline $\begin{array}{l}\text { Aggregate } \\
\text { type } \\
\text { Sand }\end{array}$ & $\begin{array}{l}\text { mass of fine } \\
\text { aggregate } \\
\text { (g) }\end{array}$ & $\begin{array}{l}\text { Fine } \\
\text { aggregate } \\
\text { angularity } \\
\text { \# }\end{array}$ \\
\hline$\#$ 9 & 146.0 & 45.9 \\
\hline$\# 8$ & 146.4 & 46.0 \\
\hline
\end{tabular}




\section{APPENDIX B MARSHALL MIX DESIGN DATA AND ANALYSIS}

Table B.1 Theoretical Maximum Specific Gravity Calculations

\begin{tabular}{|c|c|c|c|c|c|}
\hline AC & Sample & $\begin{array}{c}\text { Dry } \\
\text { Wt. (g) }\end{array}$ & $\begin{array}{c}\text { Wet } \\
\text { Wt. (g) }\end{array}$ & $\begin{array}{c}\text { Container } \\
\text { Wt. }(\mathrm{g})\end{array}$ & Gmm \\
\hline 3.9 & 1 & 2071.1 & 2769.2 & 1511.1 & 2.547 \\
\hline & 2 & 2067.5 & 2766.9 & 1511.1 & 2.547 \\
\hline & 3 & 2072.9 & 2771 & 1511.1 & 2.550 \\
\hline 4.4 & 1 & 2073.1 & 2766.2 & 1511.1 & 2.534 \\
\hline & 2 & 2072.8 & 2765.8 & 1511.1 & 2.534 \\
\hline & 3 & 2075.3 & 2767.6 & 1511.1 & 2.535 \\
\hline 4.9 & 1 & 2086.2 & 2767 & 1511.1 & 2.513 \\
\hline & 2 & 2086.7 & 2769.9 & 1511.1 & 2.520 \\
\hline & 3 & 2029.2 & 2733.5 & 1511.1 & 2.515 \\
\hline 5.4 & 1 & 2095.5 & 2583.9 & 1511.1 & 2.049 \\
\hline & 2 & 2093.2 & 2579.2 & 1511.1 & 2.042 \\
\hline & 3 & 2097 & 2583.2 & 1511.1 & 2.046 \\
\hline 5.9 & 1 & 2110.6 & 2588.2 & 1511.1 & 2.042 \\
\hline & 2 & 2110.9 & 2587.7 & 1511.1 & 2.041 \\
\hline & 3 & 2109.2 & 2587 & 1511.1 & 2.041 \\
\hline 6.4 & 1 & 2111.3 & 2583.8 & 1511.1 & 2.033 \\
\hline & 2 & 2110 & 2582.3 & 1511.1 & 2.031 \\
\hline & 3 & 2114.4 & 2586.3 & 1511.1 & 2.035 \\
\hline 6.9 & 1 & 2106.9 & 2576.6 & 1511.1 & 2.023 \\
\hline & 2 & 2105.6 & 2575.2 & 1511.1 & 2.022 \\
\hline & 3 & 2107.5 & 2577.3 & 1511.1 & 2.024 \\
\hline 7.4 & 1 & 2092.5 & 2562.6 & 1511.1 & 2.010 \\
\hline & 2 & 2098.6 & 2565 & 1511.1 & 2.009 \\
\hline & 3 & 2102.4 & 2568 & 1511.1 & 2.011 \\
\hline & & & & & \\
\hline
\end{tabular}


Table B.2 Marshall Heavy Traffic Level Mix Design

\begin{tabular}{|c|c|c|c|c|c|c|c|c|c|c|c|c|c|c|c|}
\hline \multirow{2}{*}{\multicolumn{3}{|c|}{$\begin{array}{c}\text { Asphalt Content by } \\
\text { Weight of Mix }\end{array}$}} & \multirow{4}{*}{$\begin{array}{l}\text { Specimen } \\
\text { Thickness } \\
(\mathrm{mm})\end{array}$} & \multicolumn{3}{|c|}{ Mass in Grams } & \multicolumn{2}{|c|}{ Specific Gravity } & \multirow{3}{*}{$\begin{array}{l}\text { Density } \\
\mathrm{Kg} / \mathrm{m} 3\end{array}$} & \multirow{3}{*}{$\begin{array}{l}\text { Voids in } \\
\text { Mineral } \\
\text { Aggregate }\end{array}$} & \multirow{2}{*}{\multicolumn{2}{|c|}{ Percent Air Voids }} & \multirow{2}{*}{\multicolumn{2}{|c|}{$\begin{array}{l}\text { Stability (n) } \\
\text { Pounds }\end{array}$}} & \multirow{3}{*}{$\begin{array}{l}\text { Flow } \\
0.01 \\
\text { inch }\end{array}$} \\
\hline & & & & \multirow{2}{*}{$\begin{array}{l}\text { Weight } \\
\text { in Air }\end{array}$} & \multirow{2}{*}{$\begin{array}{l}\text { Weight } \\
\text { In water }\end{array}$} & \multirow{2}{*}{$\begin{array}{l}\text { Saturated } \\
\text { surface dry }\end{array}$} & \multirow[b]{2}{*}{ Bulk } & \multirow{2}{*}{ Maximum } & & & & & & & \\
\hline Specimen & Percent & & & & & & & & & & Total Mix & Filled & Actual & Adjusted i & \\
\hline Number & $\mathrm{AC}$ & & & A & $\mathrm{C}$ & $\mathrm{B}$ & $\mathrm{D}$ & E & & $\mathrm{F}$ & & & & & \\
\hline & & & & & & & $\mathrm{A} /(\mathrm{B}-\mathrm{C})$ & & D X 1000 & & $\begin{array}{r}100 X \\
{[(E-D) / E}\end{array}$ & {$\left[\begin{array}{r}100 \mathrm{X} \\
{[(\mathrm{F}-\mathrm{G}) / \mathrm{F}]}\end{array}\right.$} & & & \\
\hline 1 & 1 & 3.9 & 66 & 1187.9 & 686.5 & 1194.2 & 2.340 & & & & & & 2425 & 2287.1 & 16.0 \\
\hline 2 & 2 & 3.9 & 65 & 1186.6 & 688.3 & 1193.2 & 2.350 & & & & & & 2350 & 2261.9 & 14.0 \\
\hline & 3 & 3.9 & 65 & 1185.6 & 687.8 & 1192.3 & 2.350 & & & & & & 2225 & 2141.6 & 13.5 \\
\hline Average & & & & & & & 2.347 & 2.55 & 2347 & 15.54 & 7.97 & 48.68 & 2333 & 2230.2 & 14.5 \\
\hline 1 & 1 & 4.4 & 66 & 1184.3 & 692.5 & 1190.1 & 2.380 & & & & & & 2000 & 1886.3 & 17.5 \\
\hline 2 & 2 & 4.4 & 64 & 1184.6 & 694.8 & 1190.4 & 2.390 & & & & & & 2350 & 2320.6 & 17.5 \\
\hline 3 & 3 & 4.4 & 66 & 1181.2 & 695.1 & 1187.2 & 2.400 & & & & & & 2475 & 2334.2 & 16.0 \\
\hline Average & & & & & & & 2.390 & 2.533 & 2390 & 14.42 & 5.64 & 60.90 & 2275 & 2180.4 & 17.0 \\
\hline 1 & 1 & 4.9 & 63 & 1187.2 & 694.8 & 1190.3 & 2.396 & & & & & & 2025 & 2050.3 & 12.5 \\
\hline 2 & 2 & 4.9 & 63 & 1174.5 & 689.5 & 1178.8 & 2.400 & & & & & & 2125 & 2151.6 & 12.5 \\
\hline 3 & 3 & 4.9 & 64 & 1190.4 & 701.5 & 1195.4 & 2.410 & & & & & & 1875 & 1851.6 & 13.0 \\
\hline Average & & & & & & & 2.402 & 2.513 & 2402 & 14.44 & 4.41 & 69.46 & 2008 & 2017.8 & 12.7 \\
\hline 1 & 1 & 5.4 & 64 & 1182 & 696 & 1186.4 & 2.410 & & & & & & 1975 & 1950.3 & 13.5 \\
\hline 2 & 2 & 5.4 & 63 & 1180.7 & 690.7 & 1184.7 & 2.390 & & & & & & 2000 & 2025.0 & 13.0 \\
\hline 3 & 3 & 5.4 & 66 & 1179.4 & 688.1 & 1183.5 & 2.381 & & & & & & 2175 & 2051.3 & 22.5 \\
\hline Average & & & & & & & 2.394 & 2.491 & 2394 & 15.19 & 3.91 & 74.28 & 2050 & 2008.9 & 16.3 \\
\hline 1 & 1 & 5.9 & 63 & 1188.9 & 695.3 & 1191.1 & 2.398 & & & & & & 2450 & 2480.6 & 15.0 \\
\hline 2 & 2 & 5.9 & 63 & 1185.3 & 693.2 & 1189.3 & 2.389 & & & & & & 2300 & 2328.8 & 15.0 \\
\hline 3 & 3 & 5.9 & 64 & $4 \quad 1184.5$ & 692.6 & 1188.2 & 2.390 & & & & & & 2275 & 2145.6 & 16.0 \\
\hline Average & & & & & & & 2.392 & 2.476 & 2392 & 15.68 & 3.38 & 78.47 & 2342 & 2318.3 & 15.3 \\
\hline
\end{tabular}


Table B.3 Marshall Medium Traffic Mix Design

\begin{tabular}{|c|c|c|c|c|c|c|c|c|c|c|c|c|c|c|}
\hline \multirow{2}{*}{\multicolumn{2}{|c|}{$\begin{array}{l}\text { Asphalt Content by } \\
\text { Weight of Mix }\end{array}$}} & \multirow{4}{*}{$\begin{array}{l}\text { Specimen } \\
\text { Thickness } \\
(\mathrm{mm})\end{array}$} & \multicolumn{3}{|c|}{ Mass in Grams } & \multicolumn{2}{|c|}{ Specific Gravity } & \multirow{3}{*}{$\begin{array}{l}\text { Density } \\
\mathrm{Kg} / \mathrm{m} 3 \\
\end{array}$} & \multirow{3}{*}{$\begin{array}{l}\text { Voids in } \\
\text { Mineral } \\
\text { Aggregate }\end{array}$} & \multirow{2}{*}{\multicolumn{2}{|c|}{ Percent Air Voids }} & \multirow{2}{*}{\multicolumn{2}{|c|}{$\begin{array}{l}\text { Stability (n) } \\
\text { Pounds }\end{array}$}} & \multirow{3}{*}{$\begin{array}{l}\text { Flow } \\
0.01 \\
\text { inch }\end{array}$} \\
\hline & & & \multirow{2}{*}{$\begin{array}{l}\text { Weight } \\
\text { in Air }\end{array}$} & \multirow{2}{*}{$\begin{array}{l}\text { Saturated } \\
\text { surface dry }\end{array}$} & \multirow{2}{*}{$\begin{array}{l}\text { Weight in } \\
\text { water }\end{array}$} & \multirow[b]{2}{*}{ Bulk } & \multirow[b]{2}{*}{ Maximum } & & & & & & & \\
\hline Specimen & Percent & & & & & & & & & Total Mix & Filled & Actual & Adjusted & \\
\hline Number & $\mathrm{AC}$ & & A & $B$ & $\mathrm{C}$ & D & E & & $\mathrm{F}$ & $\mathrm{G}$ & & & & \\
\hline & & & & & & $\mathrm{A} /(\mathrm{B}-\mathrm{C})$ & & D X 1000 & & $\begin{array}{c}100 X \\
{[(E-D) / E]}\end{array}$ & {$\left[\begin{array}{c}100 X \\
{[(F-G) / F]}\end{array}\right]$} & & & \\
\hline 1 & 4.4 & 62 & 1136.7 & 1142.3 & 658.0 & 2.347 & & & & & & 1950 & 2023 & 14 \\
\hline 2 & 4.4 & 61 & 1140.7 & 1144.6 & 662.3 & 2.365 & & & & & & 1975 & 2110 & 15 \\
\hline 3 & 4.4 & 61 & 1138.1 & 1142.5 & 661.0 & 2.364 & & & & & & 2025 & 2163 & 15 \\
\hline Average & & & & & & 2.359 & 2.534 & 2359 & 15.55 & 6.92 & 55.49 & 1983 & 2099 & 15 \\
\hline 1 & 4.9 & 61 & 1145.7 & 1150.1 & 665.0 & 2.362 & & & & & & 2025 & 2163 & 16 \\
\hline 2 & 4.9 & 61 & 1141.9 & 1147.7 & 663.9 & 2.36 & & & & & & 2050 & 2190 & 17 \\
\hline 3 & 4.9 & 61 & 1141.5 & 1146.9 & 663.8 & 2.363 & & & & & & 2050 & 2190 & 17 \\
\hline Average & & & & & & 2.362 & 2.516 & 2362 & 15.88 & 6.14 & 61.37 & 2042 & 2163 & 17 \\
\hline 1 & 5.4 & 61 & 1139.5 & 1142.9 & 663.2 & 2.375 & & & & & & 2000 & 2136 & 19 \\
\hline 2 & 5.4 & 62 & 1140.9 & 1144.5 & 665.2 & 2.380 & & & & & & 2000 & 2075 & 18 \\
\hline 3 & 5.4 & 61 & 1139.2 & 1144.0 & 664.4 & 2.375 & & & & & & 1850 & 1976 & 20 \\
\hline Average & & & & & & 2.377 & 2.491 & 2377.000 & 15.78 & 4.58 & 71.01 & 1950 & 2163 & 19 \\
\hline 1 & 5.9 & 61 & 1143.8 & 1146.6 & 667.2 & 2.386 & & & & & & 1950 & 2083 & 15 \\
\hline 2 & 5.9 & 60 & 1138.0 & 1140.3 & 664.4 & 2.391 & & & & & & 1975 & 2134 & 15 \\
\hline 3 & 5.9 & 61 & 1144.6 & 1146.8 & 671.5 & 2.408 & & & & & & 1875 & 2003 & 13 \\
\hline Average & & & & & & 2.395 & 2.476 & 2395 & 15.59 & 3.27 & 79.04 & 1933 & 2073 & 14.3 \\
\hline 1 & 6.4 & 60 & 1137.6 & 1139.4 & 669.0 & 2.418 & & & & & & 1825 & 1972 & 21 \\
\hline 2 & 6.4 & 61 & 1138.5 & 1141.5 & 662.5 & 2.377 & & & & & & 1975 & 2110 & 20 \\
\hline 3 & 6.4 & 61 & 1150.9 & 1154.2 & 673.1 & 2.392 & & & & & & 1925 & 2056 & 20 \\
\hline Average & & & & & & 2.396 & 2.452 & 2396 & 16.01 & 2.29 & 85.69 & 1908 & 2046 & 20 \\
\hline
\end{tabular}




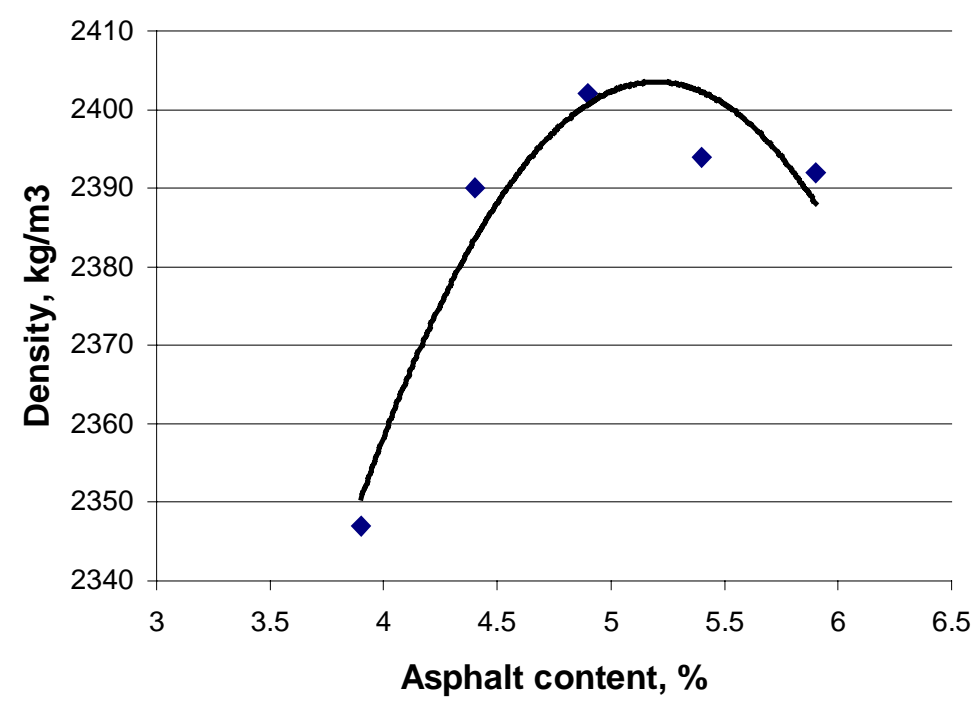

Figure B.1 Asphalt content versus Density - Marshall heavy

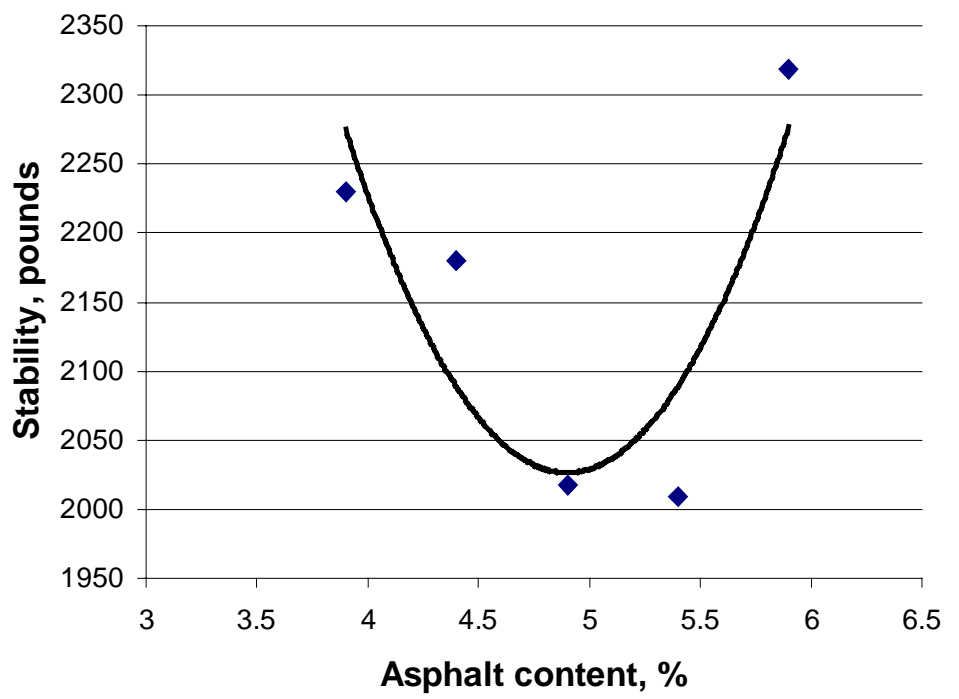

Figure B.2 Asphalt content versus Stability - Marshall heavy traffic mix. 


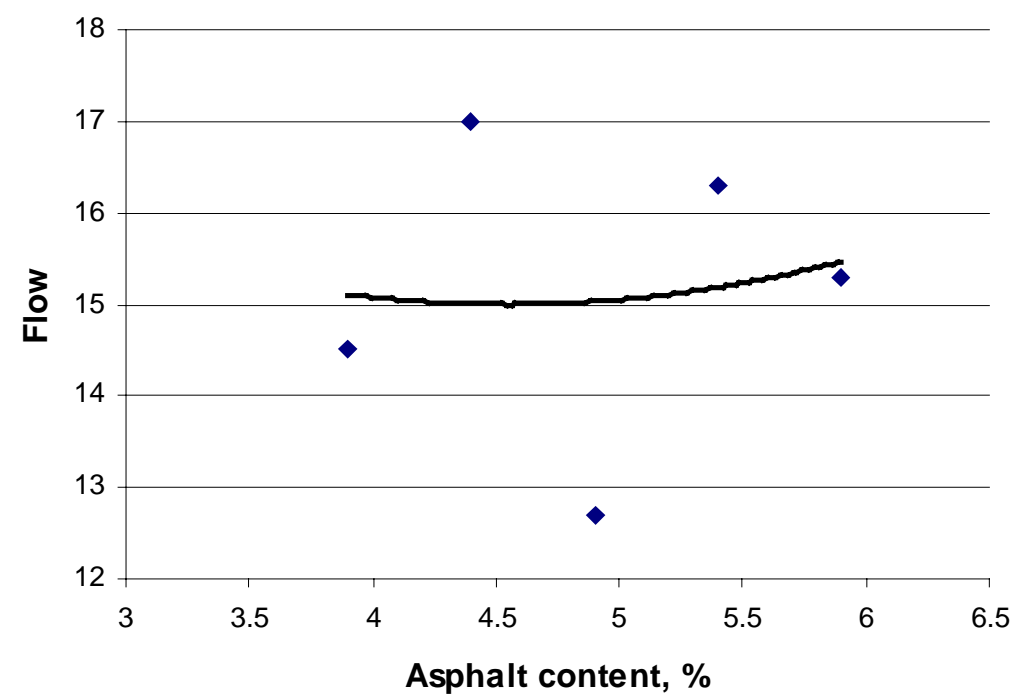

Figure B.3 Asphalt content versus Flow - Marshall heavy traffic mix

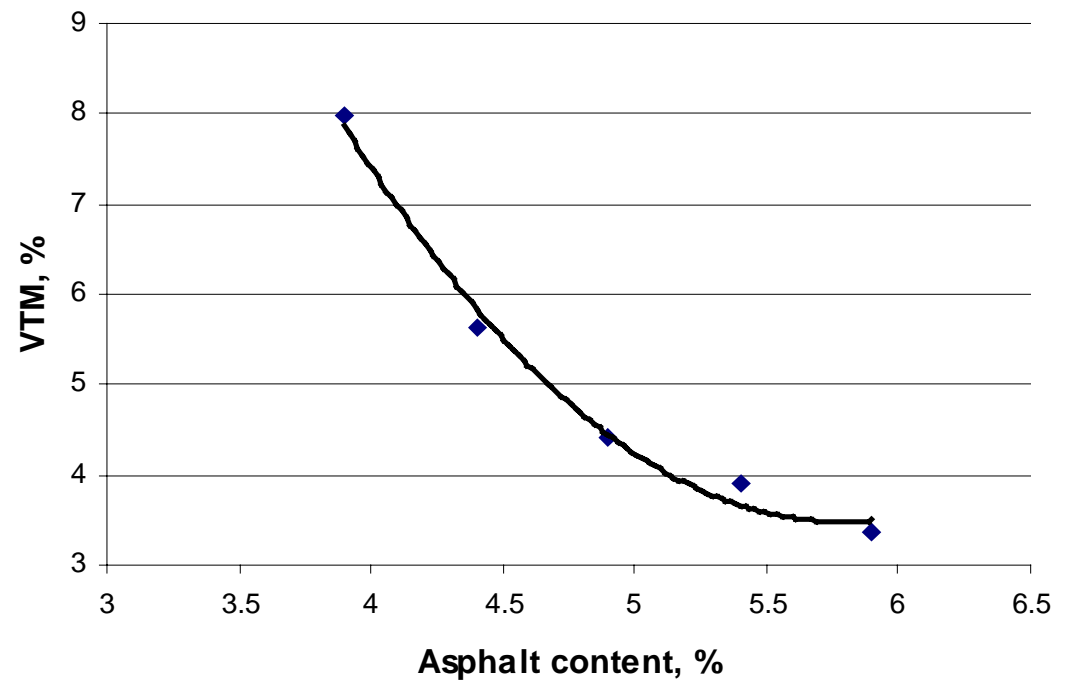

Figure B.4 Asphalt content versus VTM - Marshall heavy traffic mix 


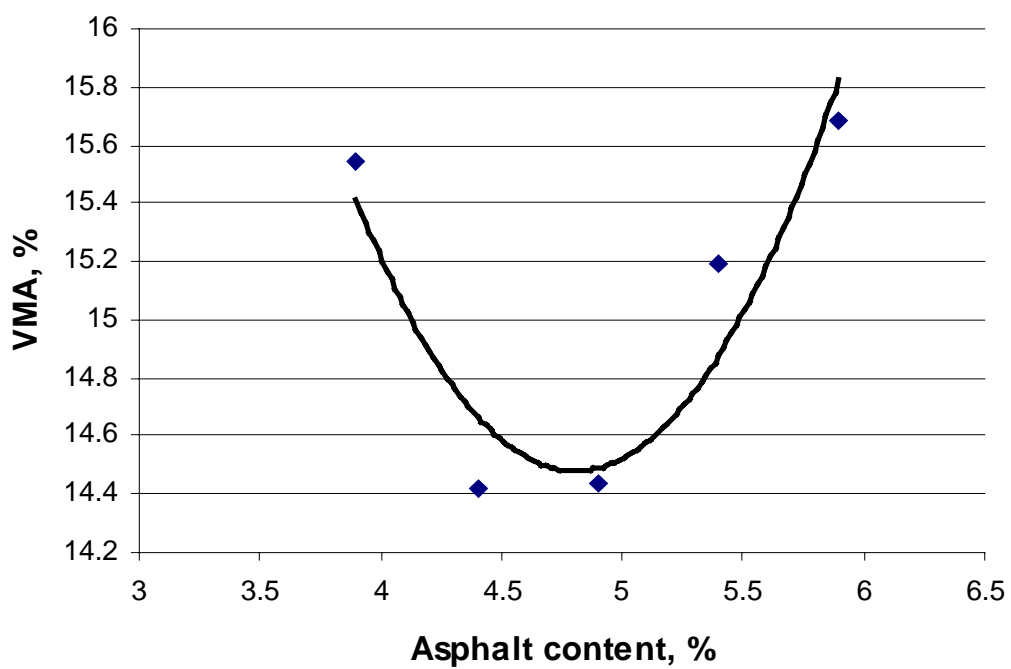

Figure B.5 Asphalt content versus VMA - Marshall heavy traffic mix

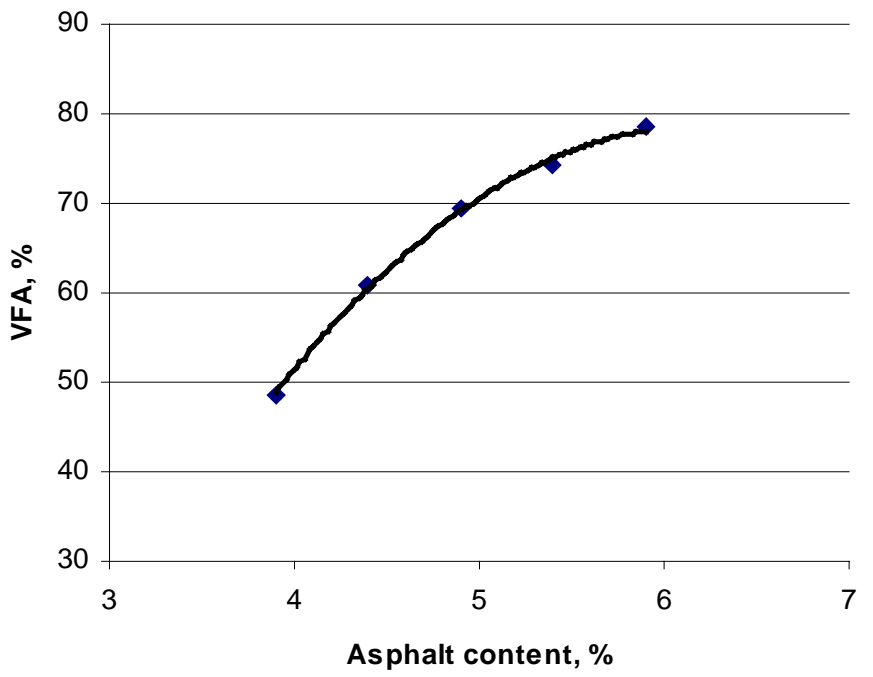

Figure B.6 Asphalt content versus VFA -Marshall heavy traffic mix. 


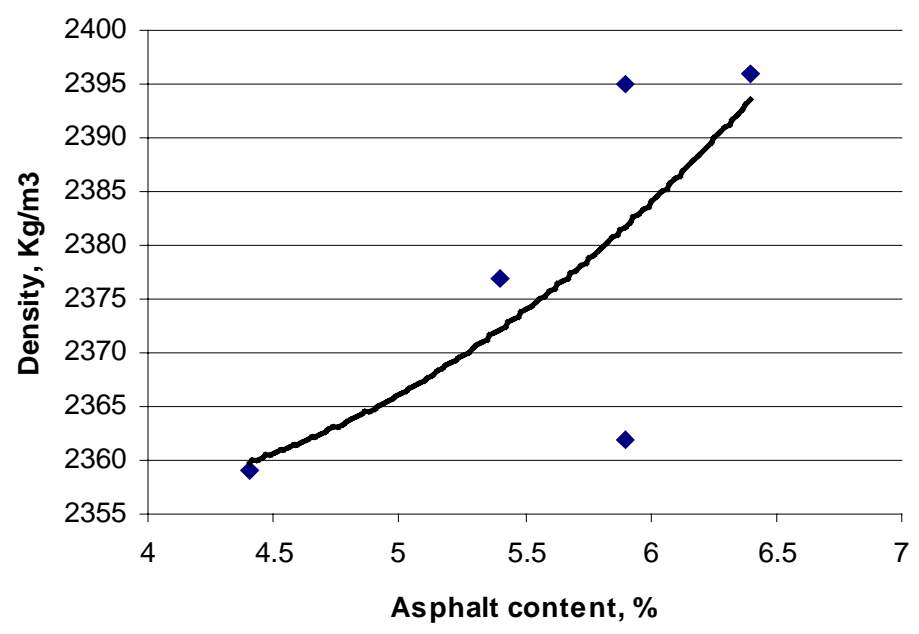

Figure B. 7 Asphalt content versus density, Marshall medium traffic mix.

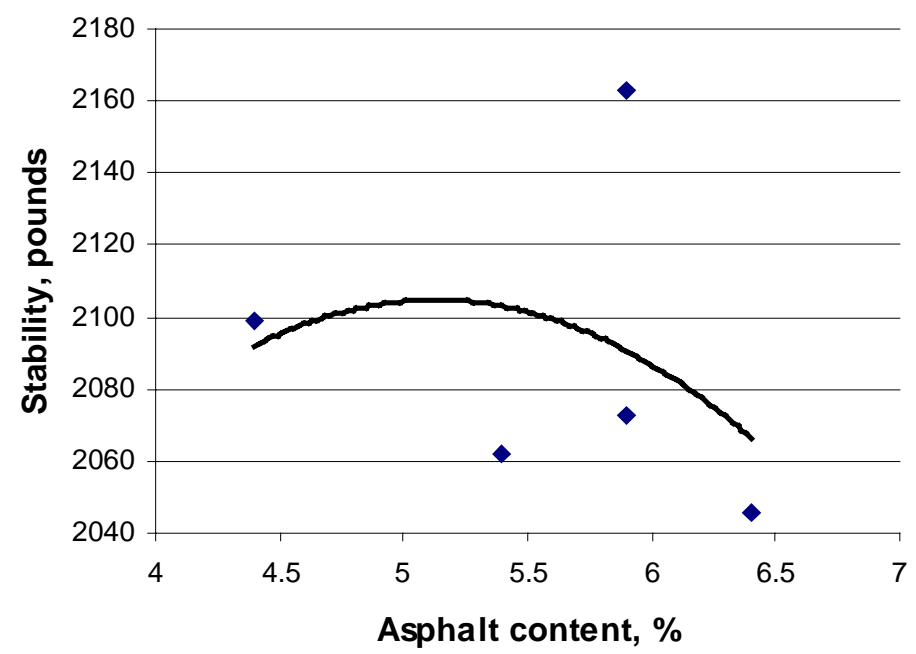

Figure B.8 Asphalt content versus Stability - Marshall medium traffic mix. 


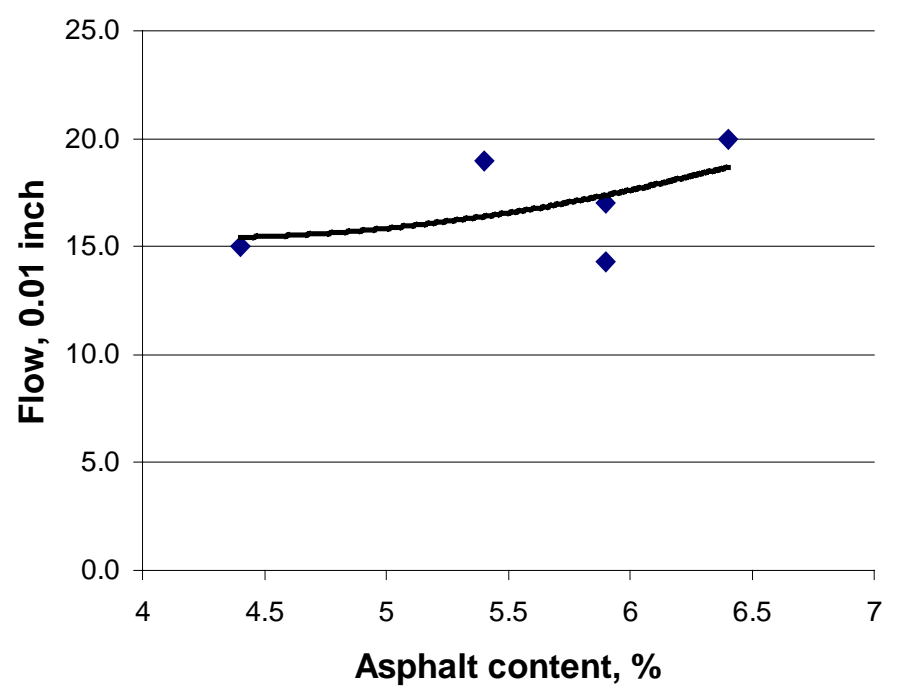

Figure B.9 Asphalt content versus Flow - Marshall light traffic level

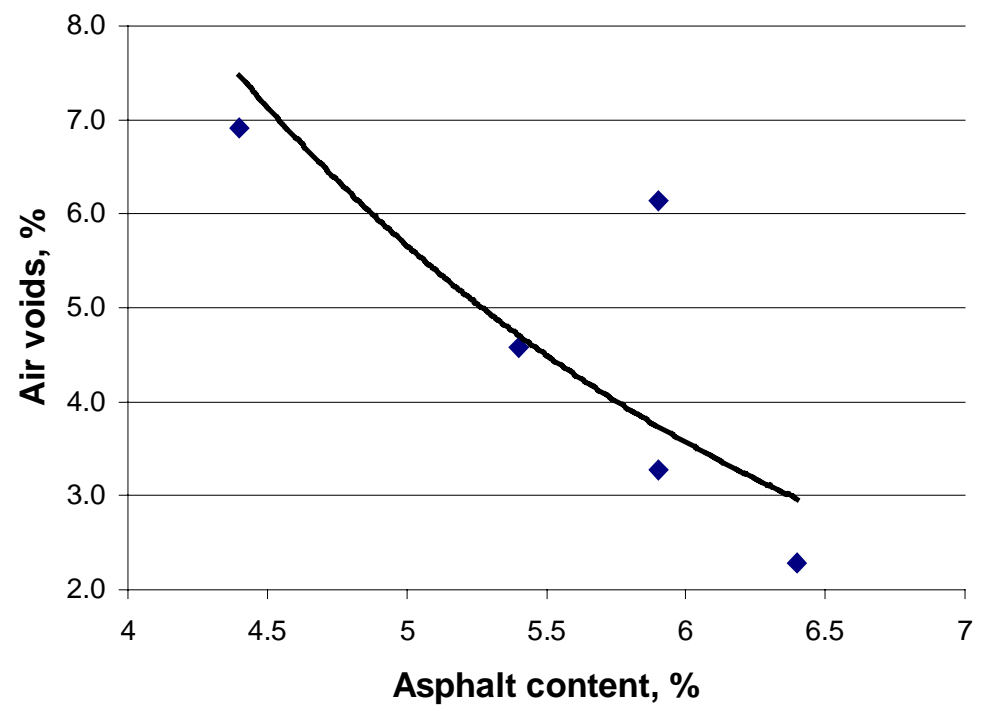

Figure B.10 Asphalt content versus Air voids -Marshall medium traffic mix. 


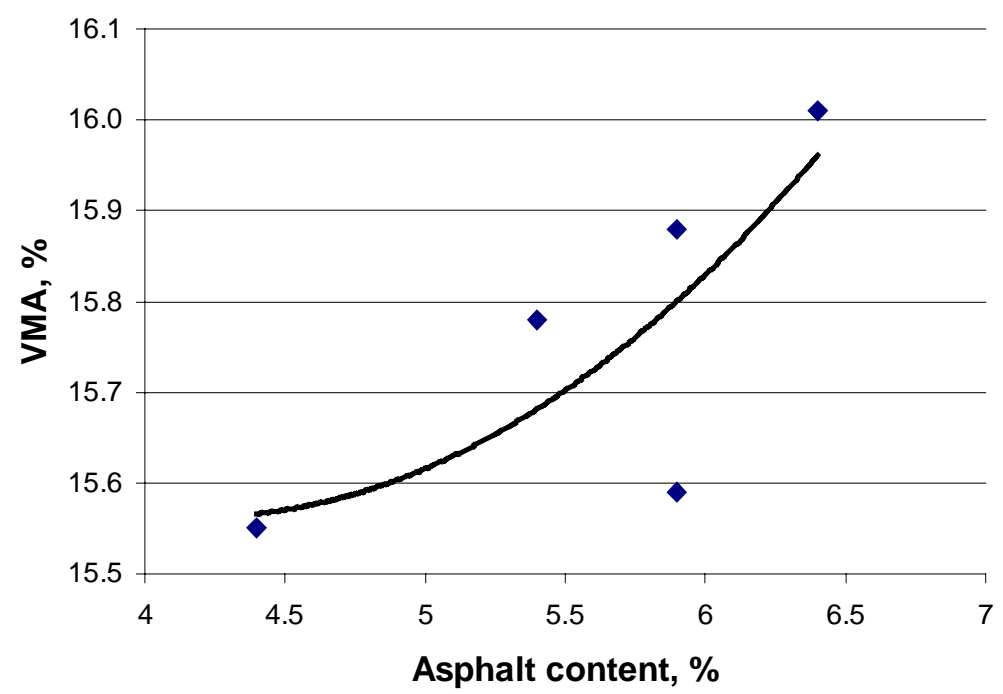

Figure B.11 Asphalt content versus VMA - Marshall light traffic mix.

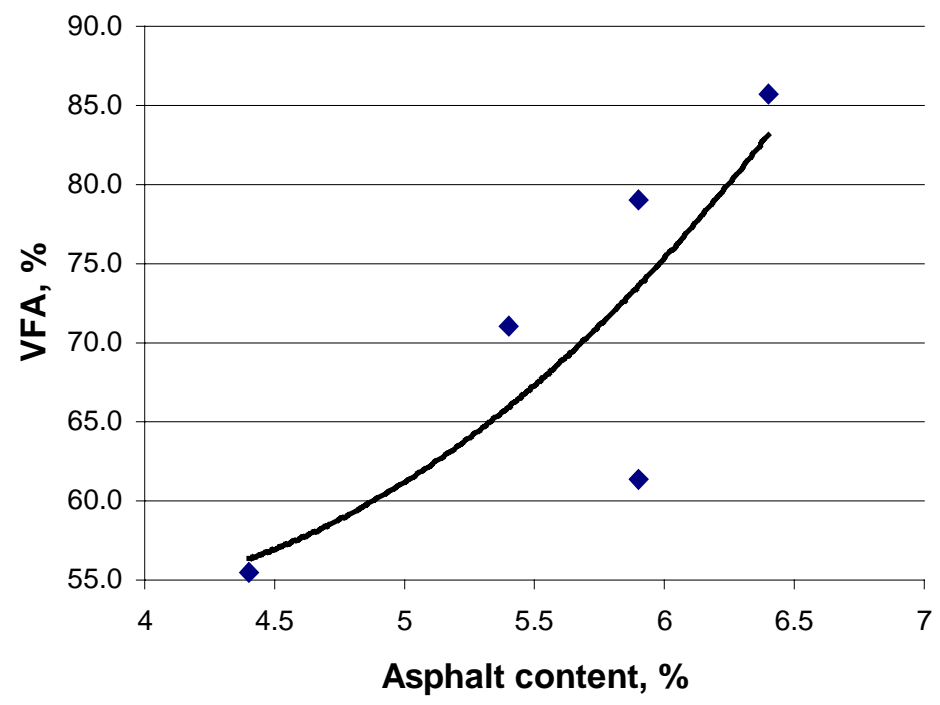

Figure B.12 Asphalt content versus VFA - Marshall 
APPENDIX C SUPERPAVE MIX DESIGN DATA AND ANALYSIS

Table C.1 Theoretical Specific Gravity for Trial Blends

\begin{tabular}{|c|c|c|c|c|c|}
\hline \multicolumn{6}{|c|}{ Weight of the container in water, (g) [D] = 1511.1 } \\
\hline \multirow{3}{*}{ BLEND } & & & A & E & A/(A+D-E) \\
\cline { 2 - 6 } & AC,\% & Sample & Dry wt.(g) & Wet wt.(g) & Gmm \\
\hline \multirow{3}{*}{1} & 4.4 & 1 & 2231.8 & 2864.0 & 2.539 \\
\cline { 2 - 6 } & & 2 & 2074.4 & 2768.2 & 2.538 \\
\cline { 2 - 6 } & & 3 & 2077.2 & 2769.8 & 2.538 \\
\hline 2 & 4.5 & 1 & 2081.5 & 2771.8 & 2.536 \\
\cline { 2 - 6 } & & 2 & 2074.4 & 2766.9 & 2.534 \\
\cline { 2 - 6 } & & 3 & 2077.5 & 2768.8 & 2.534 \\
\hline 3 & 4.5 & 1 & 2097.7 & 2770.6 & 2.503 \\
\cline { 2 - 6 } & & 2 & 2072.4 & 2771.5 & 2.552 \\
\cline { 2 - 6 } & & 3 & 2081.9 & 2771.1 & 2.533 \\
\hline
\end{tabular}

Table C.2 Bulk Specific Gravity for Trial Blends

\begin{tabular}{|l|c|l|l|l|l|}
\hline & & A & B & C & A/(C-B) \\
\hline Blend & Sample & Dry Wt. (g) & Wet Wt. (g) & SSD Wt. (g) & Gmb \\
\hline \multirow{3}{*}{ Blend 1 } & 1 & 4767.6 & 2784.4 & 4788.1 & 2.379 \\
\cline { 2 - 6 } & 2 & 4770.7 & 2791.2 & 4787.9 & 2.389 \\
\cline { 2 - 6 } & 3 & 4778.2 & 2798.1 & 4803.3 & 2.383 \\
\hline Blend 2 & 1 & 4794.6 & 2795.0 & 4818.6 & 2.369 \\
\cline { 2 - 6 } & 2 & 4786.0 & 2786.0 & 4814.0 & 2.360 \\
\cline { 2 - 6 } & 3 & 4783.0 & 2781.0 & 4809.1 & 2.358 \\
\hline Blend 3 & 1 & 4941.4 & 2892.9 & 4968.4 & 2.381 \\
\cline { 2 - 6 } & 2 & 4781.4 & 2787.2 & 4805.0 & 2.370 \\
\cline { 2 - 6 } & 3 & 4767.5 & 2779.5 & 4798.5 & 2.361 \\
\hline
\end{tabular}


Table C.3 Theoretical Maximum Specific Gravity Calculations for Superpave Heavy Traffic Mix

\begin{tabular}{|c|c|c|c|c|c|}
\multicolumn{6}{|c|}{ Weight of the container in water, (g) $[\mathrm{D}]=$} \\
\hline & & A & E & A/(A+D-E) & \\
\hline AC, \% & Sample & Dry wt. (g) & Wet wt. (g) & $\mathrm{G}_{\mathrm{mm}}$ & Avg G \\
\hline 4.7 & 1 & 2110.4 & 2785.2 & 2.523 & \\
\hline & 2 & 2009.6 & 2723.9 & 2.522 & 2.523 \\
\hline 5.2 & 1 & 2021.6 & 2724.7 & 2.502 & \\
\hline & 2 & 2022.4 & 2725.2 & 2.502 & 2.502 \\
\hline 5.7 & 1 & 2098.5 & 2768.2 & 2.494 & \\
\hline & 2 & 2095.6 & 2767.1 & 2.496 & 2.495 \\
\hline 6.2 & 1 & 2090.8 & 2760.2 & 2.484 & \\
\hline & 2 & 2099.2 & 2765.9 & 2.486 & 2.485 \\
\hline
\end{tabular}

Table C.4 Bulk Specific Gravity for Superpave Heavy Traffic Level Mix

\begin{tabular}{|c|c|c|c|l|l|l|}
\hline & Sample & A & B & C & A/(C-B) & \\
\hline AC, \% & No. & \multicolumn{1}{|c|}{ Dry wt. (g) Wet wt. (g) } & SSD Wt. (g) & $\mathbf{G}_{\mathbf{m b}}$ & Avg $\mathbf{G}_{\mathbf{m b}}$ \\
\hline 4.7 & 1 & 4774.8 & 2787.1 & 4791.2 & 2.383 & \\
\hline & 2 & 4759.6 & 2788.6 & 4776.2 & 2.395 & 2.389 \\
\hline 6.4 & 1 & 4801.0 & 2808.3 & 4810.1 & 2.398 & \\
\hline & 2 & 4765.0 & 2796.7 & 4771.5 & 2.413 & 2.406 \\
\hline 6.9 & 1 & 4800.9 & 2825.2 & 4806.6 & 2.423 & \\
\hline & 2 & 4775.2 & 2804.9 & 4781.2 & 2.416 & 2.420 \\
\hline 7.4 & 1 & 4760.9 & 2802.1 & 4766.5 & 2.424 & \\
\hline & 2 & 4755.2 & 2791.0 & 4762.0 & 2.413 & 2.419 \\
\hline
\end{tabular}




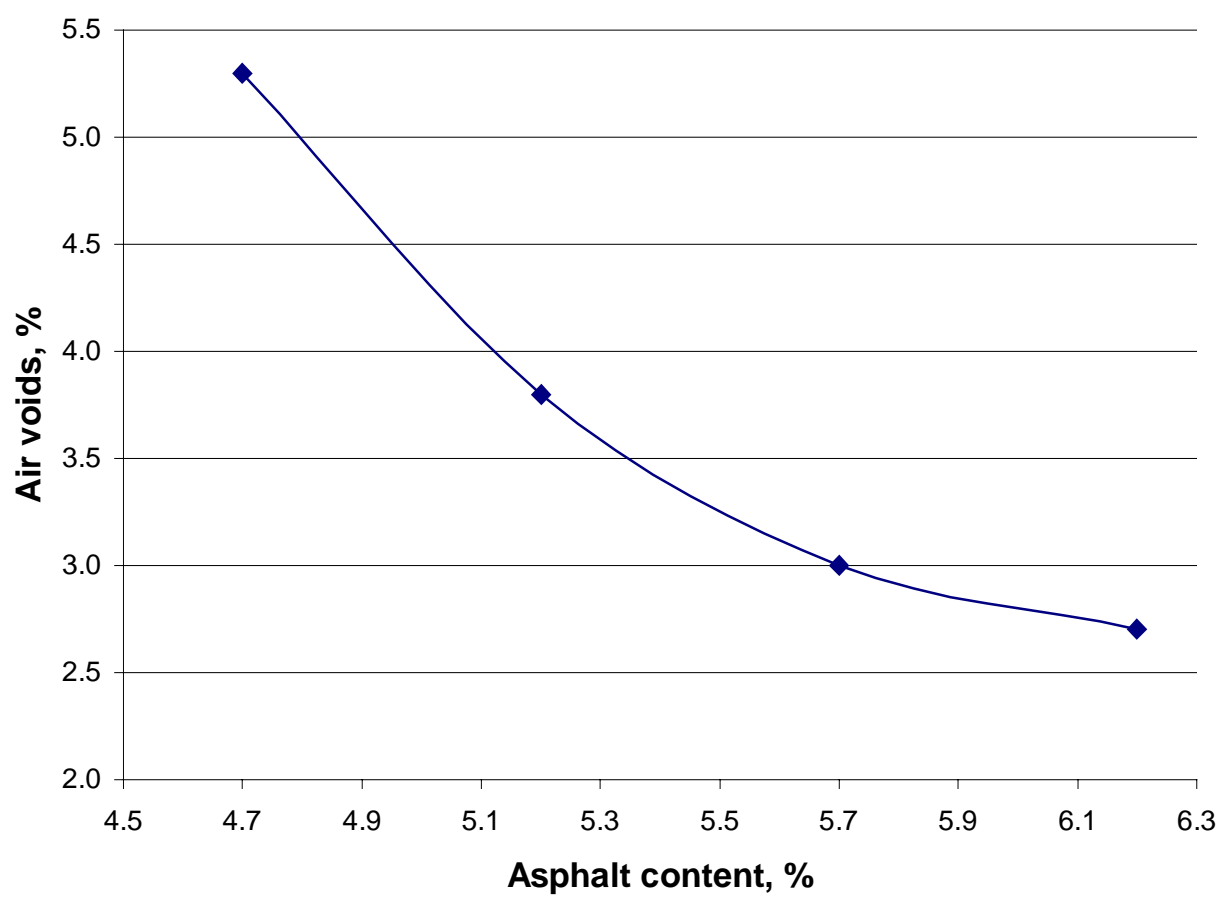

Figure C.1 Asphalt content versus Air voids-Superpave heavy traffic mix.

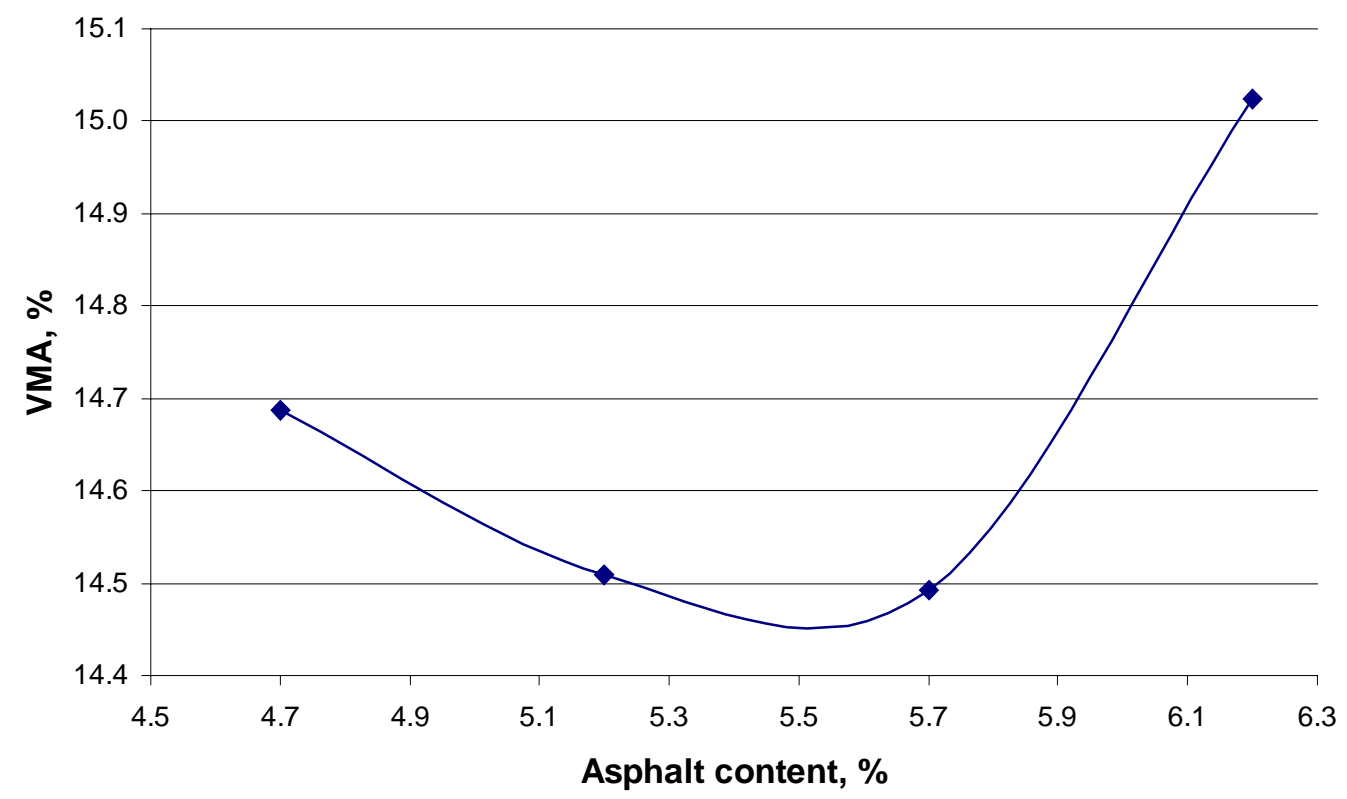

Figure C.2 Asphalt content versus VMA-Superpave heavy traffic mix. 


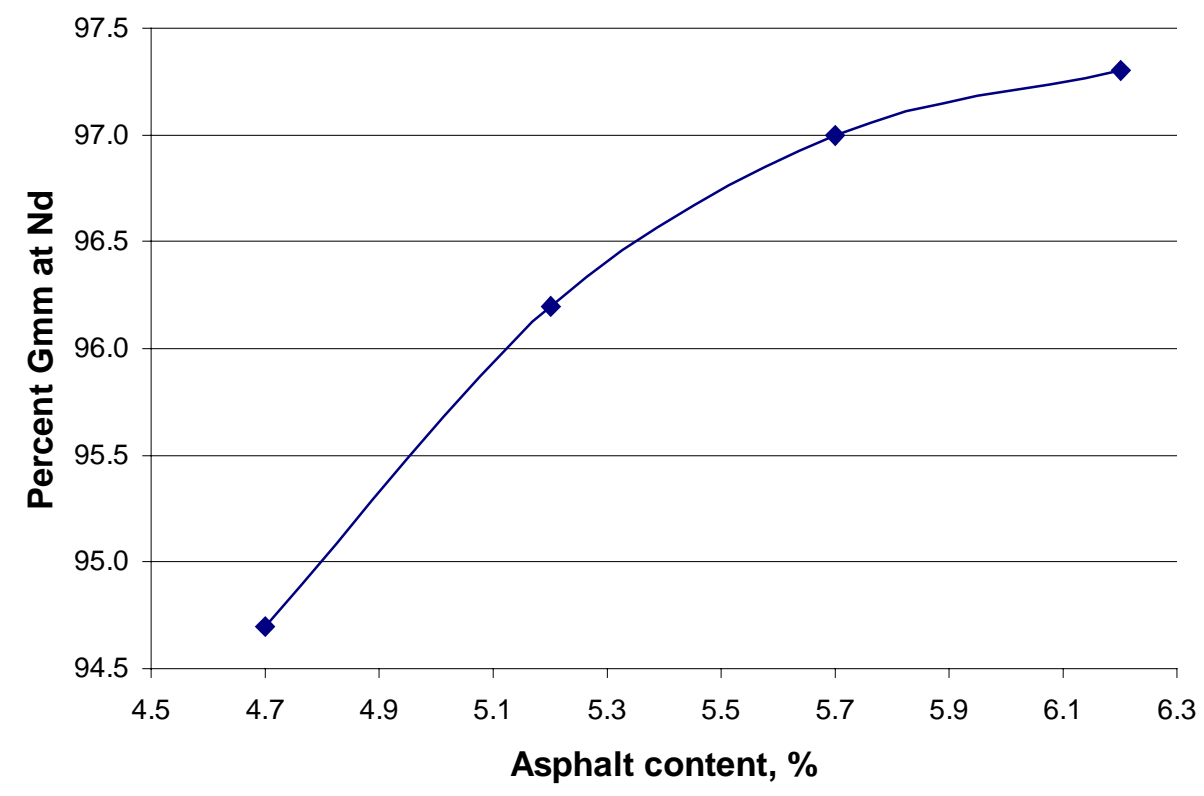

Figure C.3 Asphalt content versus Percent Gmm at Nd-Superpave heavy traffic mix

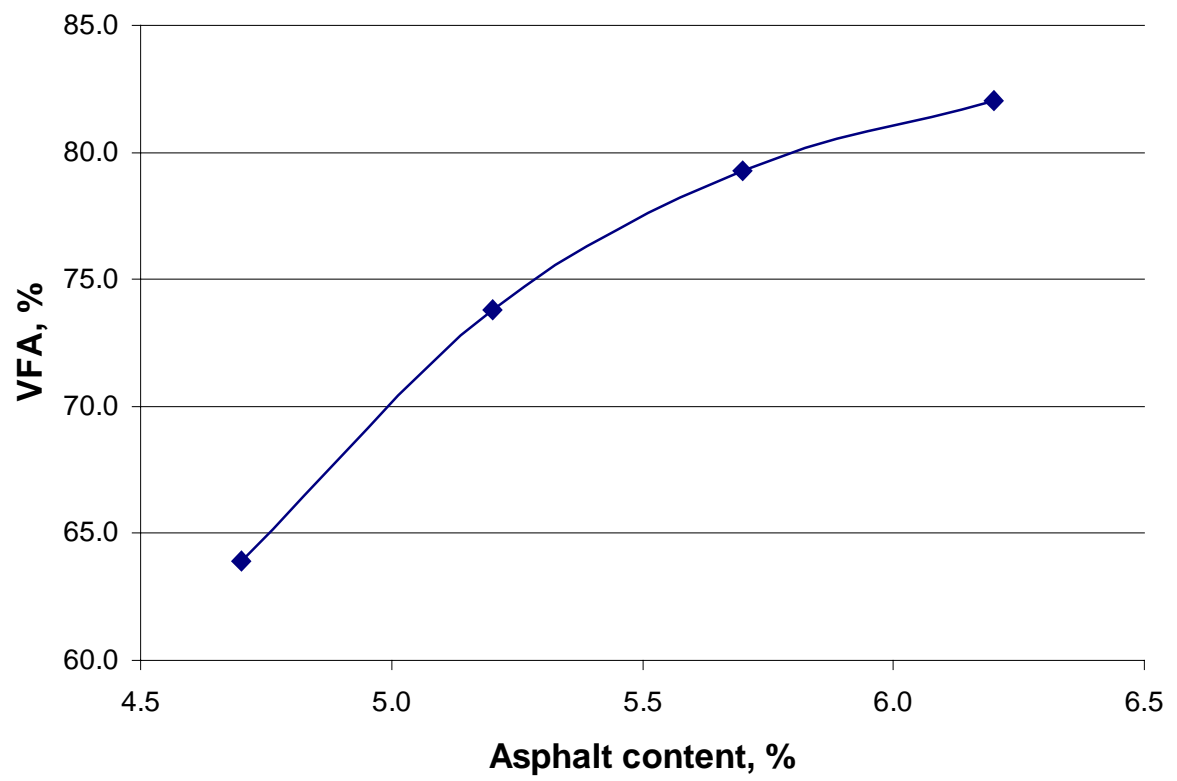

Figure C.4 Asphalt content versus VFA - Superpave heavy traffic mix. 
Table C.5 Blend Bulk Specific Gravity Calculations -Superpave Medium Traffic Mix.

\begin{tabular}{|c|c|c|c|c|}
\hline Sample & A & B & C & A/(C-B) \\
\hline No. & Dry Wt. (g) & Wet Wt. (g) & SSD Wt. (g) & Gmb \\
\hline 1 & 4745.0 & 2742.5 & 4748.8 & 2.365 \\
\hline 2 & 4753.2 & 2750.5 & 4768.8 & 2.355 \\
\hline 3 & 4739.0 & 2762.9 & 4752.9 & 2.381 \\
\hline
\end{tabular}

Table C.6 Theoretical Maximum Specific Gravity Calculations-Superpave Medium Traffic Mix

\begin{tabular}{|c|c|c|c|c|c|}
\hline \multicolumn{6}{|c|}{ Weight of the container in water, (g) $[\mathrm{D}]=1511.1$} \\
\hline & & A & E & A/(A+D-E) & \\
\hline AC, $\%$ & Sample & Dry wt. (g) & Wet wt. (g) & $\mathrm{G}_{\mathrm{mm}}$ & Avg G $\mathrm{mm}$ \\
\hline 5.2 & 1 & 2013.4 & 2719.1 & 2.500 & \\
\hline & 2 & 2021.6 & 2725.4 & 2.504 & 2.502 \\
\hline 5.7 & 1 & 2092.8 & 2764.8 & 2.494 & \\
\hline & 2 & 2098.5 & 2768.9 & 2.496 & 2.495 \\
\hline 6.2 & 1 & 2088.4 & 2758.4 & 2.483 & \\
\hline & 2 & 2090.8 & 2761.2 & 2.487 & 2.485 \\
\hline 6.7 & 1 & 2099.4 & 2759.6 & 2.467 & \\
\hline & 2 & 2110.9 & 2763.9 & 2.460 & 2.464 \\
\hline
\end{tabular}

Table C.7 Bulk Specific Gravity-Superpave Medium Traffic Mix.

\begin{tabular}{|c|c|c|c|l|l|l|}
\hline & Sample & A & B & C & A/(C-B) & \\
\hline AC, \% & No. & Dry wt. (g) & Wet wt. (g) & SSD Wt. (g) & $\mathbf{G}_{\mathbf{m b}}$ & Avg G $_{\mathbf{m b}}$ \\
\hline 5.2 & 1 & 4730.4 & 2749.6 & 4743.3 & 2.373 & \\
\hline & 2 & 4716.2 & 2740.8 & 4729.3 & 2.372 & 2.372 \\
\hline 5.7 & 1 & 4760.1 & 2773.7 & 4769.7 & 2.385 & \\
\hline & 2 & 4747.1 & 2779.2 & 4754.8 & 2.403 & 2.394 \\
\hline 6.2 & 1 & 4652.2 & 2736.9 & 4657.9 & 2.422 & \\
\hline & 2 & 4707.0 & 2765.6 & 4713.0 & 2.417 & 2.419 \\
\hline 6.7 & 1 & 4734.2 & 2770.0 & 4742.4 & 2.400 & \\
\hline & 2 & 4751.4 & 2787.5 & 4757.0 & 2.412 & 2.406 \\
\hline
\end{tabular}




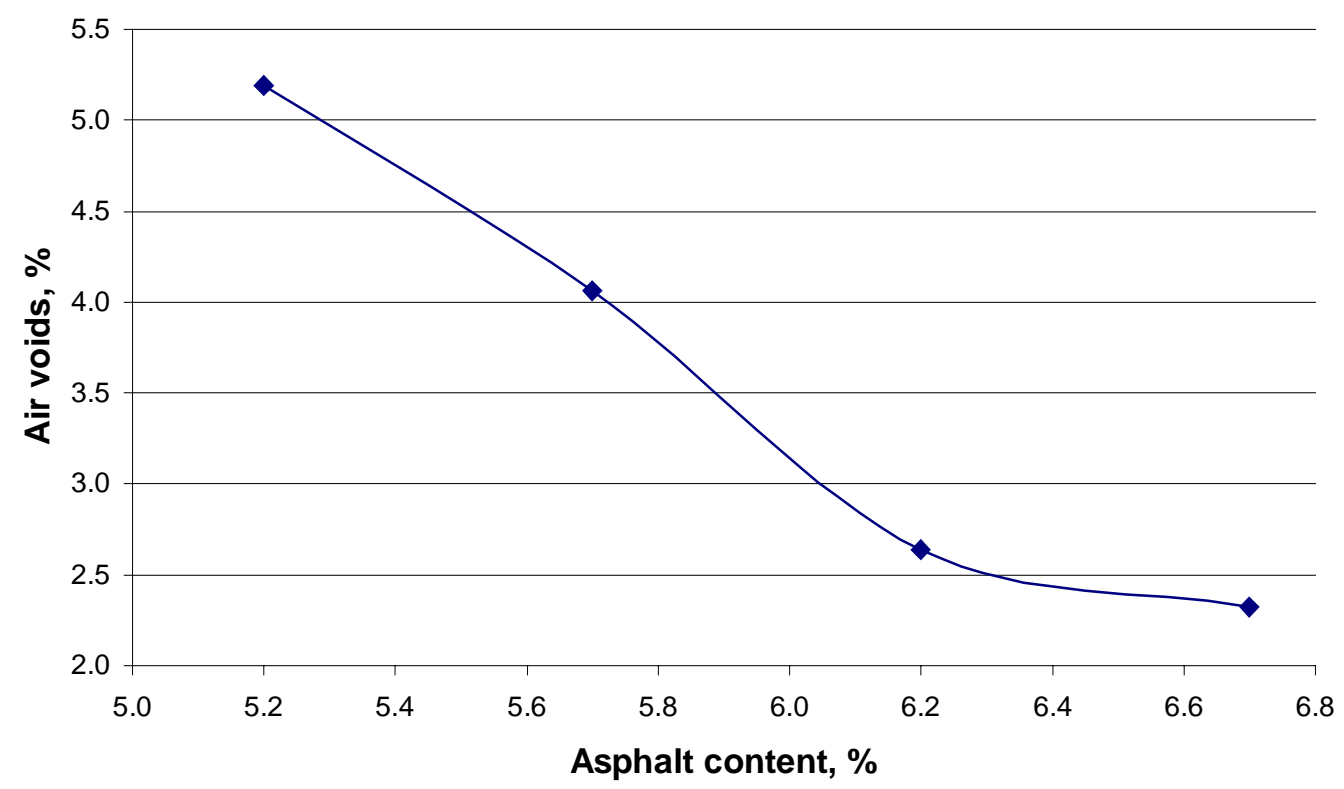

Figure C.5 Asphalt content versus Air voids-Superpave medium traffic mix.

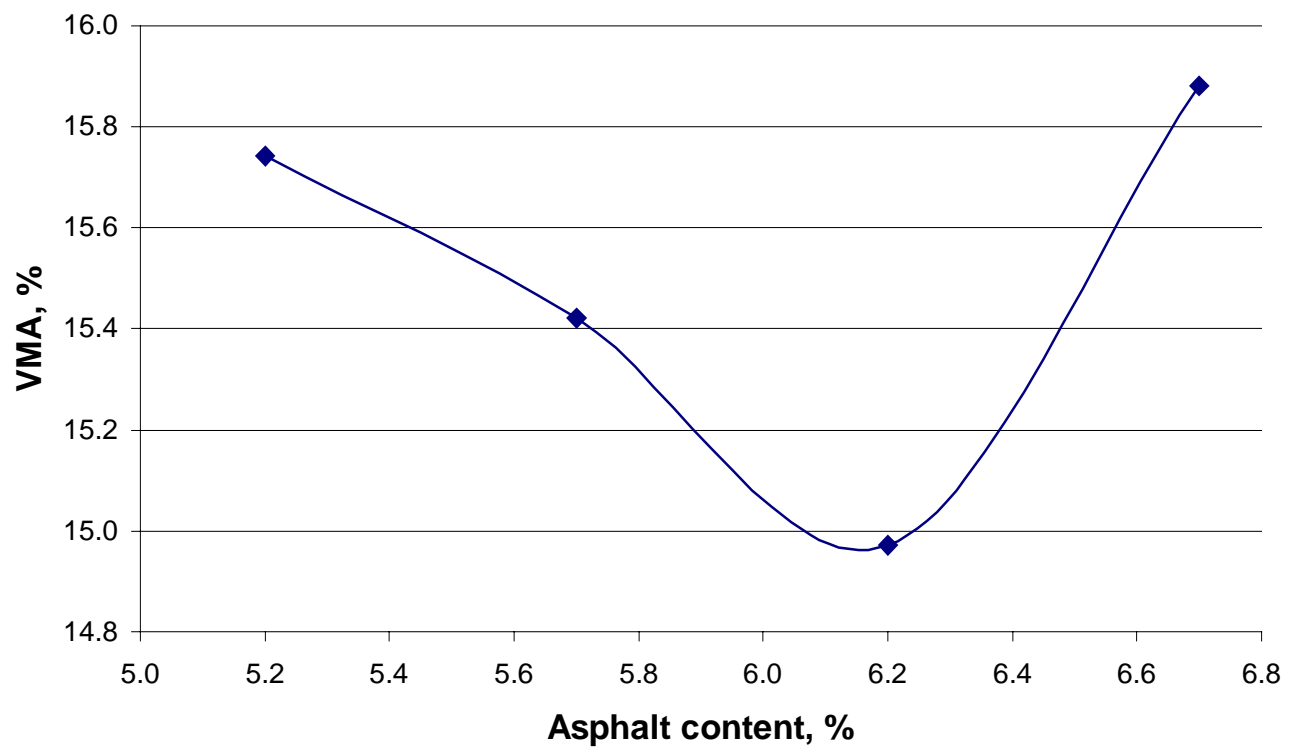

Figure C.6 Asphalt content versus VMA-Superpave medium traffic level 


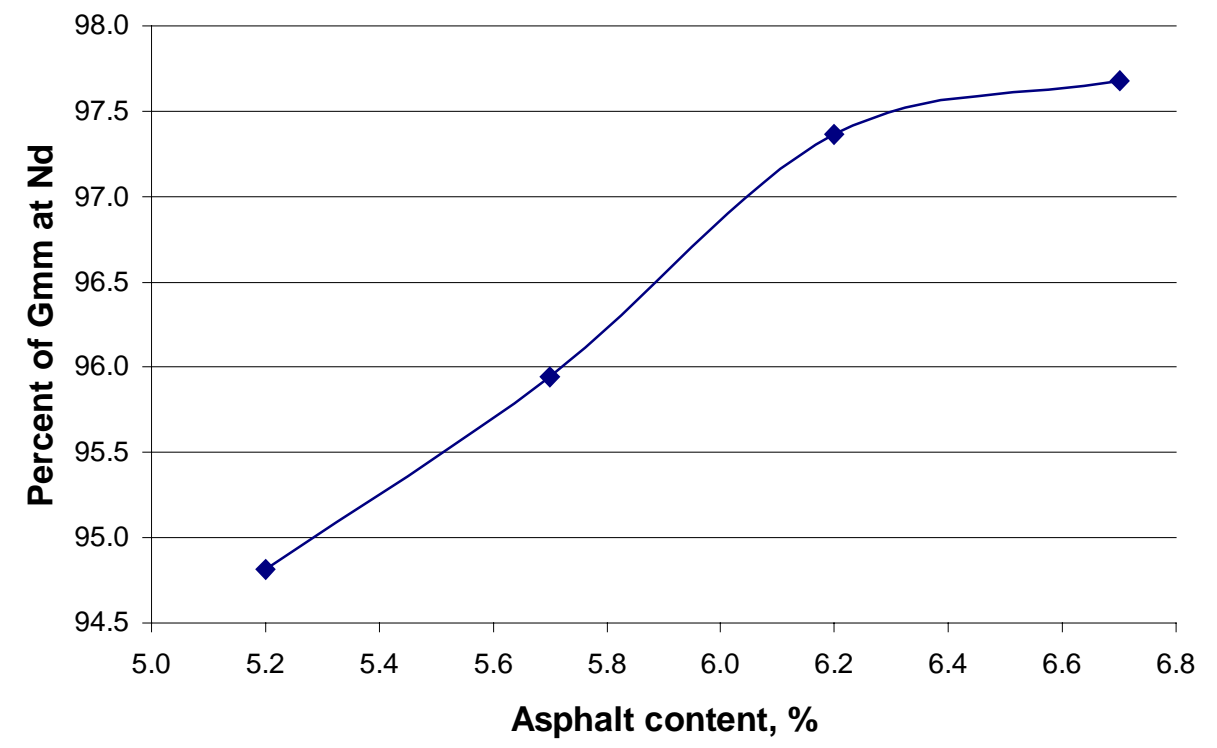

Figure C.7 Asphalt content versus Percent of Gmm at Nd-Superpave medium traffic mix

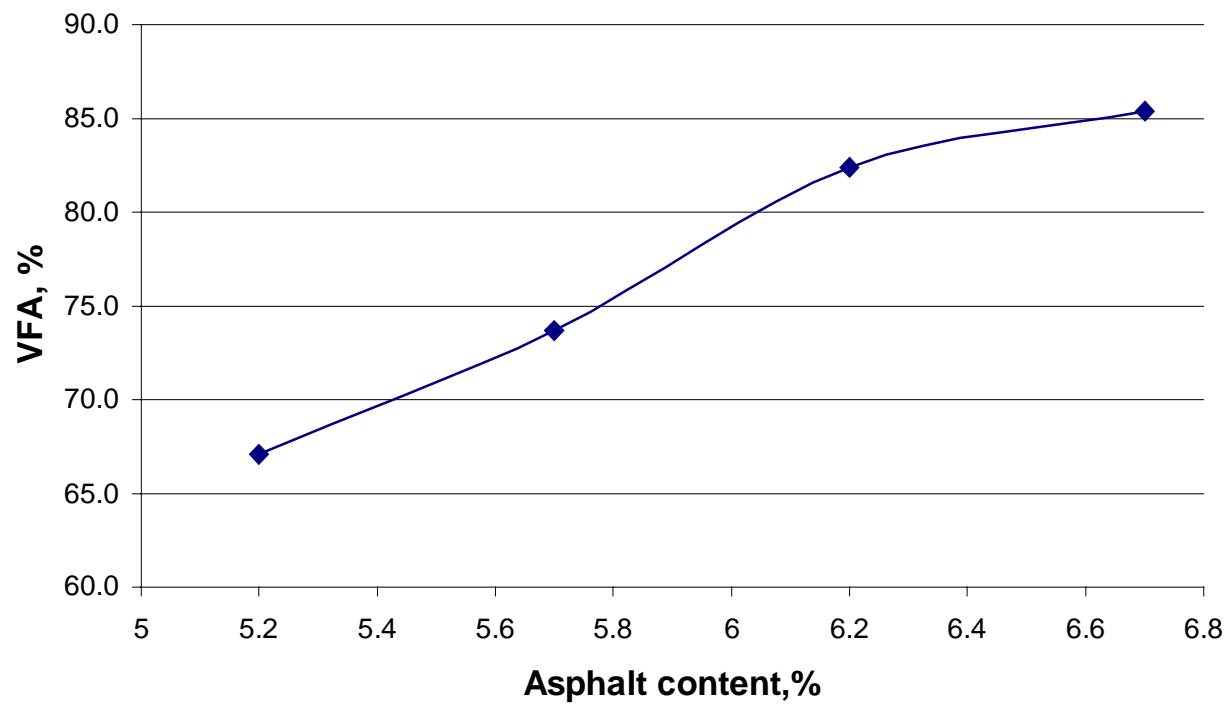

Figure C.8 Asphalt content versus VFA-Superpave medium traffic mix. 
Table C.8 Blend Bulk Specific Gravity Calculations -Superpave Light Traffic Mix.

\begin{tabular}{|l|l|l|l|l|}
\hline Sample & A & B & C & A/(C-B) \\
\hline No. & Dry Wt. (g) & Wet Wt. (g) & SSD Wt. (g) & Gmb \\
\hline 1 & 4698.6 & 2704.4 & 4720.5 & 2.331 \\
\hline 2 & 4684.5 & 2690.7 & 4711.9 & 2.318 \\
\hline 3 & 4685.8 & 2701.1 & 4721.3 & 2.319 \\
\hline
\end{tabular}

Table C.9 Theoretical Maximum Specific Gravity Calculations-Superpave Light Traffic Mix.

\begin{tabular}{|c|c|c|c|c|c|}
\hline \multicolumn{6}{|c|}{ Weight of the container in water, $(\mathrm{g})[\mathrm{D}]=1511.1$} \\
\hline & & A & $\mathrm{E}$ & $\mathrm{A} /(\mathrm{A}+\mathrm{D}-\mathrm{E})$ & \\
\hline AC, \% & Sample & Dry wt. (g) & Wet wt. (g) & $\mathrm{G}_{\mathrm{mm}}$ & Avg $_{\mathrm{mm}}$ \\
\hline 5.9 & 1 & 2061.3 & 2744 & 2.488 & \\
\hline & 2 & 2072.4 & 2749.7 & 2.485 & 2.487 \\
\hline 6.4 & 1 & 2148.0 & 2788.8 & 2.468 & \\
\hline & 2 & 2144.3 & 2787.3 & 2.470 & 2.469 \\
\hline 6.9 & 1 & 2103.6 & 2756.4 & 2.451 & \\
\hline & 2 & 2100.2 & 2754.8 & 2.452 & 2.451 \\
\hline 7.4 & 1 & 2124.9 & 2762.6 & 2.433 & \\
\hline & 2 & 2110.4 & 2754.8 & 2.435 & 2.434 \\
\hline
\end{tabular}

Table C.10 Bulk Specific Gravity-Superpave Light Traffic Mix.

\begin{tabular}{|c|c|c|c|c|c|c|}
\hline & Sample & A & B & $\mathrm{C}$ & A/(C-B) & \\
\hline $\mathrm{AC}, \%$ & No. & Dry wt. (g & Wet wt. (g) & SSD Wt. (g) & $\mathbf{G}_{\mathbf{m b}}$ & $\operatorname{Avg} G_{m b}$ \\
\hline \multirow[t]{2}{*}{5.9} & 1 & 4675.3 & 2710.7 & 4685.7 & 2.367 & \\
\hline & 2 & 4638.8 & 2692.2 & 4651.5 & 2.368 & 2.367 \\
\hline \multirow[t]{2}{*}{6.4} & 1 & 4676.5 & 2721.0 & 4685.1 & 2.381 & \\
\hline & 2 & 4653.2 & 2700.4 & 4662.3 & 2.372 & 2.376 \\
\hline \multirow[t]{2}{*}{6.9} & 1 & 4614.5 & 2682.7 & 4622.4 & 2.379 & \\
\hline & 2 & 4645.9 & 2706.6 & 4651.3 & 2.389 & 2.384 \\
\hline \multirow[t]{2}{*}{7.4} & 1 & 4555.5 & 2656.8 & 4564.0 & 2.389 & \\
\hline & 2 & 4666.0 & 2728.2 & 4670.8 & 2.402 & 2.395 \\
\hline
\end{tabular}




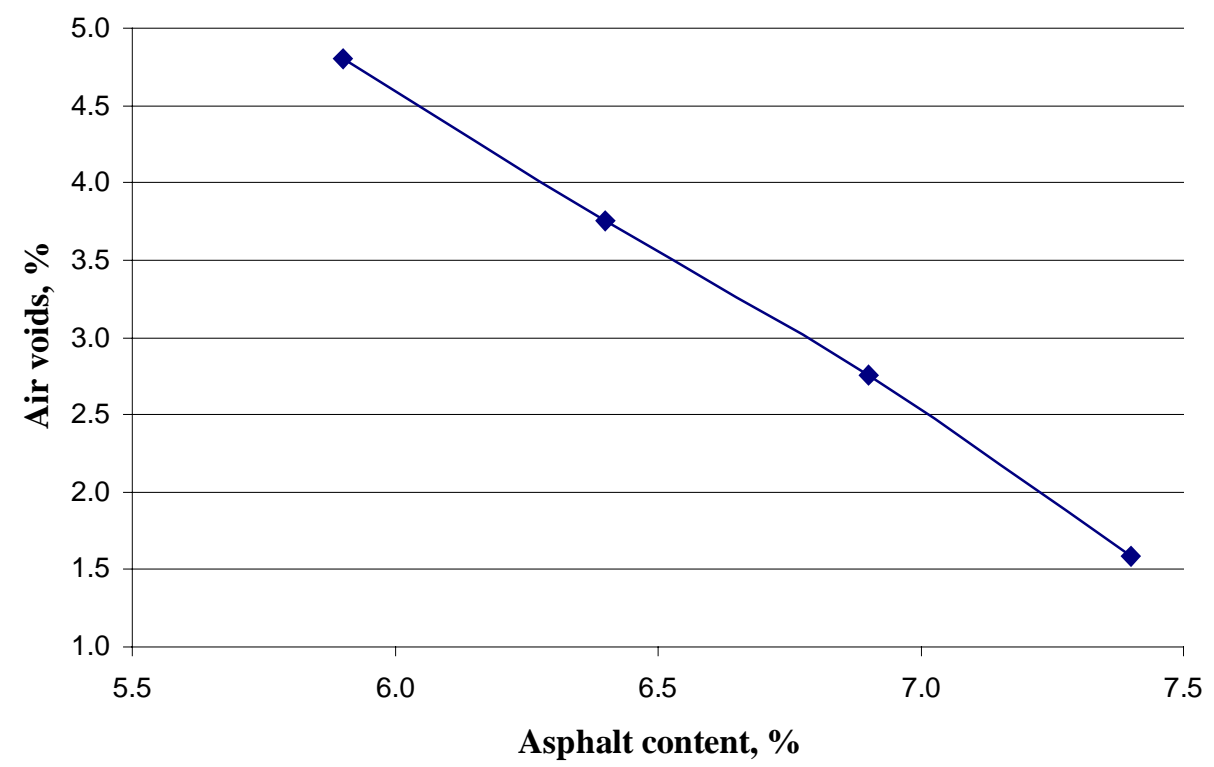

Figure C.9 Asphalt content versus Air voids-Supeprave light traffic mix.

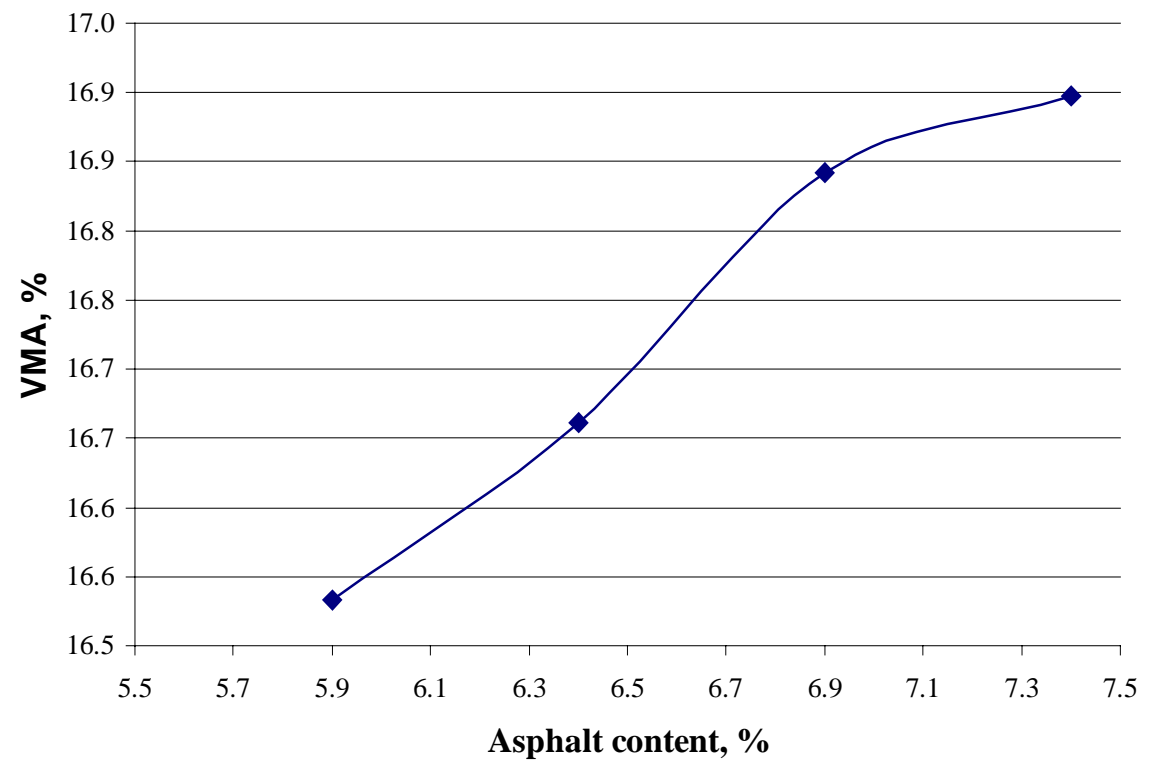

Fgure C.10 Asphalt content versus VMA-Superpave light traffic mix. 


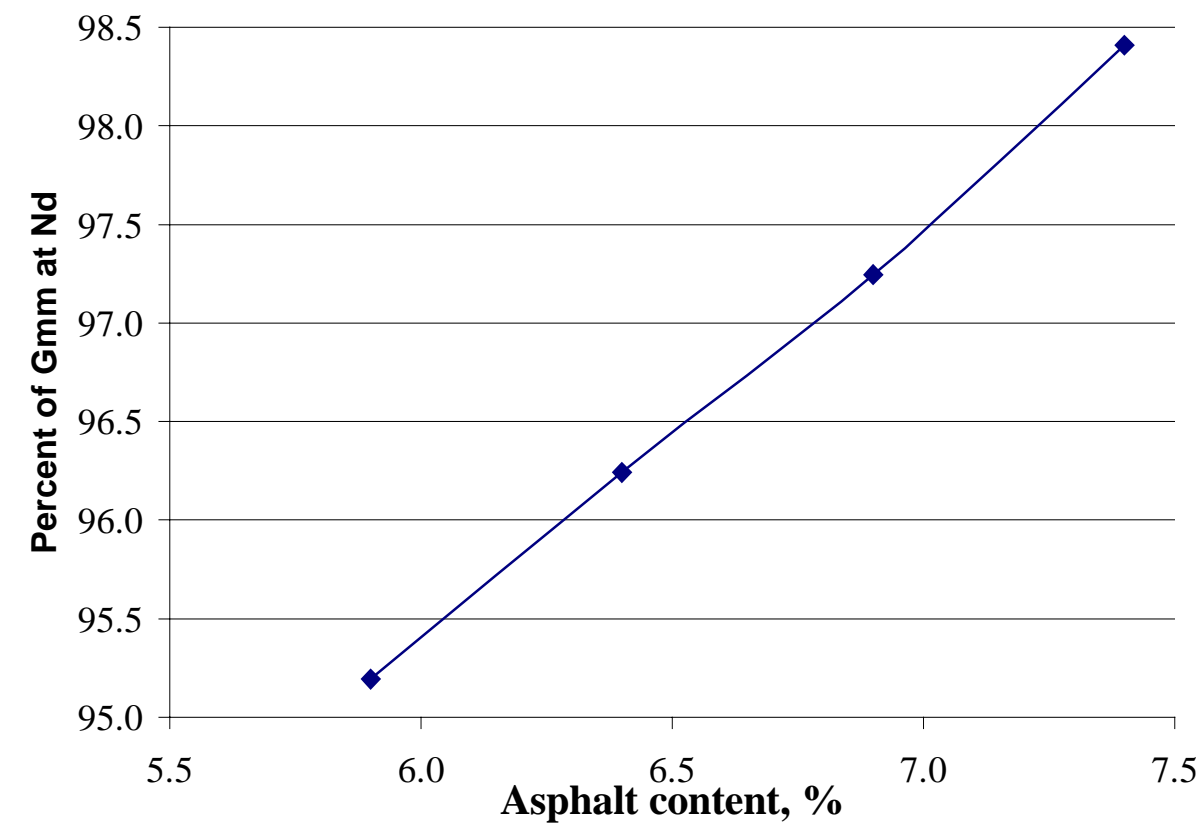

Figure C.11 Asphalt content versus percent Gmm at Nd-Supeprave light traffic mix.

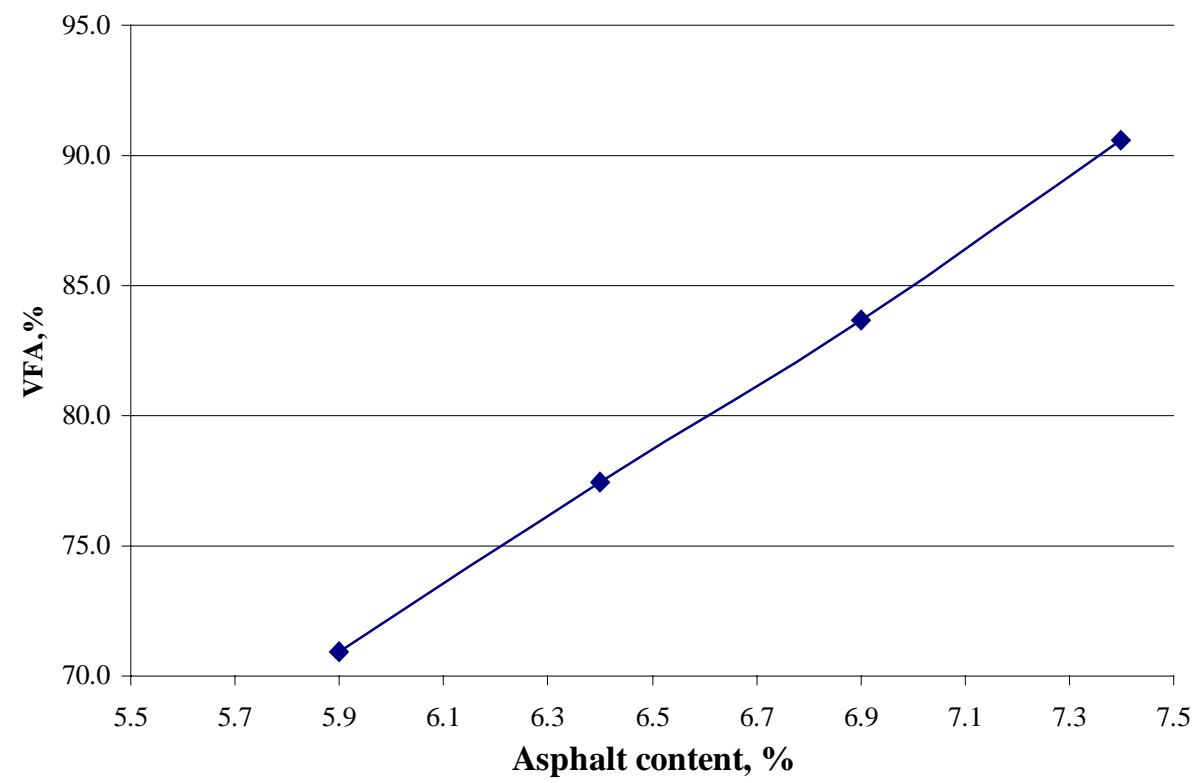

Figure C.12 Asphalt content versus VFA - Superpave light traffic level 


\section{APPENDIX D DATA AND ANALYSIS FOR EXCHANGING SUPERPAVE AND MARSHALL MIX DESIGNS}

Table D.1 Marshall Mix Designs with Superpave Methodology

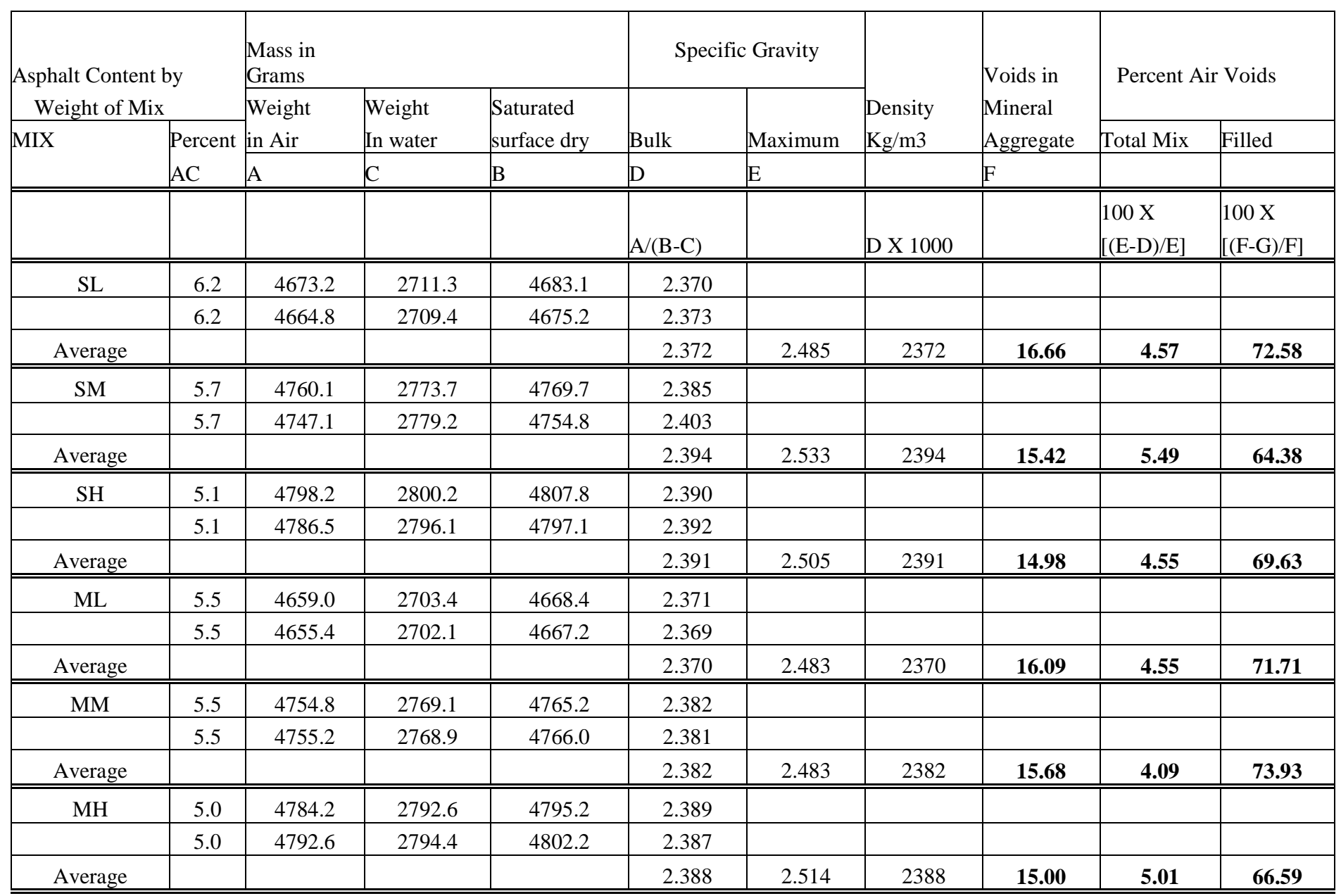


Table D.2 Superpave Mix Designs with Marshall Methodology

\begin{tabular}{|c|c|c|c|c|c|c|c|c|c|c|c|c|c|c|c|}
\hline & \multirow{2}{*}{\multicolumn{2}{|c|}{$\begin{array}{l}\text { Asphalt Content by } \\
\text { Weight of Mix }\end{array}$}} & \multirow{4}{*}{$\begin{array}{l}\text { Specimen } \\
\text { Thickness } \\
(\mathrm{mm})\end{array}$} & \multicolumn{3}{|c|}{ Mass in Grams } & \multicolumn{2}{|c|}{ Specific Gravity } & \multirow{3}{*}{$\begin{array}{l}\text { Density } \\
\mathrm{Kg} / \mathrm{m} 3\end{array}$} & \multirow{3}{*}{$\begin{array}{l}\text { Voids in } \\
\text { Mineral } \\
\text { Aggregate }\end{array}$} & \multirow{2}{*}{\multicolumn{2}{|c|}{ Percent Air Voids }} & \multirow{2}{*}{\multicolumn{2}{|c|}{$\begin{array}{l}\text { Stability (n) } \\
\text { Pounds }\end{array}$}} & \multirow{3}{*}{$\begin{array}{l}\text { Flow } \\
0.01 \\
\text { inch }\end{array}$} \\
\hline & & & & \multirow{2}{*}{$\begin{array}{l}\text { Weight } \\
\text { in Air }\end{array}$} & \multirow{2}{*}{$\begin{array}{l}\text { Weight } \\
\text { In water }\end{array}$} & \multirow{2}{*}{$\begin{array}{l}\text { Saturated } \\
\text { surface dry }\end{array}$} & \multirow{2}{*}{ Bulk } & \multirow[b]{2}{*}{ Maximum } & & & & & & & \\
\hline & Specimen & Percent & & & & & & & & & Total Mix & Filled & Actual & Adjusted & \\
\hline & Number & $\mathrm{AC}$ & & $\mathrm{A}$ & $\mathrm{C}$ & $\mathrm{B}$ & $\mathrm{D}$ & $\mathrm{E}$ & & $\mathrm{F}$ & & & & & \\
\hline & & & & & & & $\mathrm{A} /(\mathrm{B}-\mathrm{C})$ & & D X 1000 & & $\begin{array}{l}100 \mathrm{X} \\
{[(\mathrm{E}-\mathrm{D}) / \mathrm{E}]} \\
\end{array}$ & $\begin{array}{l}100 \mathrm{X} \\
{[(\mathrm{F}-\mathrm{G}) / \mathrm{F}]} \\
\end{array}$ & & & \\
\hline MH & 1 & 5.0 & 64 & 1193.8 & \begin{tabular}{|l|l}
8 & 699.7 \\
\end{tabular} & 1199.8 & 2.387 & & & & & & 2525 & 2493.4 & 15.0 \\
\hline & 2 & 5.0 & 63 & 1174 & 686.1 & 1180 & 2.377 & & & & & & 2400 & 2490.0 & 20.0 \\
\hline & 3 & 5.0 & 62 & 1190 & 696.6 & 1196.1 & 2.382 & & & & & & 2700 & 2801.3 & 17.0 \\
\hline & Average & & & & & & 2.382 & 2.51 & 2382 & 15.24 & 5.09 & 66.58 & 2542 & 2594.9 & 17.3 \\
\hline SPH & 1 & 5.1 & 64 & 1214.8 & \begin{tabular}{|l|l}
3 & 711.1 \\
\end{tabular} & 1219.6 & 2.389 & & & & & & 2975 & 2937.8 & 20.0 \\
\hline & 2 & 5.1 & 64 & 1210.3 & \begin{tabular}{|l|l}
3 & 706.6 \\
\end{tabular} & 1215.4 & 2.379 & & & & & & 2575 & 2542.8 & 14.0 \\
\hline & 3 & 5.1 & 64 & 1207.6 & \begin{tabular}{|l|l|}
5 & 704.0 \\
\end{tabular} & 1213.4 & 2.371 & & & & & & 2525 & 2493.4 & 17.0 \\
\hline & Average & & & & & & 2.379 & 2.508 & 2379 & 15.43 & 5.13 & 66.78 & 2692 & 2658.0 & 17.0 \\
\hline MM & 1 & 5.5 & 58 & 1099.1 & 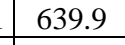 & 1103.3 & 2.372 & & & & & & 1850 & 2152.1 & 15.0 \\
\hline & 2 & 5.5 & 62 & 1131.5 & 5651.5 & 1138.6 & 2.323 & & & & & & 1725 & 1789.7 & 20.0 \\
\hline & 3 & 5.5 & 61 & 1133.4 & $\begin{array}{r}659.5 \\
\end{array}$ & 1137.4 & 2.372 & & & & & & 2000 & 2137.5 & 15.0 \\
\hline & Average & & & & & & 2.355 & 2.482 & 2355 & 16.63 & 5.10 & 69.35 & 1858 & 2026.4 & 16.7 \\
\hline SPM & 1 & 5.7 & 61 & 1141.1 & 662.7 & 1145 & 2.366 & & & & & & 2175 & 2323.2 & 22.0 \\
\hline & 2 & 5.7 & 62 & 1134.4 & 655.6 & 1139.6 & 2.344 & & & & & & 1975 & 2049.1 & 20.0 \\
\hline & 3 & 5.7 & 62 & 1137.5 & 657.4 & 1142.3 & 2.346 & & & & & & 2100 & 2178.8 & 22.0 \\
\hline & Average & & & & & & 2.352 & 2.495 & 2352 & 16.94 & 5.74 & 66.13 & 2083 & 2183.7 & 21.3 \\
\hline SPL & 1 & 6.2 & 63 & 1143.5 & 660.1 & 1148.2 & 2.343 & & & & & & 1850 & 1873.1 & 24.0 \\
\hline & 2 & 6.2 & 61 & 1134.2 & 660.3 & 1138.5 & 2.372 & & & & & & 1950 & 2082.8 & 20.0 \\
\hline & 3 & 6.2 & 61 & 1141.8 & 661.1 & 1146.4 & 2.353 & & & & & & 2075 & 2217.6 & 22.0 \\
\hline & Average & & & & & & 2.356 & 2.485 & 2356 & 17.24 & 5.20 & 69.84 & 1958 & 2057.9 & $|22.0|$ \\
\hline
\end{tabular}




\section{VITA}

Vasavi Kanneganti was born in Visakhapatnam, India in May 5, 1978. She received her Bachelor's degree in Civil Engineering from Andhra University in Visakhapatnam in June 1999. She had since completed the graduate level course work in the areas of paving materials, pavement design, and traffic engineering. Vasavi is currently a candidate for Masters of Science degree in Civil Engineering at West Virginia University, and plans to graduate in May 2002. 